\title{
Dietary interventions and intestinal defence to protect against salmonella infection = Voedingsinterventies en darmweerstand ter bescherming tegen salmonella infectie
}

Citation for published version (APA):

van Ampting, M. T. J. (2011). Dietary interventions and intestinal defence to protect against salmonella infection = Voedingsinterventies en darmweerstand ter bescherming tegen salmonella infectie. [Doctoral Thesis, Maastricht University]. Maastricht University. https://doi.org/10.26481/dis.20110406ma

Document status and date:

Published: 01/01/2011

DOI:

10.26481/dis.20110406ma

Document Version:

Publisher's PDF, also known as Version of record

Please check the document version of this publication:

- A submitted manuscript is the version of the article upon submission and before peer-review. There can be important differences between the submitted version and the official published version of record. People interested in the research are advised to contact the author for the final version of the publication, or visit the DOI to the publisher's website.

- The final author version and the galley proof are versions of the publication after peer review.

- The final published version features the final layout of the paper including the volume, issue and page numbers.

Link to publication

\footnotetext{
General rights rights.

- You may freely distribute the URL identifying the publication in the public portal. please follow below link for the End User Agreement:

www.umlib.nl/taverne-license

Take down policy

If you believe that this document breaches copyright please contact us at:

repository@maastrichtuniversity.nl

providing details and we will investigate your claim.
}

Copyright and moral rights for the publications made accessible in the public portal are retained by the authors and/or other copyright owners and it is a condition of accessing publications that users recognise and abide by the legal requirements associated with these

- Users may download and print one copy of any publication from the public portal for the purpose of private study or research.

- You may not further distribute the material or use it for any profit-making activity or commercial gain

If the publication is distributed under the terms of Article 25fa of the Dutch Copyright Act, indicated by the "Taverne" license above, 


\section{DIETARY INTERVENTIONS \\ AND INTESTINAL DEFENCE TO PROTECT AGAINST \\ SALMONELLA INFECTION}

Marleen T. J. van Ampting 


\section{Promotor:}

Prof. Dr. R.M. Brummer

\section{Copromotor:}

Dr. I.M. Bovee-Oudenhoven

\section{Beoordelingscommissie:}

Prof. Dr. C.A.M.V.A. Bruggeman (voorzitter)

Prof. Dr. A. Bast

Dr. D.M.A.E. Jonkers

Dr. M.A. Nieuwenhoven (University Hospital Örebro, Sweden)

Prof. Dr. R.F. Witkamp (Wageningen University) 


\section{DIETARY INTERVENTIONS AND INTESTINAL DEFENCE TO PROTECT AGAINST SALMONELLA INFECTION \\ VOEDINGSINTERVENTIES EN DARMWEERSTAND TER BESCHERMING TEGEN SALMONELLA INFECTIE}

\section{PROEFSCHRIFT}

ter verkrijging van de graad van doctor aan de universiteit Maastricht, op gezag van de Rector Magnificus,

Prof. Mr. G.P.M.F. Mols volgens het besluit van het College van Decanen, in het openbaar te verdedigen op woensdag 6 april 2011 om 12.00 uur

door Marleen Theodora Johanna van Ampting 
M.T.J. van Ampting

Dietary interventions and intestinal defence to protect against Salmonella infection

PhD thesis, Maastricht University (2011) - with summary in Dutch

ISBN: 978-90-6464-463-4 


\section{TABLE OF CONTENTS}

CHAPTER 17 General Introduction: Dietary interventions and intestinal defence to protect against Salmonella infection.

CHAPTER 229 Ileal mucosal and fecal pancreatitis associated protein levels reflect severity of Salmonella infection in rats

CHAPTER 349 The intestinal secreted C-type lectin RegIII $\beta$ protects against Salmonellosis but not Listeriosis in mice

CHAPTER $4 \quad 65 \quad$ Fecal pancreatitis-associated protein is increased by Eschericia coli infection and in ulcerative colitis but not in Crohn's disease: an exploratory study

CHAPTER $5 \quad 81$ Intestinal barrier function in response to abundant or depleted mucosal glutathione in Salmonella-infected rats

CHAPTER 699 Damage to the intestinal epithelial barrier by antibiotic pretreatment of Salmonella-infected rats is lessened by dietary calcium or tannic acid

CHAPTER 7117 General discussion and concluding remarks

131 Summary

135 Samenvatting (Dutch summary)

139 Acknowledgements / dankwoord

143 Curriculum vitae

144 List of publications 



\section{CHAPTER 1}

\section{DIETARY INTERVENTIONS}

AND INTESTINAL DEFENCE

TO PROTECT AGAINST

SALMONELLA INFECTION

Marleen T.J. van Ampting ${ }^{1,2}$, Robert Jan M. Brummer ${ }^{1,3,4}$,

Henrike M. Hamer ${ }^{1,3}$, Roelof van der Meer ${ }^{1,2,5}$ and

Ingeborg M.J. Bovee-Oudenhoven ${ }^{1,2}$

${ }^{1}$ TI Food and Nutrition, Wageningen, the Netherlands

${ }^{2}$ Department of Health, NIZO food research, Ede, the Netherlands

${ }^{3}$ Department of Internal Medicine, Division of Gastroenterology-

Hepatology, Nutrim, Maastricht University, the Netherlands

${ }^{4}$ Present address: School of Health and Medical Sciences, Örebro University,

Örebro, Sweden

${ }^{5}$ Present address: Department of Human Nutrition, Wageningen University,

Wageningen, the Netherlands

Manuscript in preparation. 


\section{INTESTINAL INFECTIONS}

\section{Incidence and causes of intestinal infection}

Intestinal infections are a widespread and still an emerging public health problem, in both developed and developing countries (1), and represent significant health care and economic costs in many countries $(2,3)$. Infection of the intestinal tract with an increasingly recognized array of bacterial, parasitic and viral pathogens is largely related to waterborne and foodborne outbreaks (4). These foodborne infections can profoundly disrupt intestinal function. The global incidence of foodborne disease is difficult to estimate, but it has been reported that in 2005 alone 1.8 million people died from this disease (5). In industrialized countries, the percentage of the population suffering from foodborne diseases each year has been reported to be up to $30 \%$. In the USA, for example, around 76 million cases of foodborne diseases, resulting in 325,000 hospitalizations and 5,000 deaths, are estimated to occur each year (5). Moreover, acute intestinal infection is a risk factor for various chronic diseases like inflammatory bowel disease (IBD) (6), irritable bowel syndrome (7) and reactive arthritis (8). Reports of intestinal infections continue to increase (4) partly because elderly people are more prone to developing an infection. While less documented, developing countries have a high occurrence of foodborne disease due to major underlying food safety problems (5). Some well recognized foodborne diseases are considered as emerging because they have recently become more common. For example, outbreaks of salmonellosis have been reported for decades, but within the past 25 years the incidence of the disease has increased on many continents (1). In the Western hemisphere and in Europe, Salmonella serotype Enteritidis has become the predominant strain (1).

In 2008 Salmonella serotype Saintpaul enteritidis was diagnosed in 1407 persons in the United States and Canada (9). A second outbreak concerned 600 persons in Canada who were diagnosed with S. typhimurium Enteritidis. Both strains involved were traced to food sources that had never been found contaminated previously. The first outbreak was caused by a strain detected in jalapeño and Serrano peppers, whereas the second outbreak concerned peanut butter, which was also used in various processed foods (9).

In a healthy host, intestinal infections generally result in a self-limiting gastroenteritis and there is no evidence that administration of antibiotics shortens the duration of the symptoms. In contrast, in young children, the elderly, immunocompromised people receiving immunosuppressive drugs, IBD patients and patients receiving parenteral nutrition, these infections may lead to serious complications and antibiotic therapy may be needed (10). Growing resistance of bacterial pathogens, including Salmonella species, to generally applied antibiotics is a major concern (3,11-13) and untreatable infections in the future are feared. Prevention of infections is of utmost importance and hygiene improvement is the first step. This not only applies to a large food safety problem in many developing countries (5), but also to enormous shifts during the past half century in food production in the West, where food is imported or grown and processed on a vast industrial 


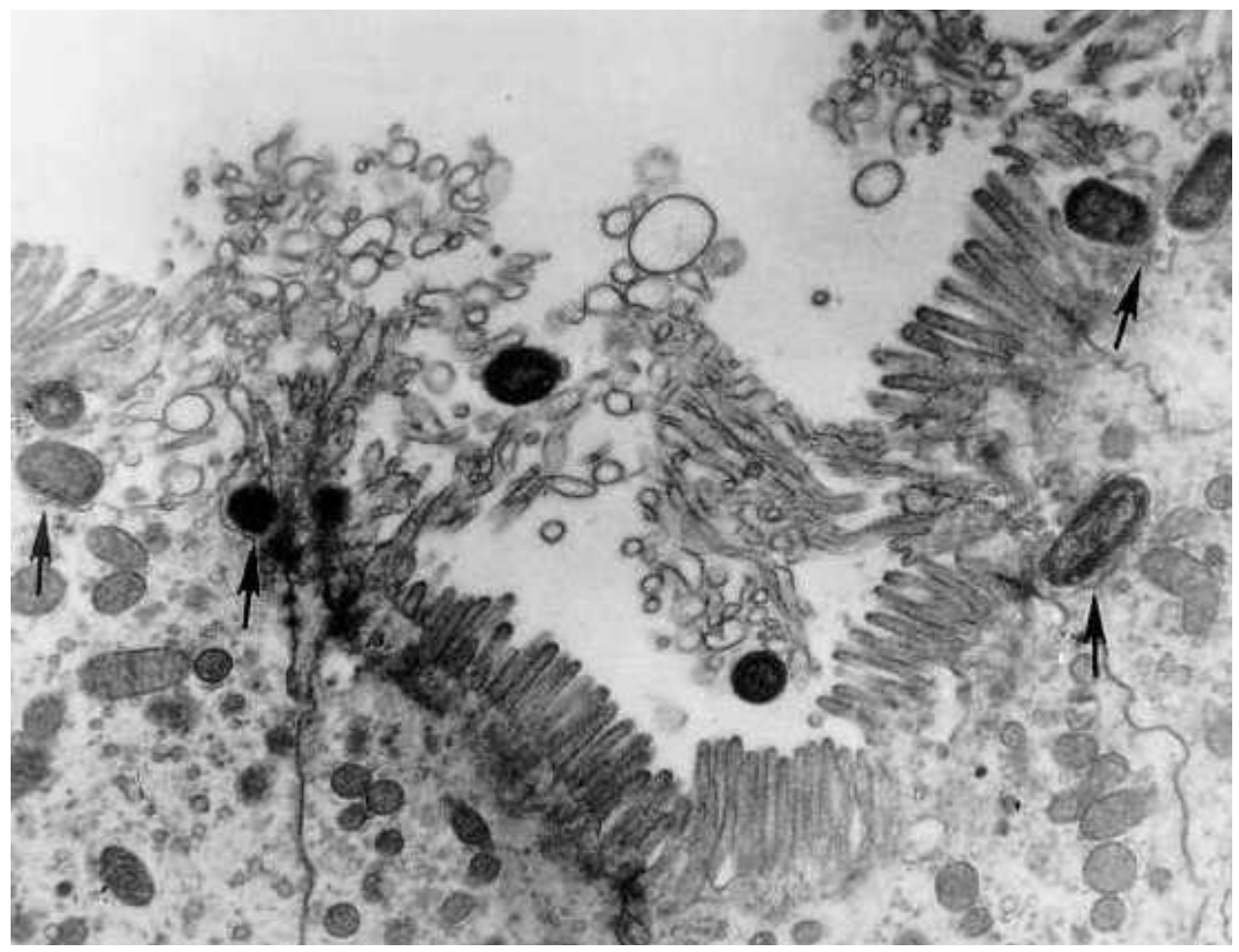

Figure 1. Electron micrograph demonstrating Salmonella invasion in guinea pig ileal epithelial cells. Arrows point to invading Salmonella organisms. (Courtesy Dr. S. Baron, the University of Texas Medical Branch at Galveston)

scale (9). Moreover, it is important to understand how foodborne pathogens cause disease, how and which host defence mechanisms are involved, and whether these host defence mechanisms can be improved.

\section{Mechanisms and crucial steps of foodborne infections}

The ingested microorganism must adhere to host cells in order to infect the host (14). Adherent microorganisms bind to the apical pole of the intestinal epithelium via a large and diverse array of adhesion and invasion molecules that enable them to exploit a variety of host-cell surface components. Fimbriae, also called pili, are adhesive hair-like organelles that protrude from the surface of bacteria and are involved in adhesion of e.g. Escherichia coli $(14,15)$. Besides pili and fimbriae, a plethora of different bacterial nonpolymeric adhesins exist which recognize many different elements on the host surface components like integrins, cadherins, selectins and carcinoembryonic antigen-related adhesion molecules (CEACAMs) (14). These are receptors of many pathogens involved in adhesion and sometimes cell entry. Certain pathogens infect the host by cellular invasion (Fig 1) (14). These invasive bacteria actively induce 


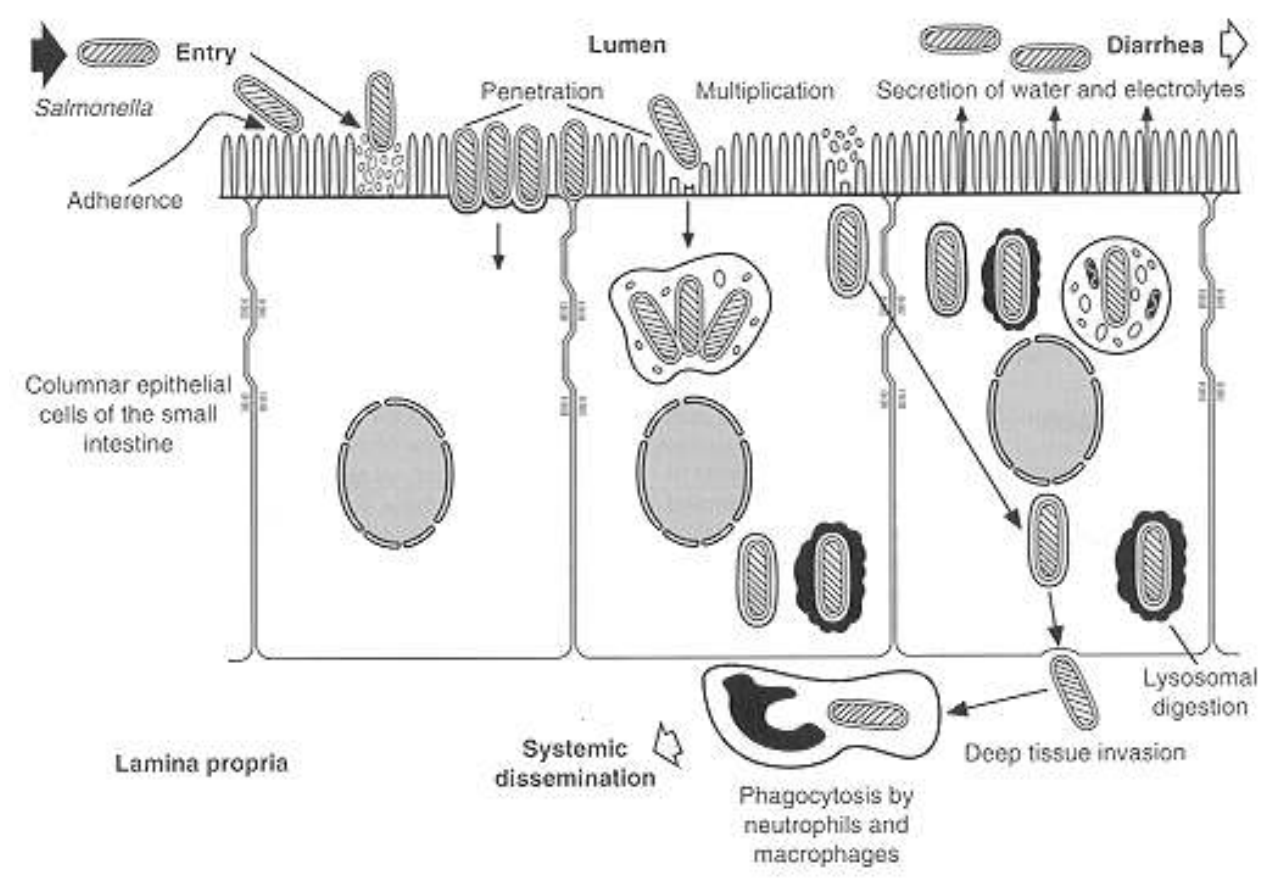

Figure 2. Schematic representation of the pathogenesis of Salmonella adherence and translocation through the intestinal epithelial cells causing enterocolitis and diarrhoea (20).

their own uptake by phagocytosis in normally non-phagocytic cells, such as epithelial cells, and then either establish a protected niche in which they survive and replicate, or disseminate from cell to cell by means of an actin-based motility process (16). The mechanisms underlying bacterial entry, phagosome maturation, and dissemination reveal common strategies as well as unique tactics evolved by individual species to establish infection (16). For example, Salmonella are capable of traversing the intestinal epithelium via three routes. The first route is via invasion into specialized epithelial cells called $\mathrm{M}$ cells, which sample antigens from the intestinal lumen for immune system maturation. Another route is through dendritic cells (DC) that intercalate epithelial cells by extending protrusions into the gut lumen. The third route involves binding of Salmonella to epithelial cells by the type III secretory system (TTSS) of this pathogen $(17,18)$.

After traversing the epithelial cell by one of these mechanisms, the bacteria encounter the basal membrane, and the invaders are ingested by macrophages or other phagocytic cells and are transported to the mesenteric lymph nodes (Fig 2). When massive translocation occurs, bacteria will spread to the bloodstream, denoted as septicaemia or bacteraemia, and may invade other organs (19), generally causing a life-threatening infection. 


\section{Symptoms and pathology}

Invasion of foodborne enteric pathogens, such as specific types of Salmonella, and translocation from the gut lumen to extra-intestinal organs $(16,20)$ is often accompanied by increased mucosal paracellular permeability $(21,22)$. Not only invasion itself but also the release of toxins and virulence factors (23) have disastrous effects. Three major physiological functions of the intestinal epithelium can be affected (Fig 3). These include alterations in the structure and function of the tight junction barrier, induction of fluid and electrolyte secretion (Fig 2), and activation of the inflammatory cascade (24). It is noteworthy that while some pathogens primarily activate one of the above mentioned pathways, others such as Salmonella and E. coli are well versed in all three languages.

The intestinal epithelium has a remarkable capacity for fluid and electrolyte absorption. In humans, approximately 8-9 $\mathrm{L}$ of fluid enters the gut on a daily basis and all except for $100-200 \mathrm{ml} /$ day is reabsorbed under normal conditions (24). Multifaceted transport pathways, under tight control of various neurotransmitters, hormones, inflammatory mediators and intraluminal contents, exist to carry out this function. Disruption of this system upon bacterial infection may result in diarrhoea. Chloride secretion is the principal determinant of luminal hydration. With chloride secretion, paracellular movement of sodium follows. The resulting accumulation of luminal sodium chloride provides an osmotic gradient for the diffusion of water. Increased intestinal chloride and concomitant water secretion results in secretory diarrhoea (25). Various pathogens, including E. coli, Campylobacter jejuni and Salmonella are known to mediate chloride secretion, usually accomplished by elaboration of enterotoxins. The enterotoxins increase cyclic AMP or cyclic GMP in epithelial cells $(24,26,27)$ and stimulate chloride transporters like the cystic fibrosis transmembrane conductance regulator (CFTR). In addition to bacterial toxins that function directly as secretagogues, bacterial infection of intestinal epithelial cells can also upregulate the expression of host derived products that, through autocrine or paracrine effects, also stimulate intestinal, primarily chloride, secretion. The other affected functions, including the tight junction barrier and inflammatory cascade, will be discussed below.

\section{DEFENCE MECHANISMS OF THE GASTROINTESTINAL TRACT}

The gastrointestinal (GI) tract is the site where the divergent needs of nutrient absorption and host defence collide. Nutrient absorption requires a large surface area and a thin epithelium. In adult humans the GI tract represents a surface of approximately $400 \mathrm{~m} 2$, largely because it is formed into millions of finger-like villi in the small bowel (28). The human intestinal surface is 100 times larger than the surface of the skin. In rats, the intestinal surface is 25 times larger than the skin (29). This intestinal surface is continuously in contact with the external environment, which makes the intestinal mucosa prone to harmful components, such as pathogenic microorganisms, toxins or harmful dietary components. 


\section{Oral Salmonella infection}
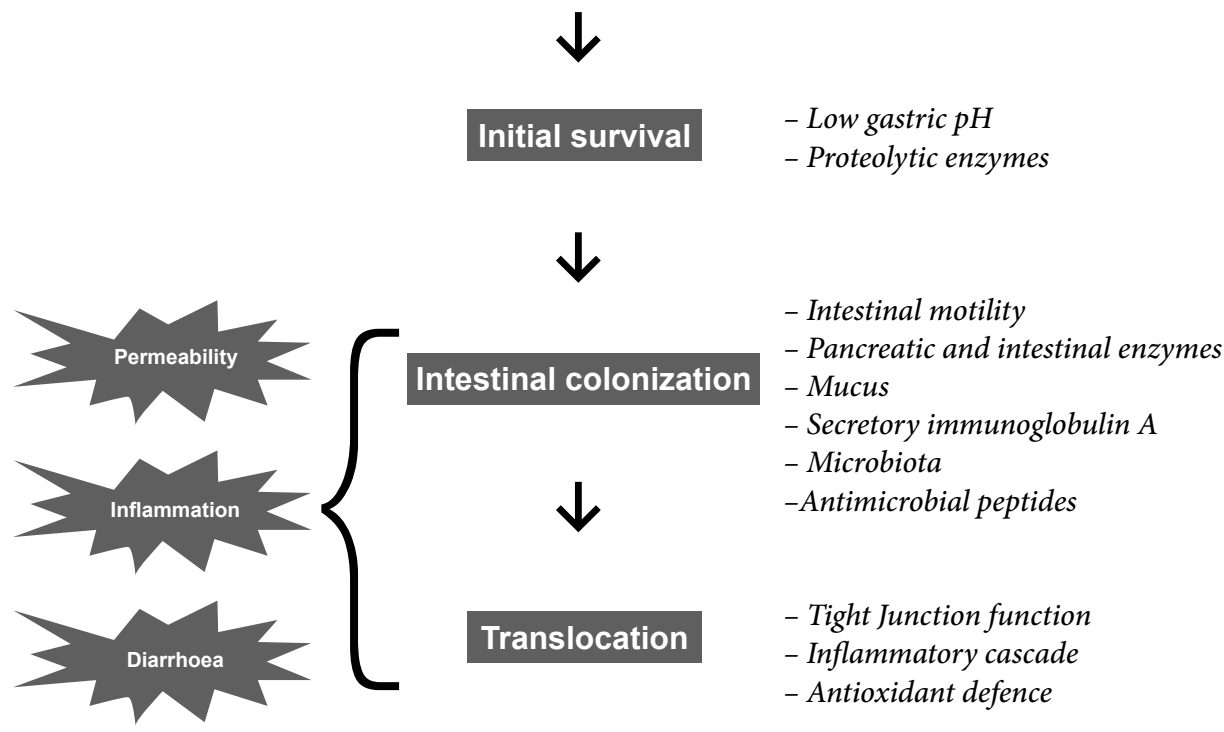

Figure 3. Cascade of Salmonella infection (stages shown in boxes) in rats and host defence mechanisms involved (italics). On the left pathophysiological consequences known to occur or increase upon infection are depicted in random order. It should be noted that events can influence each other; therefore e.g. colonization and translocation can not be separately linked to a single pathophysiological effect.

Fortunately the GI tract is equipped with several innate and adaptive mechanisms that continuously interact with each other to prevent survival of ingested microbes (Fig 3).

\section{Innate defence mechanisms against foodborne infections \\ Gastric acidity}

A complex set of defence mechanisms operating in the host, from the mouth to the rectum, helps to protect against ingested infectious pathogens. In an empty stomach a foodborne pathogen has to cope with the low $\mathrm{pH},<3.0$, and proteolytic enzyme activity of gastric juice. This is, after passage through the oropharynx and oesophagus, the first line of defence of the GI tract. Many foodborne pathogens are acid sensitive $(30,31)$ and will not survive gastric passage. Many environmental factors, like the concomitant presence of food or use of medication (e.g. antacids) can increase $\mathrm{pH}$ of the gastric content or physically protect bacteria. These factors can increase the likelihood of a pathogen surviving the gastric barrier (31-33). 


\section{Intestinal motility and mucus}

Throughout the whole intestine a thick mucus layer covers the epithelium, whereas a discontinous thinner layer covers the small intestine; the colon mucus layer gradually increases in thickness from colon to the rectum (34-37). The mucus layer acts as a lubricant for propulsion of the intestinal contents. Moreover, this mucus protects the underlying epithelial cells from gastric acid, bile acids, chemical irritants and physical damage. The mucus layer is organized around the highly glycosylated MUC 2 mucin (36) and includes stabilization proteins, denoted as trefoil factors (TFF). The sugar chains of the glycoproteins mimic epithelial receptors for bacteria and act like a physical sieve trapping microbes and bringing them in close contact with secreted antibodies (sIgA) and antibacterials like lactoferrin, lysozyme and lactoperoxidase $(36,38)$. The adhesion of pathogens to the mucosal epithelium is further decreased by specific patterns of the intensive motility of the small intestine, designated the interdigestive migrating motor complex. Due to these features, subsequent bacterial overgrowth can be prevented (32).

\section{Intestinal microbiota}

The combination of gastric acid, bile salts, pancreatic enzymes and rapid flow of contents makes the upper GI tract not a favourable site for bacteria to reside. A relatively small population of indigenous microorganisms colonizes the ileal mucosa and may be important for host defence against pathogens in the small intestine, which is the main region in the GI tract where foodborne pathogens exert their noxious effects (39).

In contrast with the small intestine, myriad bacteria reside in the colon; these are crucial for metabolism of non-digested nutrients, but also play an important role in defence of the host (32). Here the intestinal contents move slowly, which provides a good environment for a dense population of microbiota that accounts for nearly half of the human colonic content (40). Perturbation of the intestinal microbiota not only lowers resistance of the host to opportunistic bacteria like Clostridium difficile, but also increases host susceptibility to enteric pathogens like Salmonella (41). Eradication or suppression of parts of the indigenous microbiota decreases the colonization resistance of the host $(42,43)$. Colonization resistance is a complex mechanism in which the host and the resident microbiota cooperate to prevent the overgrowth of other potentially pathogenic bacteria. Competition for mucosal adhesion sites and growth substrates by the indigenous microbiota can increase and thus inhibit intestinal colonization of bacterial pathogens (44-47). Lactic acid, short-chain fatty acids and bacteriocins produced by the microbiota are other mechanisms that have been shown to inhibit growth of pathogenic bacteria $(20,32)$. 


\section{The gut epithelium}

Epithelial cells in the intestine form a physical barrier for all luminal contents, including bacteria. Each epithelial cell maintains an intimate association with its neighbours and seals the surface of the gut with the help of tight junctions (TJs). TJs are lipid-protein complexes at the apical junctions of epithelial cells, which form a controllable barrier between the luminal and serosal sides of the epithelial monolayer (barrier function) (23). The TJ can be affected by pathogens, cytotoxic compounds, cytokines $(24,48)$ and probably many other still unidentified factors. TJ function can also be regulated by bacteria from the indigenous microbiota, e.g. via toll-like receptor 2 (TLR2) activation as recently shown for the bacterium Lactobacillus plantarum (49). Bacterial invasion through epithelial gaps, which can occur due to loss of damaged cells or apoptosis, is prevented by rapid migration of adjacent epithelial cells (50). This regenerating process is a tightly regulated balance between proliferation and apoptosis, which is necessary to maintain the epithelial layer.

Epithelial cells in the intestinal mucosa are not all similar and specific types with different functions occur along the various segments of the intestine. The most abundant cell type in the intestinal epithelium is the enterocyte. The enterocyte is not only important in nutrient absorption, but also actively communicates with the immune system by producing cytokines and chemokines (48). Another dominating cell type is the goblet cell, which produces the above described protective mucus layer in the small and large intestine.

\section{Antimicrobial peptides}

Deep down in the crypt of the small intestine reside specialized Paneth cells. These Paneth cells produce a variety of antimicrobial peptides like defensins and bacteriolytic enzymes such as trypsin, lysozyme and group IIA phospholipase A2. These Paneth cell secretions protect mucosal surfaces and crypts, containing intestinal stem cells, against invading microbes. There is constitutive expression of antimicrobials at low levels and expression is induced by pro-inflammatory cytokines and exposure to bacteria. In this way Paneth cell products not only control the bacterial milieu in the intestine but also serve as signalling molecules that communicate between the innate and adaptive immune response $(51,52)$.

\section{Oxidative defence}

In response to mucosal invasion of pathogens, but also upon translocation of bacterial components like endotoxin, epithelial cells and macrophages express pro-inflammatory cytokines, e.g. interleukin-1 $\beta$ (IL-1 $\beta$ ), to recruit neutrophils $(53,54)$. These efficient killers of microbes $(55)$ contain high concentrations of the enzyme myeloperoxidase (MPO) $(55,56)$, which participates in the innate immune defence through formation of powerful reactive oxidants $(55,56)$. Oxygen or nitrogen radicals and antioxidant enzymes are produced in order to inhibit or kill the bacterial invaders. Activated antigen-presenting cells produce 
high amounts of nitric oxide (NO) from L-arginine, which can kill pathogens especially intracellular organisms, such as Salmonella $(55,57,58)$. Released into the bloodstream, most of the highly-reactive NO is rapidly bound to haemoglobulin and converted into nitrate, which is subsequently excreted in urine $(59,60)$. As a result, NO metabolites accumulate in urine during bacterial translocation (61) and systemic infectious disease (62-64). An unfortunate side-effect of this defence machinery is that the anti-bacterial reactive oxygen species also react with cellular organic molecules, more specifically with lipids, proteins and DNA, and have the potential to induce oxidative host tissue damage $(55,56,65)$. For example, in the inflamed mucosa of ulcerative colitis patients MPO is associated with oxidative stress-related damage (66). Oxidative damage can affect DNA and protein function, but is also mentioned to potentially impair the mucosal barrier function (67). Disruption of perijunctional actin and redistribution of TJ proteins caused by oxidants have been shown to affect TJ function, resulting in a compromised epithelial barrier (67). Therefore antioxidant defence mechanisms, including antioxidant enzymes, such as glutathione-S-transferase, and non-enzymatic antioxidant molecules, such as glutathione, are essential for maintaining a balance between the generation of reactive oxygen species and the antioxidant capacity to restrict tissue damage. Glutathione is a tripeptide composed of $\gamma$-glutamic acid, cysteine and glycine and is quantitatively the most important low-molecular-weight (non-protein) thiol in tissues, including those of the intestinal tract $(65,68,69)$. Glutathione, synthesized by most mammalian cells but mainly in the liver $(68,70)$, is an active free-radical-scavenging compound found in virtually all animal cells $(65,68,70)$. In comparison with a number of other tissues the liver has a particularly high content of glutathione (68). A relatively high concentration of glutathione is also detected in the intestinal epithelium (71). Here glutathione has been shown to play an important role in the protection of the intestinal mucosa against oxidative stress both in vitro $(72,73)$ and in vivo $(71,74)$. However, the role of glutathione in the course of an intestinal infection is unknown.

\section{The immune system}

The epithelial layer has the complex task of accurately identifying threats besides providing a physical barrier. The supportive immune system has to react to pathogens and harmful compounds, but it must tolerate the constant flow of food antigens and the abundant non-pathogenic commensal microbiota. The intestine is responsible for about $70-80 \%$ of the body's immune system, indicating its importance in general defence (75). The immune system can be divided into the rapid non-specific innate immune response and the more specific adaptive immune response. The former is already active in the first few days of infection and activates the adaptive immune system, which plays a role at later stages of infectious disease (76). 
The immune response of the intestine depends on specialized immune tissues, including the Peyer's patches and mesenteric lymph nodes (MLN). Besides these tissues, the immune system consists of several cell types that are scattered through the epithelial mucosal layer, such as DC, IgA-producing B-lymphocytes, and T-lymphocytes (77). Altogether these tissues and cells are denoted as gut-associated lymphoid tissue (GALT). The epithelial cells, which can activate the pro-inflammatory signalling pathways, are as well as this specialized tissue also an essential component of innate immunity (48). All these cells involved in the immune response express pattern recognition receptors, such as TLR, that recognize different pathogen components. For example TLR5 recognizes flagellin from a variety of flagellated pathogens, including Salmonella (78). The receptors are activated upon recognition of a threat and induce production of a range of cytokines and chemokines by both the enterocytes and immune cells. Cytokines communicate with the adaptive immune system and shape the response through either pro-inflammatory cytokine or anti-inflammatory cytokine production. The chemokines are responsible for the recruitment of neutrophils, macrophages and DC to the site of infection.

The adaptive defence against foodborne infections

The Peyer's patches in the small intestine are separated from the intestinal lumen by a single layer of columnar epithelium that includes microfold (M) cells. These $\mathrm{M}$ cells are specialized in antigen uptake. Absorbed antigens are transported to the basolateral cell membrane and delivered to the underlying lymphoid tissue (38). Antigen-presenting cells, like macrophages and DC which reside in the Peyer's patches, couple antigens with major histocompatibility complex (MHC) class II receptors and activate T-helper cells (CD4) to secrete cytokines (38). These cytokines then stimulate B cells within the Peyer's patches to produce immunoglobulins, specifically sIgA (79). sIgA plays an important role in antigen exclusion and bacterial agglutination, which prevents microbial contact and uptake of the intestinal epithelium (80).

\section{DIET AND INTESTINAL INFECTIONS}

Survival of pathogenic bacteria in the GI tract is directly influenced by intestinal content and thus by our diet. At the same time diet can indirectly affect pathogen survival by affecting the above described defence mechanisms of the intestinal tract. For example, when the habitual diet is deficient in one or more essential nutrients, normal functioning of all cells, including cells of the immune system, is impaired (81). Therefore diet may not only be a tool to reduce survival of the pathogen, but it may also reduce infection-associated symptoms (or sequelae). These latter events may even be reduced by dietary compounds without interfering with the survival of pathogens.

Currently, there is major interest in specific food ingredients that modulate the intestinal microbiota and subsequent infection resistance. This area is 
divided into two classes, the so-called probiotics and prebiotics. Probiotics are classically defined as a viable microbial dietary supplement that beneficially affects the host through its effects in the intestinal tract (82). Prebiotics are non-digestible food ingredients, usually non-digestible carbohydrates, which are assumed to be beneficial for host health by stimulating the protective intestinal microbiota (83). Furthermore there is another heterogeneous domain of dietary components that directly or indirectly influence the course of infection. This thesis has its focus on this domain of dietary components. This other domain of dietary components includes minerals, such as zinc and calcium, and polyphenols.

\section{Nutrient deficiencies that increase infection risk \\ Zinc}

Zinc can play an important role as it is a cofactor of approximately 120 enzymes of mammals. Zinc deficiency affects nucleic acid metabolism and thereby protein synthesis and cell growth (84). Inadequate zinc intake is associated with impaired immune function $(84,85)$, increased oxidative damage of intestinal tissue (86) and an increased risk of infection (85). Zinc supplementation, on the other hand, can reduce the incidence and prevalence of acute infectious diarrhoea $(85,87)$ and has been shown to reverse the increase in intestinal permeability during Shigella infection in children with a borderline or deficient zinc status (88). Zinc carnosine, a functional food ingredient, stimulates migration and proliferation of intestinal cells and stabilizes the gut mucosa (89). These results indicate that besides the restoration of immune-cell functioning, normalization of the epithelial cell lining and strengthening of the epithelial barrier might be responsible for the observed beneficial effects of zinc supplementation.

\section{Vitamin A}

Vitamin A, or retinol, deficiency, which is an endemic nutritional problem throughout much of the developing world, increases susceptibility to severe infection (90). Supplementation of vitamin A in this population increases resistance to infection $(90,91)$. Although vitamin A was one of the first "accessory" factors to be identified by nutritional research, the understanding of its role in human health is still evolving. The existence and properties of cellular and nuclear receptors, the conversion of carotenes to retinol, and the role that vitamin A plays in regulating gene function remain topics of continuing discovery and interest. Mechanistic studies of vitamin A deficiency in Salmonella-infected rats showed that the deficiency damaged both humoral and cellular immunity in the intestinal mucosa, resulting in aggravated damage to the intestinal mucosa (92). It is unclear whether increasing the vitamin A intake in a population that already has a sufficient intake increases intestinal defence to infection. This kind of research is limited because vitamin A can be toxic when taken in excess. Therefore the focus of vitamin A research is on the deficient population. 


\section{Dietary compounds that increase intestinal resistance to infection Calcium}

Another beneficial mineral is dietary calcium. It enhances intestinal resistance to infectious disease and protects rats (93-96) and humans (96) against Salmonella and enterotoxigenic Escherichia coli (ETEC) associated diarrhoea.

Absorption of ingested dietary calcium is generally less than 10\% (97). Beneficial health effects, especially bone health, are ascribed to absorbed calcium and for a long time unabsorbed dietary calcium has been considered without physiological benefit. However, luminal calcium exerts various effects. It should be noted that systemic (serum) calcium concentrations are tightly regulated, and thus stable, and are not influenced by dietary calcium supplementation (98). The substantial amount of ingested calcium that escapes absorption forms an insoluble complex with dietary phosphate in the upper small intestine (99). Protective effects of calcium phosphate against infection and infectious diarrhoea are associated with an increase of lactobacilli in the indigenous microbiota and reduction of luminal cytotoxicity $(93,95)$. Both these are suggested to be important for the protective effects of calcium. Studies in animals (94) and humans (97) have shown that calcium precipitates irritating bile acids and reduces cytotoxicity of the luminal contents, which prevents epitheliolysis and may strengthen intestinal barrier function. It is also suggested that the decrease in cytotoxicity is responsible for the increase of lactobacilli (100).

Anti-diarrhoeal effects found in rat and human infection studies were recently also shown in a transgenic rat model of IBD (101). Moreover these studies showed that colitis-related intestinal barrier defects were reduced by dietary calcium. Even in healthy rats it was shown that calcium decreases intestinal permeability (Schepens et al 2010 Br J Nut, In Press). Moreover, calcium increases the intestinal barrier function in healthy rats. The protective mechanism on the epithelial barrier function might be via direct effects of calcium on the TJ function, or indirectly e.g. via modulation of the microbiota. These are areas to be explored.

Similar to the property of calcium phosphate to bind or precipitate bile acids and fatty acids, it also precipitates lipopolysaccharides (LPS) at least in in vitro binding experiments. LPS includes a hydrophobic fatty acid containing part and is present in the outer membrane of Gram-negative bacteria, including Salmonella. It was hypothesised that calcium can precipitate Gram-negative bacteria and thus prevent their attachment to the intestinal epithelium (96).

\section{Polyphenols}

Another group of dietary components which potentially can improve resistance to intestinal infections are polyphenols. Polyphenols are a group of chemical substances found in plants characterized by the presence of more than one phenol unit or building block per molecule. Polyphenols are widely distributed in vegetable foods (legumes, cereals, fruits) and beverages (tea, wine) (102). In many 
cases, these substances serve as plant defence mechanisms against predation by microorganisms, insects and herbivores (103). Polyphenols have antimicrobial properties in vitro and could possibly inhibit intestinal Salmonella infections. For example, hydrolysable tannins, which are widespread in grapes, berries and wines (104), are suggested to have antimicrobial effects against Gram-negative bacteria (105). Their mode of antimicrobial action may be related to their ability to prevent microbial adhesion and to inactivate bacterial enzymes and cell envelope transport proteins (103). Tannic acid is a complex hydrolysable tannin that is used as a preservative by the food industry (106). It is composed of six to nine gallic acid molecules esterified with glucose, derived from (Chinese) gallnuts $(106,107)$, and may have protective effects against Salmonella infection. Despite the described anti-bacterial properties of polyphenols as mentioned above, their potentially beneficial effect for host resistance in vivo has not been demonstrated yet.

\section{Amino acids and fatty acids}

Sulphur-containing amino acids (such as cysteine and glutamine), n-3 fatty acids and the short chain fatty acid butyrate, are all suggested to ameliorate gastrointestinal integrity and might ameliorate the gut barrier integrity in infection-related disease $(108,109)$. Butyrate itself is not a dietary component but a fermentation product of the microbiota which increases in the intestinal lumen on high dietary fibre intake (109). In the healthy human colon butyrate was shown to beneficially affect oxidative stress (110) and thereby possibly be a candidate to improve the gut barrier function.

A wide area of intestinal diseases has been investigated concerning protective effects of $n-3$ fatty acids. For example consumption of $n-3$ fatty acid supplements reduces mucosal inflammation, diarrhoea and improved histological repair in rats with experimental colitis (109). In a study of endotoxin-induced intestinal ischaemia in rats, it was found that fish oil-supplemented parenteral diets, which contains n-3 fatty acids, improved killing of translocated bacteria (111).

Glutamine is a nonessential amino acid and is one of the most intensively studied nutrients in gastrointestinal research. However, it appears to be required in greater quantities under certain catabolic conditions in the intestine. Glutamine is a substrate in many key metabolic processes, including inter-organ nitrogen transfer, protein synthesis, gluconeogenesis, acid-base homeostasis, and nucleic acid biosynthesis. Glutamine is also utilized as a major fuel/substrate by intestinal mucosal cells and by immune cells throughout the body, including those of the gut-associated immune system (109). Therefore it must be a key player during intestinal infection. Numerous studies in animal models and an increasing number of clinical trials indicate that glutamine-supplemented nutrition has beneficial effects in certain clinical situations (109).

Cysteine is essential for glutathione synthesis (112) and cysteine availability is often the rate-limiting factor for intracellular glutathione synthesis (113). 
Cysteine may also affect host defence by other mechanisms. Trefoil peptides, which stabilize the mucosal glycoproteins in the mucus network and thereby protect the mucosa from various insults, contain several cysteine-rich domains $(35,114)$. In addition, defensins, which are antimicrobial peptides secreted by human and rodent ileal Paneth cells, contain 6 conserved cysteines (115) and are important for intestinal resistance to Salmonella infection (116). Although cysteine is not an essential amino acid and can be synthesised from methionine, it might be conditionally essential as suggested for glutamine $(109,117)$. This means that under conditions of increased demand, e.g. during infectious disease, normal production of cysteine from methionine becomes limited and this amino acid has to be additionally and directly obtained from dietary sources. However, up to now this area has not been investigated in vivo.

\section{INFECTION MODELS TO CONDUCT DIETARY INTERVENTIONS}

The ultimate goal of the dietary interventions to improve intestinal resistance against infectious disease described in this thesis is to improve human health. However, it is ethically not so simple to infect humans to perform a standardized and well-monitored infection study. There are human models, such as an oral infection model with an attenuated ETEC strain (96). Another method to investigate dietary effects on the course of infection is to perform a well-monitored dietary intervention in a high-risk population. Currently, it is being investigated whether dietary calcium can reduce incidence of diarrhoea in Indonesian children (Agustina \& Bovee-Oudenhoven et al, NCT00512824 ClinicalTrials.gov), who are a group at high risk of foodborne infection and subsequent diarrhoea (118). It is important to first conduct research in appropriate animal models before starting such investigations in humans. Therefore intestinal infection studies are primarily performed in animals, generally in rodents, to screen the efficacy of potentially protective dietary components and to investigate their functional mechanism. Fundamental studies on dietary modulation of intestinal Salmonella infection are results from a Salmonella infection model in rats. In this model $S$. enteritidis is used, since this bacterium is invasive in rodents, which enables research on bacterial colonization as well as translocation, and it is an accepted animal model for gastroenteritis (119). Moreover this is the predominant strain in the Western hemisphere and in Europe (1).

To reveal the role and importance of specific innate defence mechanisms this Salmonella infection model can be sensitized. By depletion or interruption of specific host defence mechanisms the role of these mechanisms in infection and disease outcome can be specifically investigated. Using these sensitized models also enables us to identify specific defence mechanisms associated with dietary modulation of intestinal infection. By such investigations crucial host mechanisms are revealed and lay the foundation for improvement of gut health and disease. Furthermore, investigations in infection models are a tool to identify new potential biomarkers of intestinal disease. There is great scientific and 
medical interest in identifying and validating new and especially non-invasive biomarkers of intestinal health and disease, such as gut infection and inflammation. Their implementation in clinical routine in humans is attractive because these markers yield valuable information on intestinal health status by a noninvasive means. These markers could facilitate monitoring of intestinal disease activity with time, e.g. in response to therapeutic or dietary intervention, and may reduce the need for endoscopic investigations. Dependent on the sensitivity and specificity of e.g. faecal biomarkers, their analysis can be highly quantitative and even suitable for early detection of sub-clinical activity (120).

\section{RATIONALE AND OUTLINE OF THESIS}

Diet is likely a unique tool to improve intestinal defence against infection but, at present, its potential is far from fully explored. Growing resistance of bacterial pathogens, including Salmonella species, to generally applied antibiotics makes alternative methods to improve intestinal defence against these threats a necessity. Building on one of the alternatives, this thesis contributes to the exploratory field of dietary modulation of gut infections. The first chapter elaborates on contemporary scientific knowledge of defence mechanisms of the intestine against foodborne infections. Furthermore dietary components that might improve resistance against Salmonella infection are highlighted.

Chapter 2 evaluates the new potential faecal biomarker, $\operatorname{RegIII}(\beta)$, to monitor infection severity in rats. The functional role of RegIII $\beta$ in intestinal resistance to infection, which is explored by using RegIII $\beta$ knock-out mice, is described in Chapter 3. Extrapolation to humans of the findings on the possible biomarker function of RegIII $\beta$ in rodents is described in an exploratory study in healthy subjects, ETEC infected subjects and IBD patients (Chapter 4).

Some of the intestinal defence mechanisms may be crucial for the course of Salmonella infection although in vivo evidence is often lacking. The effects of depletion of glutathione during Salmonella infection and its relevance for gut barrier function are reported in Chapter 5. In the same chapter, the efficacy of dietary cystine supplementation to increase glutathione levels aimed at enhancing resistance to infection is described. Intestinal permeability changes and the severity of infection in response to perturbation of the indigenous microbiota by antibiotic treatment are described in Chapter 6. In the same sensitized infection model it was investigated whether dietary calcium and tannic acid could counteract some of the negative antibiotic side-effects and improve health outcomes related to infection resistance in this rat model.

The main findings, general discussion and recommendations for future studies are presented in the final Chapter 7 


\section{REFERENCES}

1. (WHO), W. H. O. 2002.

Foodborne diseases, emerging.

\section{Buzby, J. C.Roberts, T.} 2009. The economics of enteric infections: human foodborne disease costs. Gastroenterology 136: 1851-1862.

3. (WHO), W. H. O. 2005.

Drug-resistant Salmonella.

4. Kaur, T.Ganguly, N. K. 2003. Modulation of gut physiology through enteric toxins. Mol Cell Biochem 253: 15-19.

5. (WHO), W. H. O. 2007. Food safety and foodborne illness.

6. Hansen, R., Thomson, J. M., El-Omar, E. M.Hold, G. L. 2010. The role of infection in the aetiology of inflammatory bowel disease. J Gastroenterology.

7. Villani, A., Lemire, M., Thabane, M., Belisle, A., Geneau, G., Garg, A. X., Clark, W. F. et al. 2010.

Genetic risk factors for postinfectious Irritable Bowel Syndrome following a waterborne outbreak of gastroenteritis. Gastroenterology 138: 1502-1513.

8. Rohekar, S.Pope, J. 2009. Epidemiologic approaches to infection and immunity: the case of reactive arthritis. Current Opinion in Rheumatology 21: 386-390.

9. Maki, D. G. 2009. Coming to grips with foodborne infection--peanut butter, peppers, and nationwide salmonella outbreaks. N Engl J Med 360: 949-953.

10. Brooks, S. G., May, J., Sedman, P., Tring, I., Johnstone, D., Mitchell, C. J.MacFie, J. 1993. Translocation of enteric bacteria in humans. Br J Surg 80: 901-902.

11. Tenover, F. C.Hughes, J. M. 1996. The challenge of emerging infectious diseases -

Development and spread of multiply-resistant bacterial pathogens. JAMA 275: 300304.

12. Lee, L. A., Puhr, N. D., Maloney, E. K., Bean, N. H.Tauxe, R. V. 1994. Increase in antimicrobial-resistant Salmonella infections in the United States, 1989-1990. J Infect Dis 170: 128-134.

13. Ramos, J. M., Alés, J. M., Cuenca-Estrella, M., Fernandez-Roblas, R.Soriano, F. 1996. Changes in susceptibility of Salmonella enteritidis, Salmonella typhimurium, and Salmonella virchow to six antimicrobial agents in a
Spanish hospital. Eur J Clin Microbiol Infect Dis 15: 85-88.

14. Pizarro-Cerda, J.Cossart, P. 2006. Bacterial adhesion and entry into host cells. Cell 124: 715-727.

15. Craig, L., Pique, $M$.

E.Tainer, J. A. 2004. Type IV pilus structure and bacterial pathogenicity. Nat Rev Microbiol 2: 363-378.

16. Cossart, P.Sansonetti, P. J. 2004. Bacterial invasion: the paradigms of enteroinvasive pathogens. Science 304: 242248.

17. Grassl, G. A.Finlay, B. B. 2008. Pathogenesis of enteric Salmonella infections. Curr Opin Gastroenterol 24: 22-26.

18. Ly, K. T.Casanova, J. E. 2007. Mechanisms of Salmonella entry into host cells. Cell Microbiol 9: 2103-2111.

19. Mims, C. A. 1987. Events occurring immediately after the entry of a microorganism. In: Pathogenisis of infectous disease. Academic press, London.

20. Salyers, A. A.Whitt, D. D. 1994. Salmonella infections. In: Bacterial pathogenesis; A molecular approach. ASM Press, Washington, D.C. 
21. Kohler, H., Sakaguchi, T., Hurley, B. P., Kase, B. A., Reinecker, H. C.McCormick, B. A. 2007. Salmonella enterica serovar Typhimurium regulates intercellular junction proteins and facilitates transepithelial neutrophil and bacterial passage. Am J Physiol Gastrointest Liver Physiol 293: G178-187.

\section{Boyle, E. C., Brown, N.}

F.Finlay, B. B. 2006. Salmonella enterica serovar Typhi-murium effectors SopB, SopE, SopE2 and SipA disrupt tight junction structure and function. Cell Microbiol 8: 1946-1957.

\section{Viswanathan, V. K.,} Hodges, K.Hecht, G. 2009. Enteric infection meets intestinal function: how bacterial pathogens cause diarrhoea. Nat Rev Microbiol 7: 110-119.

\section{Berkes, J., Viswanathan,} V. K., Savkovic, S. D.Hecht, G. 2003. Intestinal epithelial responses to enteric pathogens: effects on the tight junction barrier, ion transport, and inflammation. Gut 52: 439451.

25. Sellin, J. H. 1993. Intestinal electrolyte absorption and secretion. In: Gastrointestinal disease (Sleisenger, M. H. \& Fordtran, J. S., eds.), pp. 954971. W.B. Saunders Compagny, Philadelphia.
26. Molina, N. C.Peterson, J. W. 1980. Cholera toxin-like toxin released by Salmonella species in the presence of mitomycin C. Infect Immun 30: 224-230.

27. Ruiz-Palacios, G. M., Torres, J., Torres, N. I., Escamilla, E., Ruiz-Palacios, B.

R.Tamayo, J. 1983. Choleralike enterotoxin produced by Campylobacter jejuni. Characterisation and clinical significance. Lancet 2: 250-253.

\section{Macdonald, T. T.Monte-} leone, G. 2005. Immunity, inflammation, and allergy in the gut. Science 307: 19201925.

29. DeSesso, J. M.Jacobson, C. F. 2001. Anatomical and physiological parameters affecting gastrointestinal absorption in humans and rats. Food Chem Toxicol 39: 209-228.

\section{Gorden, J.Small, P. L.} 1993. Acid resistance in enteric bacteria. Infect Immun 61: 364-367.

\section{Giannella, R. A., Broit-} man, S. A.Zamcheck, N. 1973. Influence of gastric acidity on bacterial and parasitic enteric infections. A perspective. Ann Intern Med 78: 271-276.
32. Sarker, S. A.Gyr, K. 1992. Non-immunological defence mechanisms of the gut. Gut 33: 987-993.

33. Wingate, D. L. 1990. Acid reduction and recurrent enteritis. Lancet 335: 222.

34. Specian, R. D.Oliver, M.

G. 1991. Functional biology of intestinal goblet cells. Am J

Physiol 260: C183-193.

\section{Sands, B. E.Podolsky, D.}

K. 1996. The trefoil peptide family. Annu Rev Physiol 58: 253-273.

36. Johansson, M. E. V., Holmén Larsson, J. M.Hansson, G. C. 2010. The two mucus layers of colon are organized by the MUC2 mucin, whereas the outer layer is a legislator of host-microbial interactions. PNAS.

37. Lievin-Le Moal, V.Servin, A. L. 2006. The front line of enteric host defense against unwelcome intrusion of harmful microorganisms: mucins, antimicrobial peptides, and microbiota. Clin Microbiol Rev 19: 315-337.

38. Duncan, H. E.Edberg, S. C. 1995. Host-microbe interaction in the gastrointestinal tract. Crit Rev Microbiol 21: 85-100. 
39. Salyers, A. A. Whitt, D. D. 1994. Bacterial pathogenisis - a molecular approach. ASM Press, Washington DC.

40. Stephen, A.

M.Cummings, J. H. 1980. The microbial contribution to human faecal mass. J Med Microbiol 13: 45-56.

41. Sekirov, I., Tam, N. M., Jogova, M., Robertson, M. L., Li, Y., Lupp, C.Finlay, B. B. 2008. Antibiotic-induced perturbations of the intestinal microbiota alter host susceptibility to enteric infection. Infect Immun 76: 4726-4736.

42. Croswell, A., Amir, E., Teggatz, P., Barman, M.Salzman, N. H. 2009. Prolonged impact of antibiotics on intestinal microbial ecology and susceptibility to enteric Salmonella infection. Infect Immun 77: 2741-2753.

43. Grassl, G. A., Valdez, Y., Bergstrom, K. S., Vallance, B. A.Finlay, B. B. 2008. Chronic enteric salmonella infection in mice leads to severe and persistent intestinal fibrosis. Gastroenterology 134: 768-780.

44. Freter, R., Brickner, H., Botney, M., Cleven, D.Aranki, A. 1983. Mechanisms that control bacterial populations in continuousflow culture models of mouse large intestinal flora. Infect Immun 39: 676-685.

\section{Gopal, P. K., Prasad, J.,} Smart, J.Gill, H. S. 2001. In vitro adherence properties of Lactobacillus rhamnosus DR20 and Bifidobacterium lactis DR10 strains and their antagonistic activity against an enterotoxigenic Escherichia coli. Int J Food Microbiol 67: 207-216.

\section{Lee, Y. K., Puong, K. Y.,} Ouwehand, A. C.Salminen, S. 2003. Displacement of bacterial pathogens from mucus and Caco- 2 cell surface by lactobacilli. J Med Microbiol 52: 925-930.

47. Bernet, M. F., Brassart, D., Neeser, J. R.Servin, A. L. 1994. Lactobacillus acidophilus LA 1 binds to cultured human intestinal cell lines and inhibits cell attachment and cell invasion by enterovirulent bacteria. Gut 35: 483-489.

\section{Pitman, R. S.Blumberg,}

R. S. 2000. First line of defense: the role of the intestinal epithelium as an active component of the mucosal immune system. J Gastroenterol 35: 805-814.

49. Karczewski, J., Troost, F. J., Konings, I., Dekker, J., Kleerebezem, M., Brummer,
R. M.Wells, J. M. 2010. Regulation of human epithelial tight junction proteins by Lactobacillus plantarum in vivo and protective effects on the epithelial barrier. Am J Physiol Gastrointest Liver Physiol 298: G851-859.

50. Watson, A. J., Chu, S., Sieck, L., Gerasimenko, O., Bullen, T., Campbell, F., McKenna, M. et al. 2005. Epithelial barrier function in vivo is sustained despite gaps in epithelial layers. Gastroenterology 129: 902-912.

51. Ayabe, T., Satchell, D. P., Wilson, C. L., Parks, W. C., Selsted, M. E.Ouellette, A. J. 2000. Secretion of microbicidal alpha-defensins by intestinal Paneth cells in response to bacteria. Nat Immunol 1:

113-118.

52. Muller, C. A., Autenrieth, I. B.Peschel, A. 2005. Innate defenses of the intestinal epithelial barrier. Cell Mol Life Sci 62: 1297-1307.

53. Jung, H. C., Eckmann, L., Yang, S. K., Panja, A., Fierer, J., Morzycka-Wroblewska, E.Kagnoff, M. F. 1995. A distinct array of proinflammatory cytokines is expressed in human colon epithelial cells in response to bacterial invasion. J Clin Invest 95: 55-65. 
54. Eckmann, L., Kagnoff, M. F.Fierer, J. 1993. Epithelial cells secrete the chemokine interleukin-8 in response to bacterial entry. Infect Immun 61: 4569-4574.

55. Segal, A. W. 2005. How neutrophils kill microbes. Annu Rev Immunol 23: 197223.

56. Klebanoff, S. J. 1999. Myeloperoxidase. Proc Assoc Am Physicians 111: 383-389.

\section{Shah, V., Lyford, G.,} Gores, G.Farrugia, G. 2004. Nitric oxide in gastrointestinal health and disease. Gastroenterology 126: 903-913.

\section{Chakravortty, D.Hensel,}

M. 2003. Inducible nitric oxide synthase and control of intracellular bacterial pathogens. Microbes Infect 5: 621627.

59. Wallace, J. L.Miller, M. J. 2000. Nitric oxide in mucosal defense: a little goes a long way. Gastroenterology 119: 512-520.

60. Anggard, E. 1994. Nitric oxide: meditor, murderer, and medicine. The Lancet 343: 1199-1206.

61. Oudenhoven, I. M., Klaasen, H. L., Lapre, J. A., Weerkamp, A. H.Van der
Meer, R. 1994. Nitric oxidederived urinary nitrate as a marker of intestinal bacterial translocation in rats. Gastroenterology 107: 47-53.

62. Charmandari, E., Meadows, N., Patel, M., Johnston, A.Benjamin, N. 2001. Plasma nitrate concentrations in children with infectious and noninfectious diarrhea. J Pediatr Gastroenterol Nutr 32: 423427.

\section{Sprong, R. C., Hulstein,} M. F.van Der Meer, R. 2000. Quantifying translocation of Listeria monocytogenes in rats by using urinary nitric oxide-derived metabolites. Appl Environ Microbiol 66: 5301-5305.

\section{Forte, P., Dykhuizen, R.} S., Milne, E., McKenzie, A., Smith, C. C.Benjamin, N. 1999. Nitric oxide synthesis in patients with infective gastroenteritis. Gut 45: 355-361.

65. Meister, A. 1988. Glutathione metabolism and its selective modification. J Biol Chem 263: 17205-17208.

66. Kruidenier, L., Kuiper, I., Lamers, C. B.Verspaget, $H$. W. 2003. Intestinal oxidative damage in inflammatory bowel disease: semi-quantification, localization, and association with mucosal antioxidants. J Pathol 201: 28-36.

67. Musch, M. W., WalshReitz, M. M.Chang, E. B. 2006. Roles of ZO-1, occludin, and actin in oxidant induced barrier disruption. Am J Physiol Gastrointest Liver Physiol 290: G222-231.

\section{Kosower, N. S.Kosower,} E. M. 1978. The glutathione status of cells. Int Rev Cytol 54: 109-160.

69. Meister, A. 1984. New aspects of glutathione biochemistry and transport-selective alteration of glutathione metabolism. Nutr Rev 42: 397-410.

70. Meister, A. 1988. On the discovery of glutathione. Trends Biochem Sci 13: 185188.

71. Kelly, F. J. 1993. Glutathione content of the small intestine: regulation and function. Br J Nutr 69: 589-596.

72. Lash, L. H., Hagen, T. M.Jones, D. P. 1986. Exogenous glutathione protects intestinal epithelial cells from oxidative injury. Proc Natl Acad Sci U S A 83: 4641-4645.

73. Rao, R. K., Li, L., Baker, R. D., Baker, S. S.Gupta, A. 2000. Glutathione oxidation 
and PTPase inhibition by hydrogen peroxide in Caco-2 cell monolayer. Am J Physiol Gastrointest Liver Physiol 279: G332-340.

\section{Kelly, N., Friend, K.,} Boyle, P., Zhang, X. R., Wong, C., Hackam, D. J., Zamora, R. et al. 2004. The role of the glutathione antioxidant system in gut barrier failure in a rodent model of experimental necrotizing enterocolitis. Surgery 136: 557-566.

\section{Furness, J. B., Kunze, W.} A.Clerc, N. 1999. Nutrient tasting and signaling mechanisms in the gut II. The intestine as a sensory organ: neural, endocrine, and immune responses The American Journal of Physiology 277: G922-928.

76. Schnare, M., Barton, G. M., Holt, A. C., Takeda, K., Akira, S.Medzhitov, R. 2001. Toll-like receptors control activation of adaptive immune responses. Nat Immunol 2: 947-950.

77. Sato, A.Iwasaki, A. 2005. Peyer's patch dendritic cells as regulators of mucosal adaptive immunity. Cell Mol Life Sci 62: 1333-1338.

78. Fournier, B., Williams, I. R., Gewirtz, A. T.Neish, A. S. 2009. Toll-Like Receptor 5-dependent regulation of Inflammation in systemic Salmonella enterica serovar Typhimurium infection. Infection and Immunity 77: 41214129.

79. Macpherson, A. J.Uhr, T. 2004. Induction of protective IgA by intestinal dendritic cells carrying commensal bacteria. Science 303: 1662-1665.

\section{Macpherson, A. J., Hun-} ziker, L., McCoy, K.Lamarre, A. 2001. IgA responses in the intestinal mucosa against pathogenic and non-pathogenic microorganisms. Microbes Infect 3: 1021-1035.

81. Kelly, D. S.Bendich, A. 1996. Essential nutrients and immunologic functions. Am J Clin Nutr 63: 994S-996S.

82. Roberfroid, M. B. 2000. Prebiotics and probiotics: are they functional foods? Am J Clin Nutr 71: 1682S-1687S.

83. Gibson, G. R.Roberfroid, M. B. 1995. Dietary modulation of the human colonic microbiota: introducing the concept of prebiotics. J Nutr 125: 1401-1412.

84. Chandra, R. K.Au, B. 1980. Single nutrient deficiency and cell-mediated immune responses. I Zink. Am J Clin Nutr 33: 736-738.
85. Tuerk, M. J.Fazel, N. 2009. Zinc deficiency. Curr Opin Gastro 25: 136-143.

86. Virgili, F., Canali, R., Figus, E., Vignolini, F., Nobili, F.Mengheri, E. 1999. Intestinal damage induced by zinc deficiency is associated with enhanced $\mathrm{CuZn}$ superoxide dismutase activity in rats: effect of dexamethasone or thyroxine treatment. Free Radic Biol Med 26: 11941201.

87. Sazawal, S., Black, R. E., Bhan, M. K., Jalla, S., Sinha, A.Bhandari, N. 1997. Efficacy of zinc supplementation in reducing the incidence and prevalence of acute diarrhea - a community based-based, double blind, controlled trial. Am J Clin Nutr 66: 413-418.

88. Alam, A. N., Sarker, S. A., Wahed, M. A., Khatun, M.Rahaman, M. M. 1994. Enteric protein loss and intesstinal permeability changes in young children during acute shigellosis and after recovery: effect of zinc supplementation. Gut 35: 1707-1711.

\section{Mahmood, A., FitzGer-} ald, A. J., Marchbank, T., Ntatsaki, E., Murray, D., Ghosh, S.Playford, R. J. 2007. Zinc carnosine, a health food supplement that stabilises small bowel integrity and 
stimulates gut repair processes. Gut 56: 168-175.

90. Sommer, A. 2008. Vitamin A deficiency and clinical disease: an historical overview. J Nutr 138: 1835-1839.

91. Lima, A. A., Soares, A. M., Lima, N. L., Mota, R. M., Maciel, B. L., Kvalsund, M. P., Barrett, L. J. et al. 2010. Effects of vitamin A supplementation on intestinal barrier function, growth, total parasitic and specific Giardia spp infections in Brazilian children: a prospective randomized, double-blind, placebocontrolled trial. J Pediatr Gastroenterol Nutr 50: 309-315.

92. Yang, Y., Yuan, Y., Tao, Y.Wang, W. 2010. Effects of vitamin A deficiency on mucosal immunity and response to intestinal infection in rats. Nutrition in Press.

\section{Bovee-Oudenhoven, I.} M., Termont, D. S., Heidt, P. J.Van der Meer, R. 1997.

Increasing the intestinal resistance of rats to the invasive pathogen Salmonella enteritidis: additive effects of dietary lactulose and calcium. Gut 40: 497-504.

94. Bovee-Oudenhoven, I. M., Termont, D. S., Weerkamp, A. H., Faassen-Peters, M. A.Van der Meer, R. 1997. Dietary calcium inhibits the intestinal colonization and translocation of Salmonella in rats. Gastroenterology 113: 550557.

95. Bovee-Oudenhoven, I. M., Wissink, M. L., Wouters, J. T.Van der Meer, R. 1999. Dietary calcium phosphate stimulates intestinal lactobacilli and decreases the severity of a salmonella infection in rats. J Nutr 129: 607-612.

96. Bovee-Oudenhoven, I. M., Lettink-Wissink, M. L., Van Doesburg, W., Witteman, B. J.Van Der Meer, R. 2003. Diarrhea caused by enterotoxigenic Escherichia coli infection of humans is inhibited by dietary calcium. Gastroenterology 125: 469-476.

97. Govers, M. J., Termont, D. S., Lapre, J. A., Kleibeuker, J. H., Vonk, R. J.Van der Meer, R. 1996. Calcium in milk products precipitates intestinal fatty acids and secondary bile acids and thus inhibits colonic cytotoxicity in humans. Cancer Res 56: 3270-3275.

98. Appleton, G. V., Owen, R. W., Wheeler, E. E., Challacombe, D. N.Williamson, R. C. 1991. Effect of dietary calcium on the colonic luminal environment. Gut 32: 13741377.
99. van der Meer, R., Welberg, J. W. M., Kuipers, F., Kleibeuker, J. H., Mulder, N. H., De Vries, H. T.De Vries, E. G. E. 1990. Effects of supplemental dietary calcium on the intestinal association of calcium, phosphate, and bile acids. Gastroenterology 99: 1653-1659.

100. Boesten, R. J.De Vos, W. M. 2008. Interactomics in the human intestine: Lactobacilli and Bifidobacteria make a difference. j Clin Gastroenterol 42: S163-S167.

101. Schepens, M. A., Schonewille, A. J., Vink, C., van Schothorst, E. M., Kramer, E., Hendriks, T., Brummer, R. J. et al. 2009. Supplemental Calcium Attenuates the Colitis-Related Increase in Diarrhea, Intestinal Permeability, and Extracellular Matrix Breakdown in HLA-B27 Transgenic Rats. J Nutr.

102. Bravo, L., Abia, R., Eastwood, M. A.Saura-Calixto, F. 1994. Degradation of polyphenols (catechin and tannic acid) in the rat intestinal tract. Effect on colonic fermentation and faecal output. Br J Nutr 71: 933-946.

103. Cowan, M. M. 1999. Plant products as antimicrobial agents. Clin Microbiol Rev 12: 564-582. 
104. Beecher, G. R. 2003.

Overview of dietary flavonoids: nomenclature, occurrence and intake. J Nutr 133: 3248S-3254S.

105. Puupponen-Pimia, R., Nohynek, L., Meier, C., Kahkonen, M., Heinonen, M., Hopia, A.Oksman-Caldentey, K. M. 2001. Antimicrobial properties of phenolic compounds from berries. J Appl Microbiol 90: 494-507.

106. Chung, K. T., Wong, T. Y., Wei, C. I., Huang, Y. W.Lin, Y. 1998. Tannins and human health: a review. Crit Rev Food Sci Nutr 38: 421-464.

107. Okuda, T., Yoshida, T.Hatano, T. 1995. Hydrolyzable tannins and related polyphenols. Fortschritte der chemie organischer naturstoffe 66: 1-117.

108. Duggan, C., Gannonn, J.Walker, W. A. 2002. Protective nutrients for the gastrointestinal tract. The American Journal of clinical nutrition 75: 789-808.

109. Ziegler, T. R., Evans, M. E., Fernandez-Estivariz, C.Jones, D. P. 2003. Trophic and cytoprotective nutrition for intestinal adaptation, mucosal repair, and barrier function. Annu Rev Nutr 23: 229-261.
110. Hamer, H. M., Jonkers, D. M. A. E., Bast, A., Vanhoutvin, S. A. L. W., Fischer, M. A. J. G., Kodde, A., Troost, F. J. et al. 2009. Butyrate modulates oxidative stress in the colonic mucosa of healty humans. Clinical Nutrition 28: 88-93.

111. Pscheidl, E., Schywalsky, M., Tschaikowsky, K.BokeProls, T. 2000. Fish oilsupplemented parenteral diets normalize splanchnic blood flow and improve killing of translocated bacteria in a lowdose endotoxin rat model. Critical care medicine 28: 1489-1496.

112. Meister, A. 1998. The Liver biology and pathobiology: Glutathione, Second edition ed. Raven Press, Ltd., New York.

\section{Meister, A. 1991. Gluta-} thione deficiency produced by inhibition of its synthesis, and its reversal; applications in research and therapy. Pharmacol Ther 51: 155-194.

\section{Kindon, H., Pothoula-} kis, C., Thim, L., Lynch-Devaney, K.Podolsky, D. K. 1995. Trefoil peptide protection of intestinal epithelial barrier function: cooperative interaction with mucin glycoprotein. Gastroenterology 109: 516523.
115. Cunliffe, R. N.Mahida, Y. R. 2004. Expression and regulation of antimicrobial peptides in the gastrointestinal tract. J Leukoc Biol 75: 49-58.

116. Salzman, N. H., Ghosh, D., Huttner, K. M., Paterson, Y.Bevins, C. L. 2003. Protection against enteric salmonellosis in transgenic mice expressing a human intestinal defensin. Nature 422: 522526.

117. Furst, P. 1998. Old and new substrates in clinical nutrition. J Nutr 128: 789-796.

118. Sembra, R. D., de Pee, S., Kraemer, K., Sun, K., Thorne-Lyman, A., MoenchPfanner, R., Sari, M. et al. 2009. Purchase of drinking water is associated with increased child morbidity and mortality among urban slumdwelling families in Indonesia. Int J Hyg Environ Health 212: 387-397.

119. Finlay, B. B.Brumell, J. H. 2000. Salmonella interactions with host cells: in vitro to in vivo. Philos Trans R Soc Lond B Biol Sci 355: 623-631.

\section{Pardi, D. S.Sandborn,} W. J. 2005. Predicting relapse in patients with inflammatory bowel disease: what is the role of biomarkers? Gut 54: 321322. 


\title{
CHAPTER 2
}

\section{ILEAL MUCOSAL AND FECAL PANCREATITIS ASSOCIATED PROTEIN LEVELS REFLECT SEVERITY OF SALMONELLA INFECTION IN RATS}

\author{
Marleen T.J. van Ampting ${ }^{1,2}$, Wendy Rodenburg ${ }^{1,2,3}$, Carolien Vink ${ }^{1,2}$, \\ Evelien Kramer ${ }^{1,3}$, Arjan J. Schonewille ${ }^{1,2}$, Jaap Keijer ${ }^{1,3}$, \\ Roelof van der Meer ${ }^{1,2}$, Ingeborg M.J. Bovee-Oudenhoven ${ }^{1,2}$ \\ ${ }^{1}$ TI Food and Nutrition, Wageningen, the Netherlands \\ ${ }^{2}$ Department of Health and Safety, NIZO food research, Ede, the Netherlands \\ ${ }^{3}$ RIKILT Institute of Food Safety, Wageningen, the Netherlands
}

Dig Dis Sci. 2009; 54:2588-2597. 


\section{ABSTRACT}

Background: Microbial infections induce ileal pancreatitis associated protein/ regenerating gene III (PAP/RegIII) mRNA expression. Despite increasing interest, little is known on PAP/RegIII protein. Therefore, ileal mucosal PAP/RegIII protein expression, localization, and fecal excretion were studied in rats upon Salmonella infection.

Results: Salmonella infection increased ileal mucosal PAP/RegIII protein levels in enterocytes located at the crypt-villus junction. Increased colonization and translocation of Salmonella was associated with higher ileal mucosal PAP/RegIII levels and secretion of this protein in feces.

Conclusions: PAP/RegIII protein is increased in enterocytes of the ileal mucosa during Salmonella infection and is associated with infection severity. $\mathrm{PAP} / \mathrm{RegIII}$ is excreted in feces and might be used as a new and non-invasive infection marker. 


\section{INTRODUCTION}

Pancreatitis associated protein (PAP) is a type III member of the regenerating (Reg) gene family and was originally identified as a lectin-related secretory protein present in rat pancreatic juice during experimental pancreatitis (1). Since then, considerable attention has been given to the Reg family and its structurally related molecules. Recently, the complex terminology of the Reg family and its isoforms was elegantly reviewed (2) and a combined term of PAP/RegIII was coined, to foster a concerted effort in the investigation of PAP and the isoforms. In this study we focused on ileal PAP/RegIII in rats, represented by the genes $P A P 1$ and PAP3. Both genes encode for a protein of similar size and these genes are paralogues, which means that they derive from the same ancestral gene. The rat PAP3 (alias RegIII $\gamma$ ) and mouse RegIII $\gamma$ are orthologues, which means that they are on amino acid level the most identical genes between two species (bidirectional best hit). The other isoform, the rat PAP1 (alias PAP) is the orthologue of the mouse PAP1 (alias RegIII $\beta$ ).

Expression of PAP/RegIII mRNA has been shown in the pancreas of human (3), mouse (4) and rat (5). Moreover, PAP/RegIII was described as constitutively expressed in the rat (6) and human (7) small intestine. Intestinal expression was not altered during acute pancreatitis (6), indicating that intestinal and pancreatic expression are differentially regulated. Interestingly, increased levels of intestinal PAP/RegIII mRNA have been detected during active inflammatory bowel disease (IBD), Crohn's disease and ulcerative colitis in humans $(8,9)$, and in animal models of IBD (9-11). We recently reported a time dependent increase in intestinal PAP/RegIII mRNA, represented by the genes PAP1 and PAP3, in Salmonella infected rats $(12,13)$. These results are in line with studies showing increased PAP/RegIII mRNA upon bacterial colonization of the porcine small intestine with Salmonella (14) and enterotoxigenic Escherichia coli (ETEC) (15). Hence, it is suggested that PAP/RegIII expression is triggered by increased microbial-epithelial contact and reflects a state of enhanced host defense (16). Hitherto, few studies focused on PAP/RegIII protein levels and it was not investigated whether PAP/RegIII expression actually reflects infection severity or an improved host defense status.

Furthermore, data on localization of ileal PAP/RegIII is controversial. $P A P / R e g I I I$ mRNA is reported to be present in epithelial cells of the lower villus part (6), whereas other studies limit expression to Paneth cells in the ileal crypt bottoms (16).

To investigate intestinal localization and protein levels of PAP/RegIII we studied PAP/RegIII expression in the rat small intestine upon infection with Salmonella enteritidis, which is a common foodborne pathogen. Our study focused on the distal ileum, since this area is important in Salmonella infection pathology and sensitive for infection-induced up-regulation of PAP/RegIII genes (12). In addition, we determined whether ileal PAP/RegIII expression relates to infection severity. Modulation of this infection severity can be achieved by inoculating 
animals with different doses of the pathogen, but it has been shown that Salmonella translocation to organs (17) and the magnitude of immune response can be irrespective of the inoculated dose (18). On the other hand, we have shown in previous studies that dietary calcium has profound resistance-enhancing effects and protects against Salmonella and ETEC infection in rats (19-22) and humans (22). Therefore, we performed a dietary calcium intervention in rats to modulate Salmonella infection severity and to relate well-established infection markers with intestinal PAP/RegIII protein expression. More importantly, we determined the presence of PAP/RegIII in feces and studied the proposed antimicrobial activity of PAP/RegIII in vitro using fecal water incubates.

\section{METHODS}

\section{Diets, infection and dissection of the rats}

The experimental protocol was approved by the animal welfare committee of Wageningen University (Wageningen, the Netherlands). Specific pathogen-free male outbred Wistar rats (WU, Harlan, Horst, the Netherlands), 8 weeks old and with a mean body weight of $245 \mathrm{~g}$, were housed individually in metabolic cages as described (23). Rats were fed purified diets containing per kg: $200 \mathrm{~g}$ acid casein, $326 \mathrm{~g}$ cornstarch, $174 \mathrm{~g}$ glucose, $160 \mathrm{~g}$ palm oil, $40 \mathrm{~g}$ corn oil, $50 \mathrm{~g}$ cellulose and vitamin and mineral mix (without calcium) according to AIN-93 (24). To mimic the composition of a Western human diet, the prepared diets were relatively low in calcium and high in fat compared to standard rodent diets (24). Diets were supplemented with $\mathrm{CaHPO}_{4} \cdot 2 \mathrm{H}_{2} \mathrm{O}$ (Merck, Darmstadt, Germany), at the expense of glucose, to a final concentration of $30 \mathrm{mmol} / \mathrm{kg}$ (control diet) or $120 \mathrm{mmol} /$ $\mathrm{kg}$ (calcium diet). Food, intake recorded daily, and demineralized drinking water were supplied ad libitum. Body weight was measured every two days before infection and daily after infection. Two groups were fed the control diet and another two groups were fed the calcium-supplemented diet ( $n=9$ per group). In addition, five rats were fed the control $(n=3)$ or calcium $(n=2)$ diet and served as noninfected controls.

Animals were acclimatized to housing and dietary conditions for 14 days, after which they were orally infected with $0.5 \mathrm{ml}$ of saline containing $3.10^{9} \mathrm{col}-$ ony-forming units of Salmonella enteritidis (clinical isolate, phage type 4; strain NIZO1241, NIZO food research, Ede, the Netherlands) as described elsewhere (23). Animals in the non-infected group orally received $0.5 \mathrm{ml}$ saline only.

On day 3 or 4 after oral infection, rats from one control and one calciumsupplemented group were randomly selected and killed by carbon dioxide inhalation. The non-infected control rats were also killed by this procedure. During the dissection, the distal $12 \mathrm{~cm}$ of the ileum was excised. A $2 \mathrm{~cm}$ piece, identical location in each sample, was cut out and preserved in 10\% formalin (Sigma-Aldrich, St Louis, Missouri, USA) and embedded in paraffin for histological analysis. The remaining parts were cut open longitudinally and, after flushing with saline, the 
mucosa was scraped off and immediately frozen in liquid nitrogen for RNA isolation and protein analyses, as described below.

The other infected control and calcium groups were followed until day 7 after infection to collect fresh fecal samples with time for Salmonella quantification, as described elsewhere (21). In addition, $24 \mathrm{~h}$ feces (pooled per animal per 2 days) and urines were collected before infection and seven consecutive days after oral infection. All $24 \mathrm{~h}$ feces and urine samples were stored at $-20^{\circ} \mathrm{C}$ until further analysis. Oxytetracycline (Sigma-Aldrich) was added to the urine collection vessels of the metabolic cages to prevent bacterial deterioration. Bacterial translocation was quantified by measuring urinary $\mathrm{NO}_{\mathrm{x}}$ (sum of nitrate and nitrite) excretion by using a colorimetric enzymatic kit (Roche Diagnostics, Basel, Switzerland), as described (25). Urinary $\mathrm{NO}_{\mathrm{x}}$ is a more sensitive and quantitative marker of intestinal bacterial translocation than culturing of extra-intestinal organs $(26,27)$

\section{Myeloperoxidase analysis in ileal mucosa}

Frozen mucosal scrapings of the ileum were pulverized under liquid nitrogen. Approximately half of the pulverized tissue was suspended in a $0.2 \mathrm{M}$ sucrose buffer of pH 7.4 containing $20 \mathrm{mM}$ trishydroxymethylaminomethane (Tris), $1 \mathrm{mM}$ dithiothreitol (DTT) and a protease inhibitor cocktail (Complete, Roche Diagnostics). After mixing and centrifugation at $14000 \mathrm{~g}$ for $20 \mathrm{~min}$ the pellet was resuspended in acetate-HETAB buffer $(0.5 \%$ hexadecyltrimethylammonium bromide (HETAB) at $\mathrm{pH} 6.0,50 \mathrm{mM}$ sodium acetate, $10 \mathrm{mM}$ ethylenediaminetetraacetic acid (EDTA) and $0.25 \mathrm{M}$ sucrose) and sonicated on ice for $30 \mathrm{~s}$ at level 2-3 (Sonicator XL2020, Heat Systems, Farmingdale, NY, USA). The protein concentration of the samples was determined using BC Assay (Omnilabo, Breda, the Netherlands) according to the manufacturer's protocol. A mouse myeloperoxidase (MPO) ELISA test kit (Hycult biotechnology, Uden, the Netherlands), which is cross-reactive with rat MPO, was used according to the manufacturer's guidelines to determine the concentration of MPO in mucosal scrapings.

\section{Quantitative real-time PCR analysis of PAP/Reglll, represented by $P A P 1$ and $P A P 3$ mRNA, in ileal mucosa}

The other half of the pulverized ileal mucosal scrapings was dissolved in TRIzol reagent (Invitrogen, Carlsbad, California, USA) to isolate and purify total RNA as described before (12). By using TaqMan Reverse Transcription reagents (Applied Biosystems Inc., Foster City, California, USA) copy DNA was created from $1 \mu \mathrm{g}$ of RNA on a Perkin Elmer DNA Thermal Cycler 480, followed by SYBR Green-based real-time PCR on a 7500 Fast Real-Time PCR system (Applied Biosystems). PCR conditions used were $95{ }^{\circ} \mathrm{C}$ for $10 \mathrm{~min}$, followed by 40 amplification cycles $\left(95^{\circ} \mathrm{C}\right.$ for $15 \mathrm{~s}, 60^{\circ} \mathrm{C}$ for $\left.1 \mathrm{~min}\right)$. Data were normalized against $\beta$-actin and aldolase. Controls, methods and primer design were performed as described (12). The primer sequences are listed in Table 1. 
Table 1 Primer sequences

\begin{tabular}{llll}
\hline \hline Gene & Acc. nr & forward primer $\left(5^{\prime} \rightarrow 3^{\prime}\right)$ & reverse primer $\left(5^{\prime} \rightarrow 3^{\prime}\right)$ \\
\hline PAP1 & NM_053289 & GACTCCATGACCCCACTCTTG & GCAGACGTAGGGCAACTT CAC \\
PAP3 & NM_173097 & GCTTCCTTTGTGTCCTCCTTGATT & TACTCCACTCCCATCCACCTCTG \\
$\beta$-actin & NM_031144 & CTTTCTACAATGAGCTGCGTGTG & GTCAGGATCTTCATGAGGTAGTCTGTC \\
aldolase & NM_012495 & ATGCCCCACCCATACCCAGCACT & AGCAGCAGTTGGCGGTAGAAGCG
\end{tabular}

Sequences of primers used for quantitative real-time PCR analysis. Acc. nr describes the accession number of the used sequence ID.

\section{Analysis of PAP/Reglll protein in ileal mucosa}

Ileum paraffin sections were immunostained with a goat polyclonal antibody against rat PAP/RegIII (1:50) (PAP/ RegIII \#AF 1996; R\&D Systems, Minneapolis, MN, USA). This antibody can not discriminate between PAP1 and RegIII (PAP3), but since both PAP1 and PAP3 fall within the PAP/RegIII group, this discrimination is not essential for our investigation (2). Western blot analysis of total mucosal homogenates showed that the antibody bound to a single size protein band only, indicating specific binding of the antibody. Localization of Paneth cells was confirmed by immunostaining for lysozyme with ready to use anti-lysozyme (N1515; Dako). DAB peroxidase substrate kit (Dako) was used for signal detection of the horseradish peroxidase (HRP) labeled secondary antibody, according to the manufacturer's protocol.

PAP/RegIII protein expression in the ileal mucosa was semi-quantified by light microscopy as follows: total length of (bottom) crypt to villus (tip) and part of this length stained positive for PAP/RegIII were measured. The length stained positive for PAP/ RegIII was expressed as percentage of total crypt-villus length. For each tissue section three completely visible crypt-villus axes were analyzed, scored and averaged for that particular rat. All histological slides were recoded before microscopy to ensure blind scoring and to prevent observer's bias.

\section{Analysis of PAP/Reglll protein in feces}

Total $24 \mathrm{~h}$ feces were lyophilized in a manifold freeze dryer (FD5515; Ilshin Laboratory Co Ltd, Seoul, South Korea) and pooled per treatment group on the basis of individual daily fecal dry weight excretion. Proteins were isolated from lyophilized feces pools as described elsewhere (28) with a few modifications. Briefly, $100 \mathrm{mg}$ of feces was homogenized in $500 \mu \mathrm{l}$ buffer containing $50 \mathrm{mmol} / \mathrm{L}$ Tris-HCl (pH7.5), $100 \mathrm{mmol} / \mathrm{L} \mathrm{NaCl}, 1 \mathrm{mmol} / \mathrm{L}$ EDTA and Complete Protease Inhibitor Cocktail (Roche). After centrifugation (2 min at $15000 \mathrm{~g}$ ), the supernatant was taken and its protein concentration was determined using DC protein assay kit (Bio-rad Laboratories, Veenendaal, the Netherlands) according to 
the manufacturer's protocol. $45 \mu \mathrm{g}$ Protein was denatured at $100^{\circ} \mathrm{C}$ for $3 \mathrm{~min}$ in Tricine sample buffer (Bio-rad Laboratories), subjected to SDS- polyacrylamide gel electrophoresis (SDS-PAGE) gel (4\% stacking-gel, 14\% separation-gel) and transferred to a PVDF membrane (Bio-rad Laboratories). After blocking, the membranes were incubated with the PAP/RegIII antibody (1:100). The signal of the secondary HRP-conjugated antibody was detected using the ECL Plus chemiluminescent detection kit (GE Healthcare, Den Bosch, the Netherlands).

To evaluate recovery of PAP/RegIII protein in feces, $3 \times 50 \mathrm{mg}$ of the preinfection feces pool, from animals fed the control diet, was homogenized in PBS. One of these three samples was spiked with $1 \mu \mathrm{g}$ recombinant rat PAP (recPAP alias PAP1; pre-release reagent from R\&D Systems Inc.). The second sample was heat inactivated by incubation at $75^{\circ} \mathrm{C}$ for $10 \mathrm{~min}$, then cooled down to room temperature and identically spiked with the recombinant protein. PBS was added to the third sample and used as negative control. Subsequently, the three samples were incubated at $37^{\circ} \mathrm{C}$ for $1 \mathrm{~h}$ and protein was isolated and analyzed by immunoblotting as described above.

\section{Analysis of antimicrobial activity}

To assess antimicrobial activity of rat PAP/RegIII against Gram-negative $S$. enteritidis and Gram-positive Listeria monocytogenes (strain EGD-e, strain NIZO2364, NIZO food research, Ede, the Netherlands), analysis was performed exactly as described (16). Briefly, target organisms were grown in brain-heart infusion (BHI) broth and resuspended in $25 \mathrm{mM}$ 2-( $N$-morpholino)ethanesulfonic acid (MES) (pH 6), containing $25 \mathrm{mM} \mathrm{NaCl}$. The initial bacterial concentration of the incubates was $106 \mathrm{CFU} / \mathrm{ml}$ and recPAP was added to a final concentration of 4 and $10 \mu \mathrm{M}$. After incubation for 2 and 24 hours at $37^{\circ} \mathrm{C}$ viable bacteria were quantified by plating 10 -fold dilutions on $\mathrm{BHI}$ agar plates.

To mimic the environment in which PAP/RegIII is proposed to function as antimicrobial peptide, we performed a similar antimicrobial activity assay but replaced the MES buffer by sterile fecal water extracts from non-infected animals fed the control diet. Fecal water was prepared as described (29). Purified recPAP was added to fecal water incubates to a final concentration of 4 and $10 \mu \mathrm{M}$ and viable pathogens were quantified after 2 and 24 hours of incubation as described above. Experiments were performed in duplicate.

A control experiment was performed to check correct folding and thus binding activity of recPAP as described elsewhere (16). Briefly, $10 \mu \mathrm{g}$ recPAP was added to $50 \mu \mathrm{g}$ insoluble Bacillus subtilis peptidoglycan (Sigma-aldrich) and pelleted. Pellet and supernatant fractions were analyzed on recPAP content by SDSPAGE (as described above).

\section{Statistical analysis}

Data from the non-infected rats fed the control or calcium diet were pooled as no diet-induced differences were observed. All data are expressed as means \pm SE, 
Table 2 Fecal Salmonella excretion, translocation-induced urinary excretion of nitric oxide metabolites (NOx) and mucosal myeloperoxidase.

\begin{tabular}{lcc} 
Non-infected & \multicolumn{2}{c}{ Infected } \\
\cline { 2 - 3 } & Control & Calcium
\end{tabular}

Day after infection

\begin{tabular}{lcccc}
\hline & Day 1 & n.d. & $7.2 \pm 0.3^{\mathrm{a}}$ & $6.3 \pm 0.3^{\mathrm{b}}$ \\
Fecal Salmonella $(\log \mathrm{CFU} / \mathrm{g})$ & Day 3 & n.d. & $6.2 \pm 0.4^{\mathrm{a}}$ & $4.9 \pm 0.3^{\mathrm{b}}$ \\
& Day 7 & n.d. & $4.7 \pm 0.4^{\mathrm{a}}$ & $4.2 \pm 0.5^{\mathrm{a}}$ \\
\hline
\end{tabular}

Infection-induced urinary NOx ( $\mu$ mol/ 7 days $) \quad$ Days $1-7 \quad 0 \quad 73 \pm 14^{\text {a }} \quad 25 \pm 5^{\text {b }}$

Ileal mucosal myeloperoxidase (ng/mg protein) $\quad$ Day 3/4 $\quad 11 \pm 3^{\mathrm{a}} \quad 127 \pm 52^{\mathrm{b}} \quad 60 \pm 17^{\mathrm{b}}$

Values are means \pm SE, $n=8$ per infected group and $n=5$ for the non-infected control group. Differences between groups were tested for statistical significance using Student's $t$ test (2-sided). Except for myeloperoxidase data, which were tested by non-parametric Kruskall-Wallis ANOVA followed by Mann-Whitney U test (2-sided).

Values in the same row not sharing the same letter are significantly different $(p<0.05)$. N.d. indicates not detected
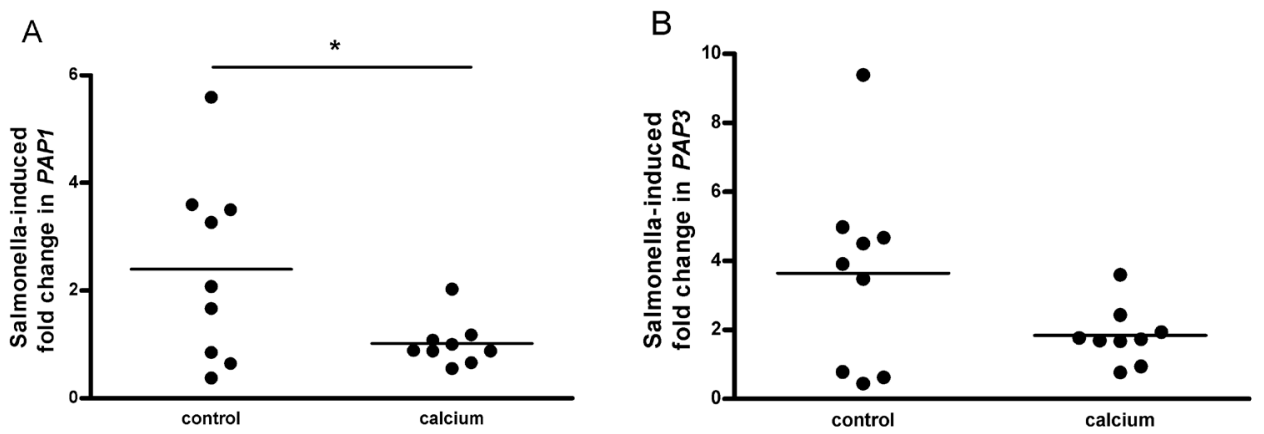

Figure 1. Relative pancreatitis associated protein 1 (PAP1, panel A) and pancreatitis associated protein 3 (PAP3, panel B) mRNA expression in ileal mucosa due to Salmonella infection in rats fed the control or calcium-supplemented diet. Individual values were first normalized to $\beta$-actin expression. These normalized data were used to calculate relative expression levels by setting the mean expression level of non-infected rats fed the identical diet at one. The mean of each diet group $(n=9)$ is indicated by a line. Differences between the calcium and control group were tested for statistical significance using Student's $t$ test (2-sided). The asterisk indicates $p<0.05$. Identical results were found when signals were normalized to aldolase (data not shown). 
except for PCR results, which are individually plotted in addition to indication of groups' mean. Data were tested for normality by the Kolmogorov-Smirnov test. If normally distributed, differences between means were tested for significance using one-way ANOVA and/or Student's $t$ test (two-tailed). For non-normally distributed data, differences between means were tested for their significance using the non-parametric Kruskall-Wallis ANOVA and/or Mann-Whitney U test (two-tailed). Statistical significance was set at $p<0.05$.

\section{RESULTS}

\section{Animals and food intake}

All data from one animal in the calcium group (followed until day 7 or 8 after infection) were excluded from the study results because that rat suffered from pneumonia due to oropharyngeal reflux of the $S$. enteritidis suspension. At the start of the experiment, mean body weight of the animals was $245 \mathrm{~g}$. Average body weight gain (mean before infection $5 \mathrm{~g} / \mathrm{d}$, after infection $3.3 \mathrm{~g} / \mathrm{d}$ ) and food intake (mean $17 \mathrm{~g}$ dry wt/d; not affected by Salmonella infection) were not affected by dietary treatment.

\section{Fecal excretion and translocation of Salmonella}

As expected, no Salmonella could be detected in feces collected before infection of the animals. The first days after Salmonella infection, rats fed the calcium diet had approximately 10 -fold less Salmonella in their feces than rats fed the control diet $(\mathrm{p}<0.05$; table 2$)$, reflecting reduced intestinal colonization of this pathogen. Furthermore, translocation of Salmonella was inhibited in rats on the calcium diet as measured by the infection-induced increase in urinary $\mathrm{NO}_{\mathrm{x}}$ excretion. Total infection-induced urinary $\mathrm{NO}_{\mathrm{x}}$ excretion (area under the curve) of the calcium group was significantly lower than that of the control group $(\mathrm{p}<0.05$; table $2)$. Results are in accordance with previous infection studies of our lab $(20,21,27)$.

\section{Ileal mucosal inflammation}

Compared to non-infected animals, ileal MPO levels increased 12-fold in the Salmonella infected control group $(\mathrm{p}<0.05$; table 2$)$ and 5 -fold in the calcium group on days 3-4 post-infection. Although post-infection MPO levels in the calcium-supplemented rats were less than half of those detected in the control group, the difference did not reach statistical significance. This was likely due to the relatively large inter-individual variation observed in the Salmonella-infected control group.

\section{Effect of infection and dietary calcium intervention on PAP/RegIll mRNA and protein expression in ileal mucosa}

During infection, ileal PAP1 was 3 fold higher expressed than PAP3 (PAP1/actin was 0.8 and 0.7 and $P A P 3 /$ actin was 0.29 and 0.27 in control and calcium groups, respectively). Salmonella infection of rats fed the control diet increased PAP1 

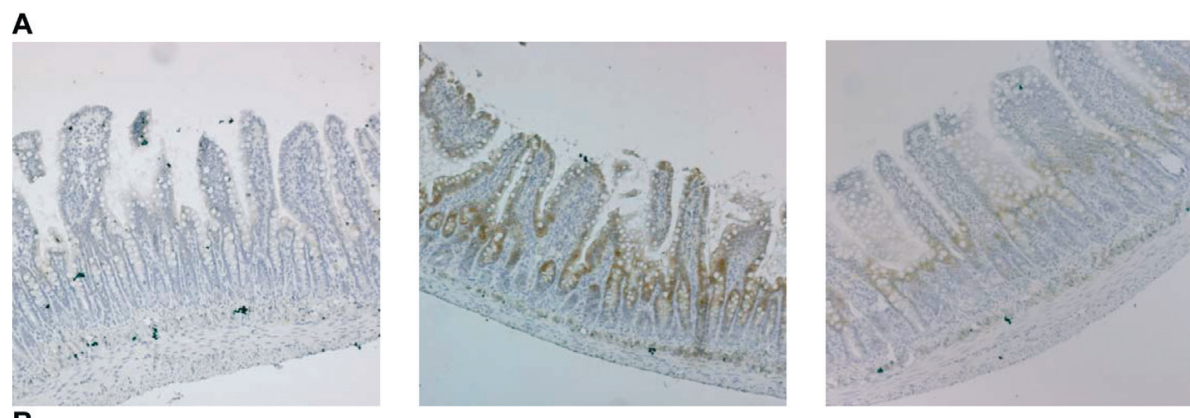

$12.5 \mathrm{x}$
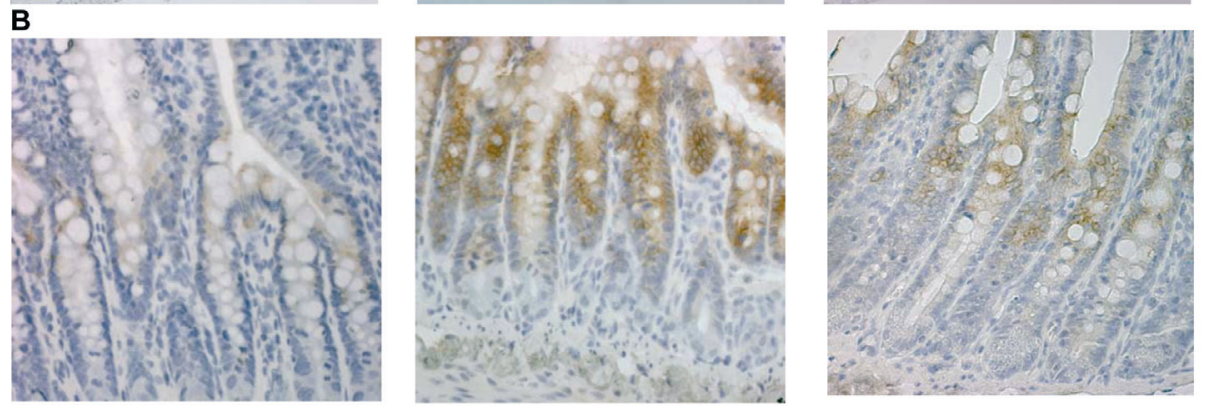

40x

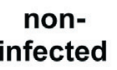

control

calcium

infected

Figure 2. Pancreatitis associated protein/regenerating gene III (PAP/RegIII) protein expression in the ileal mucosa of non-infected and Salmonella infected rats fed either the control or calcium-supplemented diet. PAP/RegIII protein was present in enterocytes at the cryptvillus junction (panel A, 12.5x; panel $\mathrm{B}, 40 \mathrm{x}$ ). The number of PAP/RegIII positive cells increased after infection, especially in the direction of villus tips (panel A). Dietary calcium reduced PAP/RegIII expression in infected animals. No staining was observed in sections incubated without primary antibody (data not shown). All sections were counterstained with haematoxylin to visualize nuclei.

mRNA 2.4-fold, whereas no up-regulation was observed in calcium-supplemented infected rats ( $<<0.05$, Fig. 1A). Furthermore, compared to non-infected rats a 3.6-and 1.8-fold induction of PAP3 mRNA was observed in infected rats fed the control and calcium diet, respectively (Fig. 1B).

Little PAP/RegIII protein was detected in the ileum mucosa of noninfected rats, whereas Salmonella infected animals showed an increased number of cells staining positive for PAP/RegIII protein (Fig. 2). PAP/RegIII protein was detected specifically in enterocytes at the crypt-villus junction. The protein was not detected within Goblet cell thecae. After infection the number of PAP/RegIII-positive enterocytes increased towards both villus tips and crypts' bottom. So, a larger area of the surface epithelium stained positive for PAP/ RegIII after infection. Semi-quantification showed that the percentage of total crypt-villus length stained positive for PAP/RegIII protein increased 34\% after 


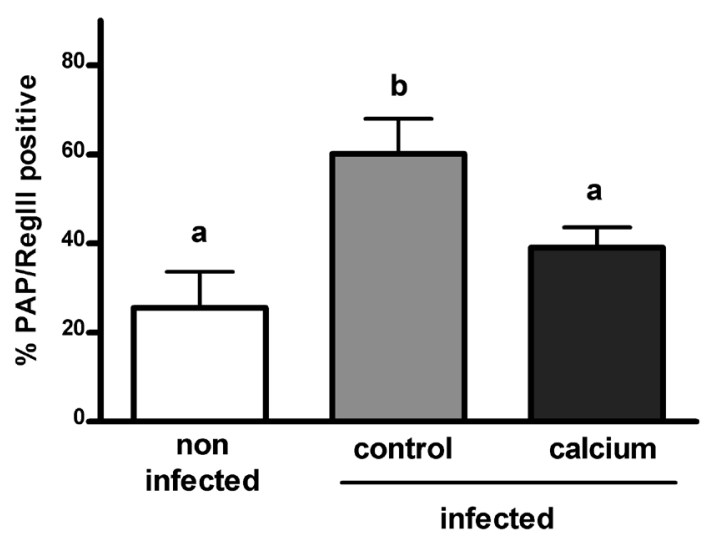

Figure 3. Pancreatitis associated protein/regenerating gene III (PAP/RegIII) protein expression in the ileum mucosa of non-infected $(n=5)$ and Salmonella infected rats fed either the control $(n=9)$ or calcium-supplemented $(n=9)$ diet. Immunohistochemical slides (representative images are shown in Fig. 2) were used to quantify the percentage of total crypt-villus length stained positive for PAP/RegIII. Total crypt-villus length was not affected by infection or calcium supplementation. Slides were recoded before microscopy to guarantee blind scoring. Results are expressed as means \pm SE. Differences between groups was tested by non-parametric Kruskall-Wallis ANOVA followed by Mann-Whitney U test (2-sided). Different letters indicate significant differences $(p<0.05)$.

Salmonella infection in the control group $(\mathrm{p}<0.05$; Fig. 3$)$. In contrast, no significant increase in PAP/RegIII protein was observed in calcium-supplemented infected animals (Fig. 3). PAP/RegIII protein was not detected in the ileal Paneth cells located at the deep crypt bottom as confirmed by Paneth cells-specific staining of lysozyme (data not shown).

\section{Presence of PAP/Reglll in feces}

Immunoblotting revealed the presence of PAP/RegIII protein in feces (Fig. 4A, lanes 1-10). Similar to the PAP/RegIII levels in the ileum mucosa, PAP/RegIII protein in feces of rats fed the control diet was considerably increased from 3-4 days and remained steady until day 7 after infection. This infection-induced increase in fecal PAP/RegIII was less in calcium-supplemented infected animals. However, basal fecal PAP/RegIII levels in non-infected rats were slightly higher in the calcium group than in the control group.

Purified recPAP protein showed a single band of approximately 16 $\mathrm{kDa}$, which is identical to the size of PAP/RegIII detected in ileum mucosa (Fig. 4B, lanes 4 and 5). When recPAP was added to feces it was hydrolyzed into two smaller forms. RecPAP incubated with pre-infection feces formed identical sized bands to that seen in feces of infected rats (data not shown). Adding recPAP to heat-inactivated feces largely prevented subsequent hydrolysis and merely preserved the $16 \mathrm{kDa}$ band (Fig. 4B, lanes 2 and 3). 
A

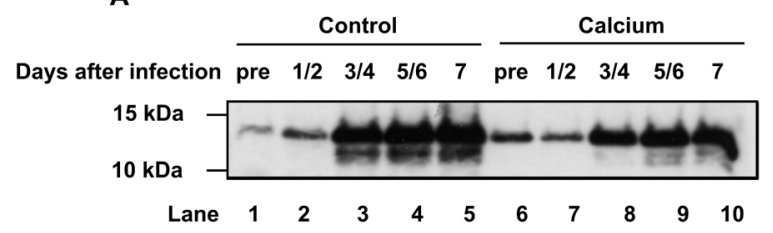

B

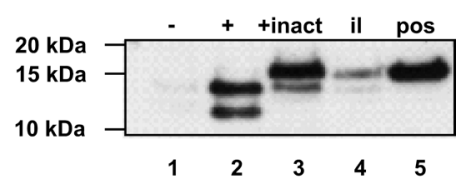

Figure 4. Effect of Salmonella infection and dietary calcium on pancreatitis associated protein/regenerating gene III (PAP/RegIII) secretion in feces with time. Lyophilized feces were pooled per group ( $n=9$ and $n=8$ for control and calcium group, respectively) and per two days. SDS-PAGE gels were loaded with equal quantities of fecal protein and analyzed for PAP/RegIII (panel A, lanes 1-10) by using PAP/RegIII anti-serum. Recombinant rat pancreatitis associated protein (recPAP) showed a single band (panel B, lane 5), similar to PAP/ RegIII detected in the ileum mucosa of animals fed the control diet (panel B, lane 4). RecPAP incubated with pre-infection feces from rats fed the control diet was hydrolyzed into two smaller fragments (panel B, lane 2). When run on one gel, these fragments were of identical size as those found in fecal extracts of infected rats (data not shown). Heat inactivation of feces before addition of recPAP largely prevented hydrolysis of the protein (panel B, lane 3). Non-spiked feces (from non-infected rats) was added to lane 1 and served as negative control. No signal was detected when immunoblots were incubated without primary antibody (data not shown).

\section{Antimicrobial activity}

No antimicrobial activity could be detected when 4 or $10 \mu \mathrm{M}$ recPAP was incubated with L. monocytogenes or S. enteritidis in a MES buffer system (Fig. 5).

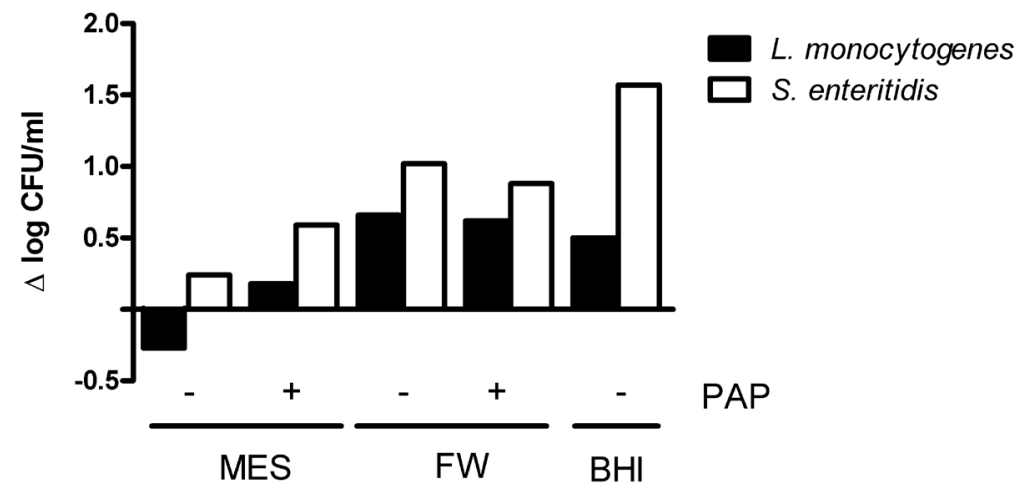

Figure 5. Rat PAP lacks anti-bacterial activity against L. monocytogenes (black bars) and $S$. enteritidis (white bars) in vitro. Bacteria were incubated in MES buffer or fecal water extract (FW) with 0,4 or $10 \mu \mathrm{M}$ recombinant rat PAP (PAP). Pathogens were also grown in brain-heart infusion (BHI) broth as positive control. The initial bacterial concentration in the incubates was 106 colony-forming units per $\mathrm{ml}(\mathrm{CFU} / \mathrm{ml})$. After incubation for 2 hours at $37^{\circ} \mathrm{C}$, viable bacteria were quantified by plating serial dilutions. The increase (positive values) or decrease (negative values) in viable pathogen counts in comparison with $t=0$ is expressed as $\Delta \log \mathrm{CFU} / \mathrm{ml}$. Elongation of the incubation time to $24 \mathrm{hrs}$ resulted in similar results (data not shown). The assays were performed in duplicate. 
Also, no bactericidal or bacteriostatic activity of rat PAP was noticed against these pathogens when fecal water was used (Fig. 5). When the incubation time was prolonged from 2 to $24 \mathrm{hrs}$, results similar to that in Fig. 5 were obtained. To investigate whether absence of antibacterial activity was due to potential incorrect folding of the recombinant protein, binding activity was tested as described by Cash et al (16). The recPAP used in the present study bound to bacterial peptidoglycan (data not shown).

\section{DISCUSSION}

This study shows that upregulation of PAP/RegIII protein expression by Salmonella infection parallels infection severity as quantified by intestinal Salmonella colonization and translocation. Interestingly, PAP/RegIII protein is also present in feces and these fecal levels reflect the concentration of this protein in infected ileal mucosa.

In support of findings reported $(6,9,30)$, our experiments clearly showed that PAP/RegIII protein was present in enterocytes at the crypt-villus junction of the ileal mucosa. The protein was not detected in the Goblet cells, Goblet cell thecae or Paneth cells. Others have reported expression of RegIII $\gamma$ in mouse ileal Paneth cells isolated by laser capture microdissection before mRNA analysis (16). In that study possible production of RegIII $\gamma$ by other mucosal cell types was not described. Moreover, the latter study was performed in (ex-)germ-free mice, whereas, our and other (6) studies were performed in animals with a conventional flora. First time exposure of germ-free animals to micro-organisms initiates a period of intense contact between microbes and the gut mucosa, until their naïve immune system has matured and e.g. secretion of $\operatorname{sIgA}$ is normalized (31). Therefore, results obtained in germ-free animals should be extrapolated with caution, as those might not be relevant for the normal host with a conventional flora. Furthermore, differences between animal species and the various RegIII isoforms should be considered. However, the ileal PAP/RegIII localization results of the present study are in line with those reported in mice (9), so there is no evidence that mice behave differently from rats in this respect. Other studies reporting Paneth cells as expression site mostly concerned so-called metaplastic Paneth cells in the colon of IBD patients $(8,10)$. As Paneth cells are absent in the healthy colon, it can be questioned whether these cells are identical to ileal Paneth cells.

Increased mRNA levels of PAP or Reg in the intestinal mucosal after bacterial infection has been reported by our and other groups $(12,14,15)$. We now confirmed that this increase actually occurs at the protein level. The former and our results indicate that $P A P /$ RegIII expression is triggered by increased microbial-epithelial contact at mucosal surfaces. In order to establish infection, foodborne pathogens like S. enteritidis and ETEC bind to the small intestinal mucosa by using adhesins or colonization factors which are known virulence factors (32-34). Situations of increased host epithelium-microbial contact often coincide with gut mucosal inflammation, especially when pathogenic 
bacteria are involved (35). Inflammation in general, is also suggested as trigger for PAP/RegIII upregulation, as increased mRNA levels have been documented in inflamed colonic mucosa from patients with active IBD $(8,9)$ as well as in experimental models of colitis $(9,11)$. It should be realized that during active inflammation the mucosa might be damaged, its barrier function impaired, and mucosal cells are likely more exposed to micro-organisms from the gut lumen in comparison to a healthy non-inflamed mucosa (36-38). Hence, it is very difficult to point out whether it is the inflammation or the microbe-host contact only that induces PAP/RegIII upregulation. In a previous study we have shown that $P A P /$ RegIII mRNA is not upregulated till day 3 after oral Salmonella administration (12). This is in line with the time-dependent fecal PAP/RegIII excretion pattern of the present study (Fig. 4A). As translocation of Salmonella already takes place on day 1-2 (12,20), initial bacterial contact is less likely the main driver for PAP/RegIII upregulation. From day 3 after oral Salmonella administration, infection-induced mucosal inflammation is starting and many genes of immune function are upregulated (12). Together these results suggest inflammation as trigger for PAP/RegIII increase. It is becoming increasingly recognized that epithelial cells, besides being crucial for absorption of nutrients and maintenance of the gut barrier, function through an interactive process with components of the underlying immune system. Intestinal epithelial cells play an important role in both innate and adaptive immune responses. Intraepithelial lymphocytes, triggered by bacterial translocation, exist in direct contact with epithelial cells and their interaction can lead to epithelial expression of a variety of regulatory molecules e.g. involved in adhesion, bacterial recognition and antigen presentation, chemotaxis, and mucosal inflammation (32). Follow-up infection studies, for instance in immuno-deficient animal models can reveal whether this interplay is important for PAP expression and functionality. Furthermore, a study in which SPF animals are inoculated with an organism known to adhere to the gut mucosa without causing inflammation can show whether inflammation is indeed required for PAP/RegIII upregulation.

The function of intestinal PAP/RegIII is of most interest. Studies suggesting antimicrobial activity of PAP/RegIII have shown that mouse RegIII $\gamma$ was able to bind to Gram-positive bacteria in vitro (16). Analogous to defensins, PAP/ RegIII is a small protein $( \pm 16 \mathrm{kDa})$, it consists of a secretion signal and a carbohydrate-binding motif. Carbohydrates are present in the gut mucosa (for example mucins) and on the surface of Gram-positive bacteria. Up to now, actual secretion of PAP/RegIII to the gut lumen has only been briefly mentioned without showing data (6). The results of our infection study clearly show that PAP/RegIII is present in feces and is upregulated within the same timeframe as the mucosal levels of this protein. This suggests that fecal PAP/RegIII originates from ileal mucosa and the gut lumen might be the functional site. Our recovery experiments identified hydrolysis of PAP/RegIII in intestinal contents (Fig. 4B). RecPAP incubated with pre-infection feces formed identical sized bands to that seen in the feces 
of infected mice. The hydrolysis of PAP might activate its function like shown for pancreatic derived PAP/RegIII (39). Therefore, the proposed antimicrobial properties of PAP/RegIII reported by others (16) were further explored. Besides repetition of the bactericidal activity assay in MES buffer as performed (16), we also included incubates of L. monocytogenes and S. enteritidis in fecal water in the presence or absence of PAP/RegIII. Fecal water, containing intestinal enzymatic activity and gut surfactants like bile acids and fatty acids, better represents the natural (in vivo) environment than a clean MES buffer system. The concentration of recPAP used in our experiments was $4 \mu \mathrm{M}$, as this was the estimated concentration in feces after Salmonella infection as detected by immunoblotting. Moreover, this concentration fits well in the range applied and found active in reported experiments (16). In addition, a higher PAP concentration $(10 \mu \mathrm{M})$ and a longer incubation time were included. Remarkably, we found no evidence for any bactericidal or bacteriostatic activity against $L$. monocytogenes or S. enteritidis. These results are in line with unpublished results from another research group, who also failed to confirm the antimicrobial activities of rat PAP as well as human PAP (J.L. Iovanna, personal communications). In view of the suggested exclusive antimicrobial function against Gram-positive bacteria (16), it also remains unexplained why Gram-negative bacterial pathogens, like S. enteritidis in our present and previous (12) studies and ETEC (15), are the most potent inducers of intestinal PAP/RegIII, whereas this mucosal protein has no anti-bacterial effect against its inducers. It might indicate that PAP/RegIII functions only at the mucosal interface, where most of the protein would be unhydrolyzed still containing its signal sequence. On the other hand, it cannot be excluded that hydrolysis of PAP/RegIII in the intestinal lumen reflects activation, as is suggested for pancreatic derived PAP/RegIII (39), rather than inactivation of a function yet to be discovered. Furthermore, PAP/RegIII will face a myriad of carbohydrates associated with the mucosa upon epithelial secretion. In that respect, binding of PAP/RegIII to mucins and effects on gut barrier function are areas to be investigated in the near future. It should be noticed that PAP1, or RegIII $\beta$, applied in our in vitro experiments is a homologue but not the orthologue of mouse RegIII $\gamma$ which was used in published in-vitro experiments on bactericidal activity. It might well be that PAP1 (RegIII $\beta$ ) and RegIII $\gamma$ have different functions. Binding assays showed that the recombinant-rat-PAP protein we used was able to bind peptidoglycan, indicating proper folding of the protein.

Diet is known to modulate gene and protein expression in the gut. As we used a calcium intervention to modulate severity of Salmonella infection in rats, we can not exclude a direct effect of dietary calcium on intestinal PAP expression. In fact, the Western blots seemed to indicate that PAP protein in feces of noninfected rats fed the calcium diet was higher than that of non-infected rats fed the control diet (Fig. 4A, lanes 1 and 4). Despite a possible difference in basal excretion, the situation was totally reversed after infection showing the highest ileal and fecal PAP/RegIII protein levels in the low-calcium control group. 
In conclusion, this study demonstrates that PAP/RegIII protein levels present in the ileal mucosa and feces reflect infection severity. As fecal PAP/ RegIII levels can be monitored non-invasively and with time, its use as new infection and/or inflammation marker in animal and in human studies is worthwhile to be further explored. Considering the growing interest in intestinal PAP/RegIII, elucidation of its functionality is scientifically important and might be achieved by generation of PAP/RegIII knock-out animals. Recently a PAP/HIP knock-out mice study on experimentally induced pancreatitis was published (40). Investigation of the reaction of these mice to intestinal infection and inflammation would be very interesting.

\section{ACKNOWLEDGEMENTS}

We would like to thank the biotechnicians at the Small Animal Centre of Wageningen University (Wageningen, The Netherlands) for excellent assistance. We also like to thank Professor J.H. van Krieken at the Department of Pathology, University Medical Centre Nijmegen for his advice on histology results, our colleagues at the Department of Health and Safety of NIZO food research and Professor Robert-Jan Brummer of TI Food and Nutrition for fruitful discussions. 


\section{REFERENCES}

1. Keim, V.Loffler, H. G. 1986. Pancreatitis-associated protein in bile acid-induced pancreatitis of the rat. Clin Physiol Biochem 4: 136-142.

\section{Graf, R., Schiesser, M.,} Reding, T., Appenzeller, P., Sun, L. K., Fortunato, F., Perren, A. et al. 2006. Exocrine meets endocrine: pancreatic stone protein and regenerating protein--two sides of the same coin. J Surg Res 133: 113-120.

3. Watanabe, T., Yonekura, H., Terazono, K., Yamamoto, H.Okamoto, H. 1990. Complete nucleotide sequence of human reg gene and its expression in normal and tumoral tissues. The reg protein, pancreatic stone protein, and pancreatic thread protein are one and the same product of the gene. J Biol Chem 265: 7432-7439.

4. Unno, M., Yonekura, H., Nakagawara, K., Watanabe, T., Miyashita, H., Moriizumi, S., Okamoto, H. et al. 1993. Structure, chromosomal localization, and expression of mouse reg genes, reg I and reg II. A novel type of reg gene, reg II, exists in the mouse genome. J Biol Chem 268: 15974-15982.
5. Iovanna, J., Orelle, B., Keim, V.Dagorn, J. C. 1991. Messenger RNA sequence and expression of rat pancreatitisassociated protein, a lectinrelated protein overexpressed during acute experimental pancreatitis. J Biol Chem 266: 24664-24669.

\section{Iovanna, J. L., Keim, V.,} Bosshard, A., Orelle, B., Frigerio, J. M., Dusetti, N.Dagorn, J. C. 1993. PAP, a pancreatic secretory protein induced during acute pancreatitis, is expressed in rat intestine. Am J Physiol 265: G611-618.

\section{Christa, L., Carnot, F.,} Simon, M. T., Levavasseur, F., Stinnakre, M. G., Lasserre, C., Thepot, D. et al. 1996. HIP/ $\mathrm{PAP}$ is an adhesive protein expressed in hepatocarcinoma, normal Paneth, and pancreatic cells. Am J Physiol 271: G993-1002.

\section{Dieckgraefe, B. K., Stenson,} W. F., Korzenik, J. R., Swanson, P. E.Harrington, C. A. 2000. Analysis of mucosal gene expression in inflammatory bowel disease by parallel oligonucleotide arrays.

Physiol Genomics 4: 1-11.

9. Ogawa, H., Fukushima, K., Naito, H., Funayama, Y., Unno, M., Takahashi, K., Kitayama, T. et al. 2003. Increased expression of HIP/
PAP and regenerating gene III in human inflammatory bowel disease and a murine bacterial reconstitution model. Inflamm Bowel Dis 9: 162-170.

10. Gironella, M., Iovanna, J. L., Sans, M., Gil, F., Penalva, M., Closa, D., Miquel, R. et al. 2005. Anti-inflammatory effects of pancreatitis associated protein in inflammatory bowel disease. Gut 54: 12441253.

11. te Velde, A. A., de Kort, F., Sterrenburg, E., Pronk, I., ten Kate, F. J., Hommes, D. W.van Deventer, S. J. 2007. Comparative analysis of colonic gene expression of three experimental colitis models mimicking inflammatory bowel disease. Inflamm Bowel Dis 13: 325-330.

\section{Rodenburg, W., Bovee-} Oudenhoven, I. M., Kramer, E., van der Meer, R.Keijer, J. 2007. Gene expression response of the rat small intestine following oral Salmonella infection. Physiol Genomics 30: 123-133.

13. Rodenburg, W., Keijer, J., Kramer, E., Roosing, S., Vink, C., Katan, M. B., van der Meer, R. et al. 2007. Salmonella induces prominent gene expression in the rat colon. BMC Microbiol 7: 84. 
14. Niewold, T. A., Veldhuizen, E. J., van der Meulen, J., Haagsman, H. P., de Wit, A. A., Smits, M. A., Tersteeg, M. H. et al. 2007. The early transcriptional response of pig small intestinal mucosa to invasion by Salmonella enterica serovar typhimurium DT104. Mol Immunol 44: 1316-1322.

\section{Niewold, T. A., Kerstens,} H. H., van der Meulen, J., Smits, M. A.Hulst, M. M. 2005. Development of a porcine small intestinal cDNA micro-array: characterization and functional analysis of the response to enterotoxigenic $\mathrm{E}$. coli. Vet Immunol Immunopathol 105: 317-329.

16. Cash, H. L., Whitham, C. V., Behrendt, C. L.Hooper, L. V. 2006. Symbiotic bacteria direct expression of an intestinal bactericidal lectin. Science 313: 1126-1130.

17. Havelaar, A. H., Garssen, J., Takumi, K., Koedam, M. A., Dufrenne, J. B., van Leusden, F. M., de La Fonteyne, L. et al. 2001. A rat model for dose-response relationships of Salmonella Enteritidis infection. J Appl Microbiol 91: 442-452.

\section{Takumi, K., Garssen,} J.Havelaar, A. 2002. A quantitative model for neutrophil response and delayed-type hypersensitivity reaction in rats orally inoculated with various doses of Salmonella Enteritidis. Int Immunol 14: 111-119.

19. Bovee-Oudenhoven, I. M., Termont, D. S., Heidt, P. J.Van der Meer, R. 1997. Increasing the intestinal resistance of rats to the invasive pathogen Salmonella enteritidis: additive effects of dietary lactulose and calcium. Gut 40: 497-504.

20. Bovee-Oudenhoven, I. M., Termont, D. S., Weerkamp, A. H., Faassen-Peters, M. A.Van der Meer, R. 1997. Dietary calcium inhibits the intestinal colonization and translocation of Salmonella in rats. Gastroenterology 113: 550557.

\section{Bovee-Oudenhoven, I.} M., Wissink, M. L., Wouters, J. T.Van der Meer, R. 1999. Dietary calcium phosphate stimulates intestinal lactobacilli and decreases the severity of a salmonella infection in rats. J Nutr 129: 607-612.

22. Bovee-Oudenhoven, I. M., Lettink-Wissink, M. L., Van Doesburg, W., Witteman, B. J.Van Der Meer, R. 2003. Diarrhea caused by enterotoxigenic Escherichia coli infection of humans is inhibited by dietary calcium. Gastroenterology 125: 469476.

23. Bovee-Oudenhoven, I. M., ten Bruggencate, S. J., Lettink-Wissink, M. L.van der Meer, R. 2003. Dietary fructooligosaccharides and lactulose inhibit intestinal colonisation but stimulate translocation of salmonella in rats. Gut 52: 1572-1578.

\section{Reeves, P. G., Nielsen, F.} H.Fahey, G. C., Jr. 1993. AIN93 purified diets for laboratory rodents: final report of the American Institute of Nutrition ad hoc writing committee on the reformulation of the AIN-76A rodent diet. J

Nutr 123: 1939-1951.

\section{Ten Bruggencate, S. J.,} Bovee-Oudenhoven, I. M., Lettink-Wissink, M. L., Katan, M. B.Van Der Meer, R. 2004. Dietary fructo-oligosaccharides and inulin decrease resistance of rats to salmonella: protective role of calcium. Gut 53: 530-535.

26. Gianotti, L., Alexander, J. W., Pyles, T.Fukushima, R. 1993. Arginine-supplemented diets improve survival in gutderived sepsis and peritonitis by modulating bacterial clearance. The role of nitric oxide. Ann Surg 217: 644-653; discussion 653-644. 
27. Oudenhoven, I. M., Klaasen, H. L., Lapre, J. A., Weerkamp, A. H.Van der Meer, R. 1994. Nitric oxidederived urinary nitrate as a marker of intestinal bacterial translocation in rats. Gastroenterology 107: 47-53.

28. He, W., Wang, M. L., Jiang, H. Q., Steppan, C. M., Shin, M. E., Thurnheer, M. C., Cebra, J. J. et al. 2003. Bacterial colonization leads to the colonic secretion of RELMbeta/FIZZ2, a novel goblet cell-specific protein. Gastroenterology 125: 1388-1397.

29. Ten Bruggencate, S. J., Bovee-Oudenhoven, I. M., Lettink-Wissink, M. L.Van der Meer, R. 2003. Dietary fructo-oligosaccharides dosedependently increase translocation of salmonella in rats. J Nutr 133: 2313-2318.

30. Carroccio, A., Iovanna, J. L., Iacono, G., Li Pani, M., Montalto, G., Cavataio, F., Marasa, L. et al. 1997. Pancreatitis-associated protein in patients with celiac disease: serum levels and immunocytochemical localization in small intestine. Digestion 58: 98-103.

31. Shi, H. N.Walker, A. 2004. Bacterial colonization and the development of intestinal defences. Can J Gastroenterol 18: 493-500.
32. Pitman, R. S.Blumberg, R.

S. 2000. First line of defense: the role of the intestinal epithelium as an active component of the mucosal immune system. J Gastroenterol 35: 805-814.

33. Cossart, P.Sansonetti, P. J. 2004. Bacterial invasion: the paradigms of enteroinvasive pathogens. Science 304: 242 248.

34. Pizarro-Cerda, J.Cossart, P. 2006. Bacterial adhesion and entry into host cells. Cell 124: 715-727.

35. Berkes, J., Viswanathan, V. K., Savkovic, S. D.Hecht, G. 2003. Intestinal epithelial responses to enteric pathogens: effects on the tight junction barrier, ion transport, and inflammation. Gut 52: 439-451.

36. Kleessen, B., Kroesen, A. J., Buhr, H. J.Blaut, M. 2002. Mucosal and invading bacteria in patients with inflammatory bowel disease compared with controls. Scand J Gastroenterol 37: 1034-1041.

37. Swidsinski, A., Ladhoff, A., Pernthaler, A., Swidsinski, S., Loening-Baucke, V., Ortner, M., Weber, J. et al. 2002. Mucosal flora in inflammatory bowel disease. Gastroenterology 122: 44-54.
38. Swidsinski, A., LoeningBaucke, V., Theissig, F., Engelhardt, H., Bengmark, S., Koch, S., Lochs, H. et al. 2007. Comparative study of the intestinal mucus barrier in normal and inflamed colon. Gut 56: 343-350.

39. Graf, R., Schiesser, M., Scheele, G. A., Marquardt, K., Frick, T. W., Ammann, R. W.Bimmler, D. 2001. A family of $16-\mathrm{kDa}$ pancreatic secretory stress proteins form highly organized fibrillar structures upon tryptic activation. J Biol Chem 276: 2102821038.

40. Gironella, M., Folch-Puy, E., LeGoffic, A., Garcia, S., Christa, L., Smith, A., Tebar, L. et al. 2007. Experimental acute pancreatitis in PAP/HIP knock-out mice. Gut 56: 1091-1097. 



\section{CHAPTER 3}

\section{THE INTESTINAL SECRETED C-TYPE LECTIN REGIII $\beta$ PROTECTS AGAINST SALMONELLOSIS BUT NOT LISTERIOSIS IN MICE}

Marleen T.J. van Ampting ${ }^{1,2}$, Linda M.P. Loonen ${ }^{1,3}$, Arjan J. Schonewille ${ }^{1,2}$, Irene Konings ${ }^{1,3}$, Carolien Vink ${ }^{1,2}$, Juan Iovanna ${ }^{4}$, Mathias Chamaillard ${ }^{5}$, Jan Dekker ${ }^{1}$, Jerry M. Wells ${ }^{1,3}$, Roelof van der Meer ${ }^{1}$, Ingeborg M.J. Bovee-Oudenhoven ${ }^{1,2}$

${ }^{1}$ TI Food and Nutrition, Wageningen, the Netherlands

${ }^{2}$ Department of Health, NIZO food research, Kernhemseweg 2, 6718 ZB, Ede, the Netherlands

${ }^{3}$ Host Microbe Interactomics, Wageningen University, Marijkeweg 40, 6709 AG, Wageningen, the Netherlands ${ }^{4}$ INSERM U624, Marseille, France

${ }^{5}$ INSERM U801, Lille, France

Submitted for publication. 


\section{ABSTRACT}

Background: The RegIII protein family, including the human member designated pancreatitis-associated protein, are secreted proteins that contain a C-type lectin domain involved in carbohydrate binding. They are expressed by intestinal epithelial cells. Colonization of germ-free mice and intestinal infection with pathogens increases the expression of RegIII $\gamma$ and $\operatorname{RegIII} \beta$ in the murine ileum. RegIII $\gamma$ is directly bactericidal for Gram-positive bacteria but the exact role of $\operatorname{RegIII} \beta$ in bacterial infections is unknown.

Methods: To investigate the possible protective role of RegIII $\beta$ in intestinal infection RegIII $\beta$-knockout $\left(^{-/}\right)$mice and wild-type (wt) mice were orally infected with the Gram-negative Salmonella enteritidis or the Grampositive Listeria monocytogenes. At day 2 (Listeria infection) and at day 4 (Salmonella infection) after oral infection mice were sacrificed to collect intestinal and other tissues for pathogen quantification. Protein expression of RegIII $\beta$ and RegIII $\gamma$ was determined in intestinal mucosal scrapings of infected and non-infected mice. In addition, binding of faecal derived RegIII $\beta$ to Listeria and Salmonella was investigated.

Results: Whereas recovery of Salmonella or Listeria from faeces of $\operatorname{RegIII} \beta^{-/-}$and wt mice was not different, significantly higher numbers of viable Salmonella, but not Listeria, were recovered from the colon, mesenteric lymph nodes, spleen and liver of the RegIII $\beta^{-/-}$mice than from those of wt mice. Protective effects of RegIII $\beta$ were associated with direct binding of the protein to Salmonella and to a lesser extent to Listeria.

Conclusion: RegIII $\beta$ protects mice against intestinal translocation of the Gram-negative bacterium $S$. enteritidis, but not against the Gram-positive bacterium L. monocytogenes. 


\section{INTRODUCTION}

In many countries in the industrialized world, foodborne intestinal infections are continuing to increase (1). For example, outbreaks of salmonellosis and listeriosis have been reported for decades, but within the past 25 years their incidence has increased on many continents (2). To inhibit the colonization (adhesion to the intestinal epithelium) and translocation (invasion of host tissues) of foodborne pathogens and commensals the intestinal mucosal surfaces are armed with an array of physical and chemical defence mechanisms. The low $\mathrm{pH}$ of the gastric compartment, and bile acids secreted in the proximal intestine, reduce the number of bacteria that will survive within the gut $(3,4)$. Other important defence mechanisms against pathogens include competition for nutrients and adhesion sites from commensal bacteria, a thick mucus layer on the luminal side of the epithelium and the rapid innate response of the intestinal epithelium $(5,6)$.

Studies in rodents indicate that innate recognition of bacteria or bacterial components triggers epithelial expression of secreted C-type lectins RegIII $\gamma$ and RegIII $\beta$ (7-10). In rodents mucosal and faecal levels of RegIII protein are associated with the severity of infection (9). The human paralogue of this protein, pancreatitis-associated protein (PAP), is also detectable in faeces and its use as biomarker to monitor or discriminate human intestinal disease is the subject of ongoing studies.

Currently, the role and function of the RegIII family members is of much interest. The murine RegIII $\gamma$ and human PAP have been shown to have antimicrobial activity against Gram-positive bacteria but not the Gram-negative Escherichia coli (8). PAP and RegIII $\gamma$ were shown to bind peptidoglycan carbohydrate, which is critical for bacterial killing (11). Expression of RegIII $\gamma$ is greatly reduced in mice deficient in MyD88, an intracellular adaptor protein involved in most Toll-like receptor (TLR)-mediated signaling. MyD88deficient mice have been shown to be more susceptible to L. monocytogenes infection compared with wild-type (wt) mice (12). Injection of recombinant RegIII $\gamma$ into the lumen of MyD88-deficient ligated ileal loops before inoculation with $L$. monocytogenes was shown to reduce L. monocytogenes survival in the gut. Other in vivo studies showed that genetic ablation of RegIII $\beta$, which is another RegIII murine isoform, resulted in impaired clearance of the bacterial load in ileal Peyer's patches during Yersinia pseudotuberculosis infection without affecting luminal bacterial levels (13). It remains unclear, however, how RegIII $\beta$ protects against bacterial translocation and whether this is specific for Gram-negative pathogens.

In this study we used RegIII $\beta$-knockout $\left({ }^{-/}\right)$mice and their wt littermates to investigate the protective role of RegIII $\beta$ following oral challenge with Gram-negative Salmonella enteritidis or Gram-positive L. monocytogenes. Additional in-vitro experiments were performed to gain insights into the mechanisms involved in the protective function of RegIII $\beta$. 


\section{MATERIALS AND METHODS}

Animals and diet

The experimental protocol was approved by the animal welfare committee of Wageningen University (Wageningen, the Netherlands). RegIII $\beta^{-/-}$mice with a Bl6/129SV background were generated as described (14). Genotyping of the mice was performed as described previously (14). Mice were fed a semi-purified AIN93-G (15) diet (Abdiets, Woerden, The Netherlands). At 7-9 weeks of age mice with an average body weight of $22 \mathrm{~g}$ (range $16-31 \mathrm{~g}$ ) were housed individually. They received a purified diet containing per kg: $200 \mathrm{~g}$ acid casein, 326 g cornstarch, $174 \mathrm{~g}$ glucose, $160 \mathrm{~g}$ palm oil, $40 \mathrm{~g}$ corn oil, $50 \mathrm{~g}$ cellulose, and vitamin and mineral mix (without calcium) according to AIN93 (15). Diets were supplemented with $\mathrm{CaHPO}_{4} \cdot 2 \mathrm{H}_{2} \mathrm{O}$ (Merck, Darmstadt, Germany) to a final concentration of $30 \mathrm{mmol} / \mathrm{kg}$. To mimic the composition of a Western human diet, the prepared diets were relatively low in calcium and high in fat compared to standard rodent diets (15). Food and demineralized drinking water were supplied ad libitum. Mice were separated into groups and age and gender were randomized over all groups as much as possible. In total 3 RegIII $\beta^{-/-}$and 3 wt groups were formed. From each mouse strain one group was orally infected with Salmonella $\left(^{-/}: \mathrm{n}=10\right.$, wt: $\left.\mathrm{n}=12\right)$, a second group of each strain was orally infected with Listeria $\left({ }^{-/}: \mathrm{n}=7\right.$, wt: $\left.\mathrm{n}=8\right)$ and a final group was sham treated $\left({ }^{-/-}: \mathrm{n}=5\right.$, wt: $\left.\mathrm{n}=6\right)$. The power analysis used to calculate the minimal number of animals needed per group was based on previously performed infection studies in this model (unpublished results). Body weight was measured every two days before infection and daily after infection.

\section{Infection}

After adaptation to individual housing and diet for 8 days, mice were orally infected by gavage with $0.2 \mathrm{~mL}$ saline containing $5^{\star} 10^{8}$ colony-forming units (CFU) of $S$. enteritidis (clinical isolate, phage type 4; strain NIZO1241, NIZO food research, Ede, the Netherlands) or L. monocytogenes (animal isolate, EGDe, serotype $1 / 2 \mathrm{a}, \mathrm{NIZO}$ food research). The virulence of each strain was sustained by routine oral passage in RegIII $\beta^{+/-}$mice and subsequent isolation of the pathogen from extra-intestinal organs. S. enteritidis was grown on BGAM agar plus Sulphamandalate supplement (Oxoid, Basingstoke, United Kingdom) and quantified as described (16). L. monocytogenes was grown and determined by similar culturing methods but by using PALCAM agar (17) plus PALCAM selective supplement (Oxoid).

\section{Collection of biological samples and bacterial quantification}

A pilot study indicated that determination of the number of L. monocytogenes and S. enteritidis in organs of mice was optimal, which means that Listeria and Salmonella CFUs could be detected in organs, at 2 and 4 days after oral infection, respectively (unpublished results). Non-infected mice were sacrificed 3 
days after oral sham treatment. Mice were anaesthetized by isoflurane and blood was collected via an orbital puncture to isolate heparin plasma. After cervical dislocation the colon and the distal $1 / 3$ of the small intestine, representing the ileum, were excised. Approximately $1 \mathrm{~cm}$ was cut from the middle of each intestinal segment to quantify the number of viable Salmonella or Listeria present in colonic and ileal tissue. This piece was cut open longitudinally, briefly flushed in sterile saline, homogenized in $250 \mu \mathrm{L}$ of saline and 10-fold dilutions were plated for bacterial growth on selective agar for Salmonella or Listeria (as described above). The remaining parts of the ileum and colon were cut open longitudinally, flushed with saline and the mucosa was isolated by scraping with a spatula. Mucosal samples were immediately frozen in liquid nitrogen for protein analysis. Furthermore, the mesenteric lymph nodes (MLN), spleen and liver were removed, and after homogenization in sterile saline, directly used for Salmonella or Listeria quantification as described above. Bacterial counts were expressed as the total $\log 10 \mathrm{CFU}$ per gram tissue.

\section{RegIII $\beta$ and Regllly protein analysis in the ileal mucosa}

RegIII $\gamma$ and RegIII $\beta$ expression were determined in the ileum because this is the area where expression is upregulated during infection of rats $(9,10)$ and upon microbial colonization of germ-free mice (8). Frozen mucosal scrapings of the ileum were pulverized under liquid nitrogen. Approximately $2 / 3$ of the pulverized tissue was suspended in a $0.2 \mathrm{~mol} / \mathrm{L}$ sucrose buffer of $\mathrm{pH} 7.4$ containing $20 \mathrm{mmol} / \mathrm{L}$ trishydroxymethylaminomethane (Tris) and a protease inhibitor cocktail (Complete, Roche Diagnostics). To homogenize the samples they were sonicated on ice for $30 \mathrm{~s}$ at level 4 (Sonicator XL2020, Heat Systems, Farmingdale, NY, USA) and protein concentrations were determined using the BC Assay (Omnilabo, Breda, the Netherlands) according to the manufacturer's protocol. One hundred $\mu \mathrm{g}$ protein was denatured at $95^{\circ} \mathrm{C}$ for $10 \mathrm{~min}$ in sample buffer (4x buffer: $160 \mathrm{mM}$ Tris, $\mathrm{pH} 6.8,8 \%$ SDS, $40 \%$ glycerol, $0.05 \% \mathrm{w} / \mathrm{v}$ bromophenol blue), subjected to SDS-polyacrylamide gel electrophoresis (SDS-PAGE) (4.8\% stacking-gel, $\mathrm{pH} 6.8,12.5 \%$ separation-gel, $\mathrm{pH} 8.8$ ) and transferred to a PVDF membrane (Immobilon-P, Millipore, Billerica, MA, USA). After blocking, the membranes were incubated with polyclonal anti-RegIII $\beta$ (1:50000) or antiRegIII $\gamma$ (1:10000) antibodies (custom made by Eurogentec, Seraing, Belgium). These antibodies were generated in rabbits against synthetically produced peptides, using the peptide sequences GEDSLKNIPSARISC (RegIII $\beta$ ) and EVAKKDAPSSRSSC (RegIII $\gamma$ ). The chosen peptide sequences correspond to unique sequences within the REGIII protein and allow differentiation between the RegIII $\beta$ and RegIII $\gamma$ proteins. Serum from immunized rabbits was affinity purified using the same peptides. The signal of the secondary HRP-conjugated antibody (Goat-anti-Rabbit HRP, 1:100000, Jackson ImmunoResearch, Suffolk, UK) was detected by using the ECL Plus chemiluminescent detection kit (GE Healthcare, Den Bosch, the Netherlands). 


\section{Myeloperoxidase analysis in ileal mucosa and serum amyloid $A$ detection in plasma}

A mouse myeloperoxidase (MPO) ELISA test kit (Hycult biotechnology, Uden, the Netherlands), was used according to the manufacturer's guidelines to determine the concentration of MPO in ileal mucosal scrapings.

Serum amyloid A (SAA) 2, an acute phase apolipoprotein present in plasma (18), was determined to investigate systemic inflammation. A mouse SAA2 ELISA kit (Life Diagnostics, Inc. West Chester, Pennsylvania, USA) was used according to the guidelines of the manufacturer.

\section{Pull-down assay}

In order to investigate whether RegIII $\beta$ present in the luminal content of mice was able to bind Salmonella or Listeria a pull-down assay was performed. First faecal-water extracts were prepared from faeces of infected RegIII $\beta^{-/}$and wt mice as described previously (9). Briefly, faeces from day 4 or day 2 post Salmonella or Listeria infection, respectively, were pooled per group. One hundred mg of each pool was homogenized in $1 \mathrm{~mL}$ buffer containing $50 \mathrm{mmol} / \mathrm{L}$ Tris- $\mathrm{HCl}$ (pH7.5), $100 \mathrm{mmol} / \mathrm{L} \mathrm{NaCl}, 1 \mathrm{mmol} / \mathrm{L}$ EDTA and Complete Protease Inhibitor Cocktail (Roche). After incubation at $37^{\circ} \mathrm{C}$ for $1 \mathrm{~h}$ and centrifugation at 15000 $g$ for $2 \mathrm{~min}$, the supernatant was taken and used as faecal-water extract. Presence of bacteria in the faecal-water extracts was investigated by plating undiluted extracts on Luria-Bertani (LB) agar.

$S$. enteritidis and L. monocytogenes, identical to the strains used in the infection study, were grown overnight $\left(37^{\circ} \mathrm{C}\right.$ in a horizontal shaker at $\left.250 \mathrm{rpm}\right)$ in $\mathrm{LB}$ and $\mathrm{BHI}$ broth, respectively. Overnight grown bacteria were spun down $(6 \mathrm{~min}$ at $5000 \mathrm{~g}$ ) and $4.3^{\star} 10^{6}$ bacteria were resuspended in $30 \mu \mathrm{L}$ faecal water extracts from RegIII $\beta^{-/-}$or wt mice. The bacteria were incubated for $1 \mathrm{~h}$ at $37^{\circ} \mathrm{C}$ in faecalwater extracts or in the buffer that was used to prepare extracts as described above. After spinning down the bacteria presence of RegIII $\beta$ was investigated in the pellet (resuspended in $20 \mu \mathrm{L}$ PBS), supernatant $(20 \mu \mathrm{L})$, and original faecal extracts $(20$ $\mu \mathrm{L})$ by SDS-PAGE as described above. Proteins were transferred to an ImmobilonFL membrane (Millipore) and after blocking exposed to rat anti-mouse RegIII $\beta$ antibodies (MAB5110; R\&D systems, Minneapolis, USA, 1:2000). The secondary antibody used was Goat-anti-Rat IRDye ${ }^{\varpi} 680 \mathrm{CW}$ (Li-Cor, Nebraska, USA, 1:20 000) and the blots were scanned by using the Odyssey scanner (Li-Cor).

\section{Statistics}

All data are expressed as mean \pm SEM and statistical analysis was performed by using Prism 5.0 Software (GraphPad, San Diego, California, USA). Our aim was to investigate the role of RegIII $\beta$ in infection. Therefore the pre-defined comparisons were RegIII $\beta^{-/-}$versus wt. Except for in vitro investigations to evaluate binding of RegIII $\beta$ to Salmonella and Listeria when binding to these pathogens are compared. Data were tested for normality by Kolmogorov-Smirnov normality 
test and Shapiro-Wilk normality test. If normally distributed, differences were tested for significance using Student's $t$ test (two-tailed). Data with unequal variances were tested by using the Mann-Whitney U test. Salmonella output in faeces was determined at multiple time points and therefore these data were analysed by repeated-measures two-way ANOVA (mixed-model). Differences were considered statistically significant when $P<0.05$.

\section{RESULTS}

\section{Body weight}

To monitor the general condition of the mice, body weight was determined during the experiment. At the start of the experiment average body weight was 22 $\pm 0.7 \mathrm{~g}$. During the study there was no significant difference between the body weight of RegIII $\beta^{-/-}$and wt mice (data not shown). Average body weight before infection (average weight of 2 weeks prior to infection) was $23.0 \pm 1.4 \mathrm{~g}$ and post-infection (average of the post infection period) $23.2 \pm 1.5 \mathrm{~g}$.

Bacterial infection increases Reglll $\beta$ and Regllly in the ileum mucosa To evaluate presence of RegIII $\beta$ and RegIII $\gamma$ protein in the ileal mucosa of wt and $\operatorname{RegIII} \beta^{-/-}$mice, and subsequent levels upon oral infection, mucosal scrapings were evaluated by immunoblotting using antibodies specific for RegIII $\beta$ and RegIII $\gamma$. As expected, RegIII $\beta$ was not detected in the ileal mucosa of RegIII $\beta^{-/-}$animals (Fig 1). After Salmonella and Listeria infection the protein level was higher in the mucosal samples of wt mice than before infection (Fig 1). The isoform RegIII $\gamma$ was not detectable in mucosal scrapings of non-infected RegIII $\beta^{-/-}$mice (Fig 1$)$. In contrast, the wt mice had detectable levels of this RegIII isoform and levels increased during Salmonella and Listeria infection in wt and RegIII $\beta^{-/-}$mice.

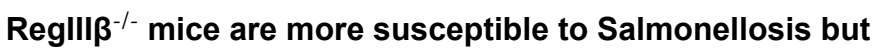 not to Listeriosis than wi mice.}

To investigate the role of RegIII $\beta$ in intestinal colonization, the numbers of viable Salmonella were investigated in fresh faecal samples of infected wt and RegIII $\beta^{-/-}$ mice. Colonization of Salmonella in RegIII $\beta^{-/-}$mice was not different from that of wt mice (Fig 2). In the colonic tissue, which was first flushed with saline to remove intestinal content, higher numbers of Salmonella were recovered in RegIII $\beta^{-/-}$mice than in wt mice (Fig 3A; $P<0.05$ ). In the ileal tissue Salmonella levels were identical in RegIII $\beta^{-/-}$and wt mice. Furthermore, in MLN, spleen and liver these levels were higher in RegIII $\beta^{-/-}$mice than in their wt counterparts (Fig 3B; $P<0.05$ ).

Intestinal colonization of Listeria was identical in RegIII $\beta^{-/-}$and wt mice as found for Salmonella (Fig 2). To further investigate effects of RegIII $\beta$ on Listeria translocation the CFU in ileal and colonic tissue and extra-intestinal organs were determined. The number of Listeria recovered from wt did not differ from RegIII $\beta^{-/-}$mice in ileal and colonic tissues, (Fig 4A) and in MLN, spleen, and liver (Fig 4B). 


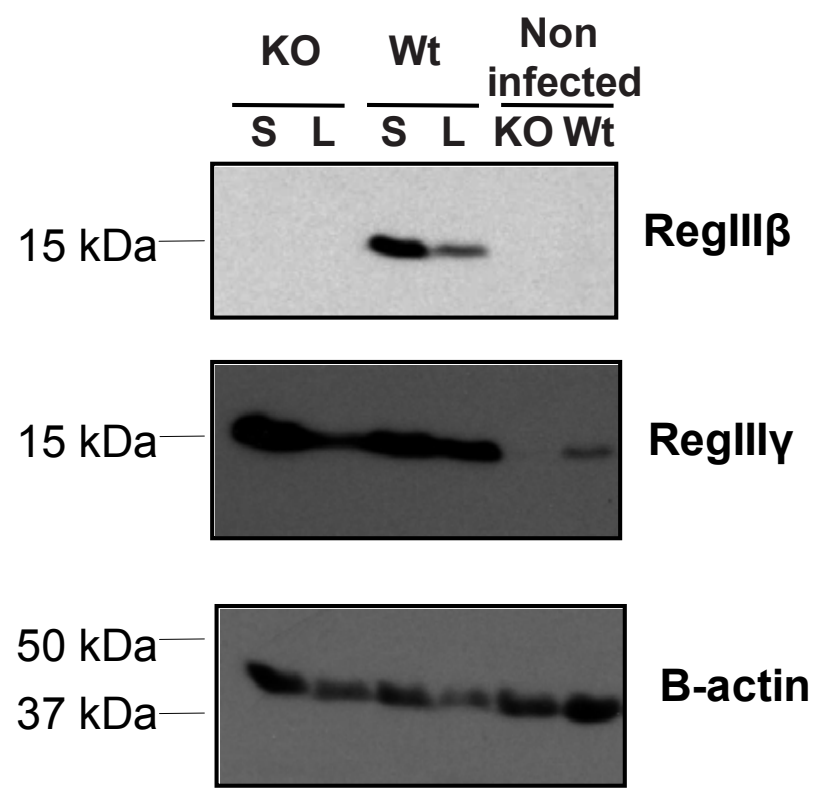

Figure 1. Western blot analysis of RegIII $\beta$ and RegIII $\gamma$ in the ileal mucosa of RegIII $\beta-/-$ mice $(\mathrm{KO})$ or wt mice $(\mathrm{Wt})$. RegIII $\beta-/-$ mice $(\mathrm{n}=10)$ and wt mice $(\mathrm{n}=12)$ were orally infected with $S$. enteritidis (S) or RegIII $\beta-/-$ mice $(n=7)$ and wt mice $(n=8)$ were orally infected with $L$. monocytogenes $(\mathrm{L})$. Non-infected mice $(\mathrm{n}=5)$ received saline as control treatment. Equal amounts of protein from mucosal pools were separated by SDS-PAGE and subsequently transferred to PVDF membranes. Proteins on the membranes were detected with anti-RegIII $\beta$, anti-RegIII $\gamma$ and anti- $\beta$-actin.

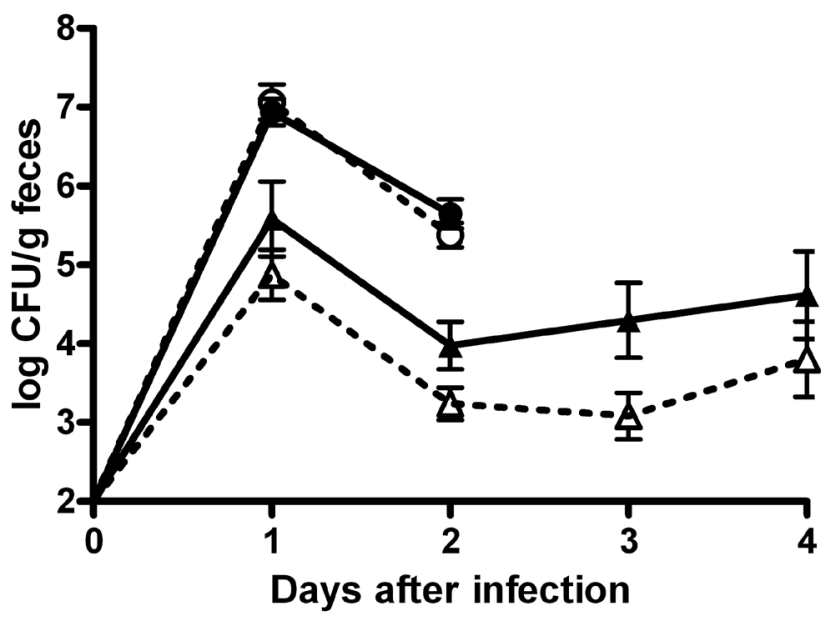

Figure 2. Salmonella $(\boldsymbol{\Delta}, \triangle)$ and Listeria $(\bullet, \bigcirc)$ excretion in faeces. Individually housed mice were orally infected at day 0 . RegIII $\beta$-/- mice (closed symbols) were infected with $5^{\star} 108$ colony-forming units (CFU) of $S$. enteritidis $(\mathrm{n}=10)$ or L. monocytogenes $(\mathrm{n}=7)$ and wt littermates (open symbols) with identical CFU of $S$. enteritidis $(\mathrm{n}=12)$ or L. monocytogenes $(\mathrm{n}=8)$. Values are means \pm SEM. 
A

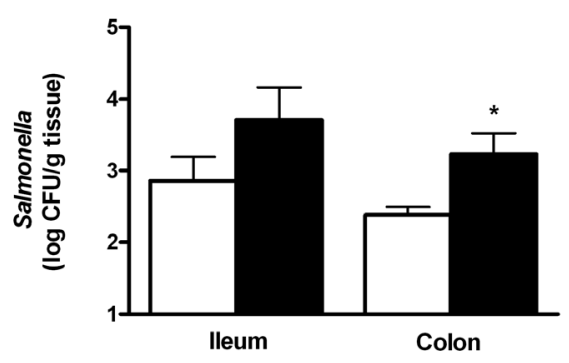

B

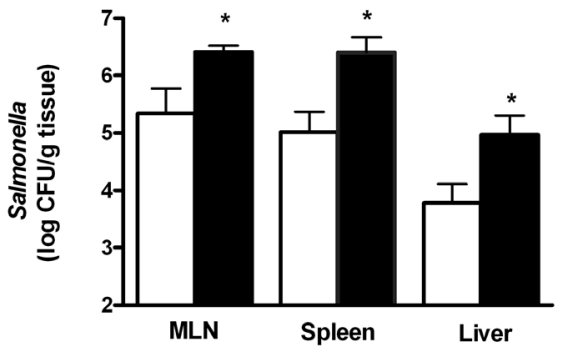

Figure 3. Salmonella in intestinal and extra-intestinal tissues. CFU of Salmonella in (A) the ileal and colonic mucosa and in (B) mesenteric lymph nodes (MLN), spleen and liver of RegIII $\beta-/$ - mice ( $n=10$; black bars) or wt mice ( $n=12$; white bars) four days after oral $S$. enteritidis infection. Values are means $+\mathrm{SEM}$. ${ }^{\star}$ Different from wt, $P<0.05$.

A

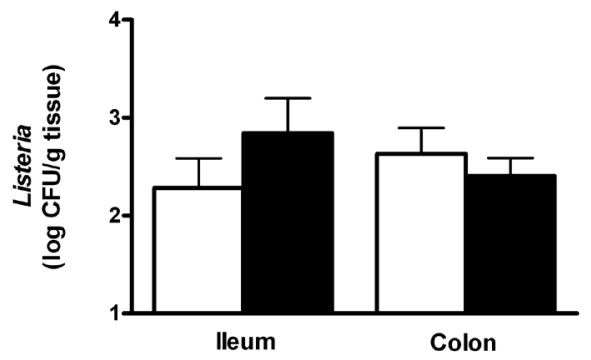

B

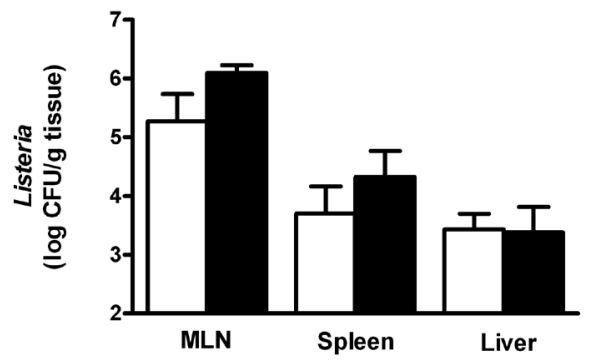

Figure 4. Number of Listeria in intestinal and extra-intestinal tissues. CFU of Listeria in (A) the ileal and colonic mucosa and in (B) mesenteric lymph nodes (MLN), spleen and liver of RegIII $\beta$-/-mice ( $\mathrm{n}=7$; black bars) or wt mice ( $\mathrm{n}=8$; white bars) two days after oral $L$. monocytogenes infection. Values are means + SEM.

\section{Mucosal and systemic inflammation}

The role of RegIII $\beta$ in inflammation was investigated by measuring the levels of the inflammation marker myeloperoxidase (MPO) in the ileum mucosa. MPO levels of all infected groups did not differ significantly from the non-infected groups $(0.35 \pm 0.05 \mathrm{ng} / \mathrm{mg}$ protein; data not shown). To study systemic inflammation SAA levels in plasma were determined. The levels were elevated from $0.1 \pm 0.001 \mu \mathrm{g} / \mathrm{ml}$ (non-infected mice) to $1164 \pm 186$ and $502 \pm 174 \mu \mathrm{g} / \mathrm{ml}$ upon Salmonella and Listeria infection, respectively $(P<0.05$; data not shown). However, there were no significant differences between wt and $\operatorname{RegIII} \beta^{-/-}$mice. 


\section{RegIII $\beta$ aggregates preferentially with Salmonella than with Listeria}

To investigate whether RegIII $\beta$ present in the faecal-water extracts is able to bind S. enteritidis or L. monocytogenes, pull-down assays were performed. Faecal water extracted from faeces of infected wt mice showed a band of approximately $15 \mathrm{kDa}$ and a slightly lower molecular weight band (Fig 5). Faecal-water extracts were negative for presence of microbiota-derived bacteria. Upon incubation of the extract with Salmonella most of the RegIII $\beta$ protein was found in the pellet that contained the Salmonella bacteria. A minor part of the protein was detected in the supernatant (Fig 5 panel A). In contrast, lower levels of RegIII $\beta$ were detected in the pellet than in the supernatant when this assay was performed with Listeria (Fig 5 panel B). Previous experiments of protein isolation from faeces including microbiota indicated that the protein is normally present in the supernatant, even when centrifuged at $15000 g$ (9). Therefore the results presented here indicated that secreted RegIII $\beta$ recovered from faeces is able to directly bind Salmonella and binds to a lower level to Listeria.

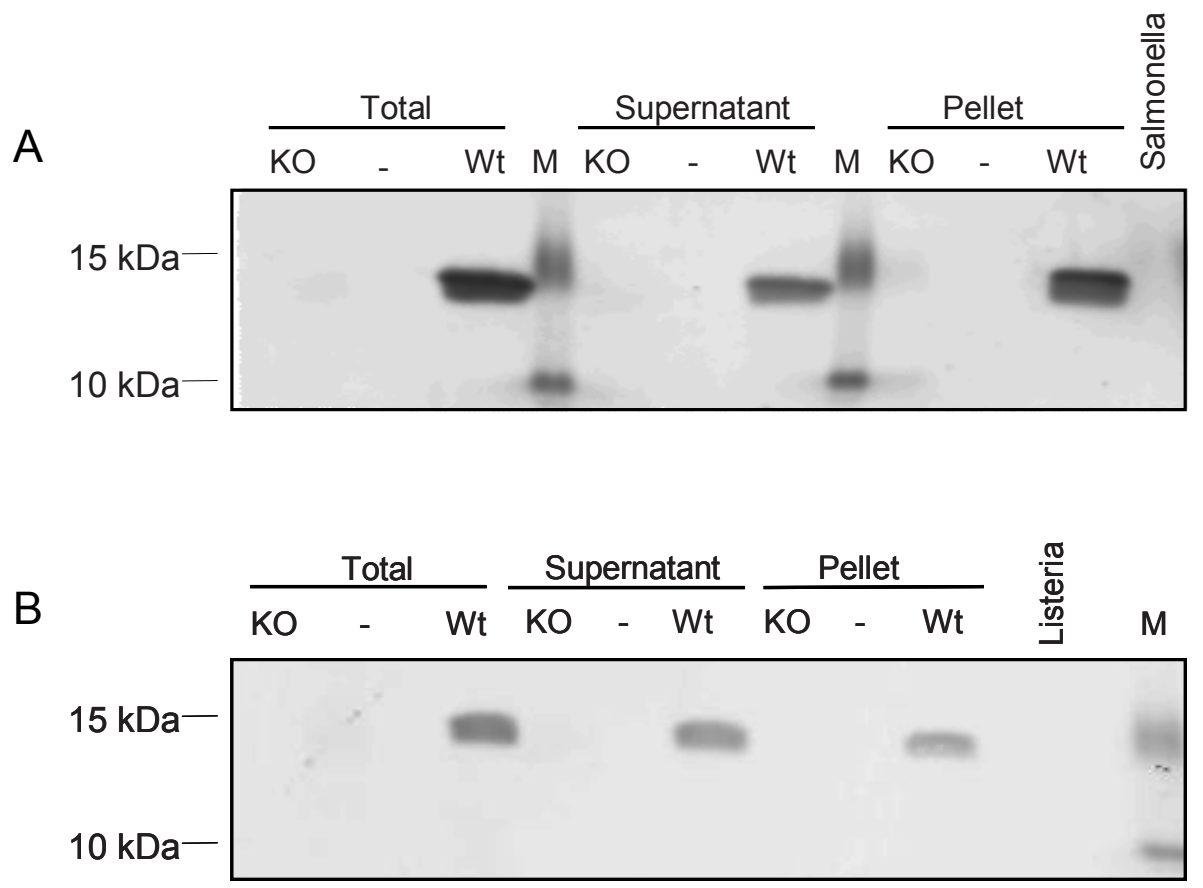

Figure 5. Listeria and Salmonella pull-down assays. Presence of RegIII $\beta$, detected by Western blot analysis, in pellet and supernatant fractions of faecal-water extracts from $S$. enteritidis (panel A) or L. monocytogenes (panel B) infected wt (Wt) or RegIII $\beta$-/- (KO) mice incubated with Salmonella or Listeria. Bacteria that were incubated with the faecal-water extraction buffer served as negative control (-) and bacterial culture alone was also loaded as control. The pre-stained marker is indicated by $\mathrm{M}$. 


\section{DISCUSSION}

Both microbial infections of conventional mice and intestinal colonization of germ-free mice by commensals increases ileal expression of the secreted C-type lectins RegIII $\gamma$ and RegIII $\beta$ (7-10) . While RegIII $\gamma$ has been shown to have a bactericidal activity against Gram-positive bacteria (8), the physiological function of RegIII $\beta$ remains unknown . This study now shows an essential role of RegIII $\beta$ in protecting the intestine against infection with the Gram-negative S. enteritidis. Despite similar levels of viable Salmonella recovered from faeces an increased number was recovered from MLN, spleen and liver from infected RegIII $\beta^{-/-}$mice compared to wt mice, indicating that the translocation and dissemination of Salmonella in host tissues is increased in the absence of RegIII $\beta$.

In colonic tissue Salmonella levels were also increased in RegIII $\beta^{-/-}$mice compared with wt mice. The MLN drain the small intestine, which is a main site of Salmonella invasion (18). Therefore reduced levels of Salmonella in the MLN of wt mice suggest protective effects of RegIII $\beta$ on Salmonella translocation in the ileum. Although we did not observe differences in Salmonella counts in the ileal tissues of wt and RegIII $\beta^{-/-}$mice, this may be due to lack of statistical power in this assay, as SEM levels are higher in ileal tissue than those in colonic tissue. Moreover the investigated ileal tissue did not contain Peyer's patches and $M$ cells, which are considered, in addition to absorptive enterocytes, to be important sites of Salmonella translocation $(19,20)$. Together the experimental infection data strongly suggest that RegIII $\beta$ inhibits Salmonella translocation from the gut lumen into intestinal tissues and further extra-intestinal tissues but does not kill Salmonella in the gut lumen. These results are supported by recent findings of Dessein et al., who showed that genetic ablation of RegIII $\beta$ did not affect the bacterial load of the Gram-negative pathogen Yersinia pseudotuberculosis in the intestinal lumen (13) but significantly increased bacterial burden in the Peyer's patches, which are the main route of entry for this pathogen. In contrast, RegIII $\beta$ did not to influence resistance to infection with the Gram-positive Listeria monocytogenes, as identical numbers of this pathogen were recovered from intestinal and extra-intestinal tissues in RegIII $\beta^{-/-}$and wt mice in our study.

As murine RegIII $\gamma$ and human PAP are directly bactericidal for Grampositive bacteria in vitro $(8,21)$ it seemed possible that RegIII $\beta$ would have similar antimicrobial activity. However, in this study there was no effect of RegIII $\beta$ on the colonization and translocation of $L$. monocytogenes. The strain of $L$. monocytogenes used in our infection study was identical to that used previously for in vitro antibacterial assays with RegIII $\gamma$ (8). Previous investigations with rat PAP1, which is the orthologue of the murine RegIII $\beta$, also showed no direct bactericidal effect against L. monocytogenes in vitro (9). Others also report a lack of bactericidal effect of this protein (13). The co-existence of the two closely related RegIII proteins in the mouse strongly suggests a different function for each of these proteins. Here we provide evidence that RegIII $\beta$ has a protective role against Gram-negative Salmonella translocation but not Listeria infection. The 
exact mechanism by which RegIII $\beta$ inhibits Salmonella translocation into host tissues is unclear.

The observed difference of RegIII $\beta$ functionality between Listeriosis and Salmonellosis might be due to differences in physical appearance and host invasion tactics between the two pathogens but might also be related to differences in host responses induced by these pathogens. We can only speculate about the latter as we did not monitor the exact (immune) response of the mice. Previous studies by Brandl et al. indicated that the innate immune defence against $L$. monocytogenes, which requires Toll-like receptor (TLR)-mediated signals, plays a crucial role in RegIII $\gamma$ related protection against this pathogen. As $S$. enteritidis and L. monocytogenes may trigger different (TLR-mediated) innate immune signals (22), this might be a cause a differential regulation of RegIII $\beta$ expression and thus regulate its subsequent protective effects. On the other hand, it might be that RegIII $\beta$ modulates the immune response directed against Salmonella but not the response against Listeria. Although measured at a single time point in the current study, RegIII $\beta$ did not affect the systemic inflammatory response as measured by SAA levels in serum. The local inflammatory response in our infection models was relatively low, as MPO levels did not increase upon infection in the ileal mucosa. This was likely due to the relatively short period that mice were exposed to the orally administered pathogens because our focus was on pathogen colonization and translocation which normally precedes inflammation. Thus based on our study design, we can not fully exclude absence of effects of RegIII $\beta$ on the inflammatory response. However, previous investigations in our lab with a similar Salmonella infection model in rats indicated that mucosal inflammation in this infection model is relatively low at day 4 post infection (23). Further analysis of the collected intestinal tissues from the current study might give insight on the role of the innate (immune) response in RegIII $\beta$ related protective effects. For example, micro-array analysis of intestinal tissues may identify whether and which host defence pathways are associated with protective effects of RegIII $\beta$. Performing additional Listeria and Salmonella infection experiments in mice deficient in specific TLRs might reveal the involvement of specific innate immune signaling in RegIII $\beta$ mediated protection against intestinal infection.

Besides the proposed association of the host response with $\operatorname{RegIII} \beta$ related protection of intestinal infection, this lectin might also directly and differentially affect Listeria and Salmonella. The outer membrane of these pathogens is different, for example Salmonella contains immuno-reactive lipopolysaccharides (LPS) which are absent in Gram-positive bacteria like Listeria. This influences host signaling pathways, e.g. TLR recognition. Our biochemical analysis revealed that faecal RegIII $\beta$ showed increased affinity to Salmonella than to Listeria, providing a mechanism whereby RegIIIß-deficient mice showed increased susceptibility to salmonellosis but not to listeriosis. Bactericidal activities of RegIII $\gamma$ depend on binding to cell wall peptidoglycan, a molecule exposed on the Grampositive bacterial surface (8). This peptidoglycan recognition is determined by 
the so called Loop1 EPN tripeptide motif, which is also present in RegIII $\beta$ (11). This motif is involved in peptidoglycan binding, and binding affinity for carbohydrate ligands depends on carbohydrate chain length (11). Moreover RegIII $\beta$ binds to the Gram-positive Bacillus subtilis peptidoglycan, mannose polysaccharides and chitin, which is a long-chain polymer of $\mathrm{N}$-acetylglucosamine (11). Our results suggest that $\operatorname{Reg} \beta$ possibly recognizes carbohydrate structures on the Gram-negative bacterial surface. Currently we do not know what the specific target of RegIII $\beta$ is on the outer membrane of Gram-negative bacteria. It may be related to LPS, which are large molecules consisting of a lipid and a polymeric carbohydrate structure (24). The latter may be a binding target for the EPN motif in RegIII $\beta$. The molecular mechanism by which RegIII $\beta$ may recognize (the peptidoglycan of) Salmonella remains to be determined. Studies with purified RegIII $\beta$ are needed to determine what ligands specifically bind to this protein. To address this question it will be necessary to have purified biologically active RegIII $\beta$ protein, and efforts are under way to produce and purify this protein in active form.

Another important difference between the pathogens is that Listeria and Salmonella use complex and very different mechanisms of cellular attachment and invasion $(25,26)$. Listeria can invade the human intestinal epithelium via the epithelial receptor E-cadherin. A single amino acid change in the murine E-cadherin, however, makes mice relatively resistant to intestinal infection (27). As also shown in the present study, relatively high doses of Listeria, do achieve a significant invasive infection in rodents (27). This probably involves a second but less well characterized surface protein of L. monocytogenes Internalin B, which enables Listeria to enter and survive within epithelial cells via interaction with three different epithelial membrane receptors $(25,26)$. In the case of Salmonella the bacteria are not highly adherent, but their invasion machinery is particularly efficient (26). Salmonella has another mechanism to invade cells which involves binding to epithelial cells by its type III secretory system (TTSS) $(20,28)$. The TTSS allows direct activation of components of the host-cell cytoskeleton by intracellular delivery of dedicated bacterial effectors, resulting in membrane ruffling and endocytosis. By this event Salmonella invade and reside in an atypical acidic compartment called the SCV (Salmonella containing vacuole) and survive inside the cell (25). It might be possible that RegIII $\beta$ interferes with the expression or function of Salmonella pathogenicity island 1 (SPI-1) TTSS invasion machinery.

In conclusion, RegIII $\beta$ inhibits intestinal bacterial translocation upon oral infection with the Gram-negative Salmonella. In contrast, this protein does not protect against intestinal infection with the Gram-positive Listeria. Inhibitory effects of RegIII $\beta$ on bacterial infection may be linked to its observed preferential binding to Salmonella. The protective mechanism of RegIII $\beta$ is not associated with direct bactericidal affects but may interfere with Salmonella virulence mechanisms or host responses to the pathogen. 


\section{ACKNOWLEDGEMENTS}

The authors would like to thank the biotechnicians at the Small Animal Centre of Wageningen University (Wageningen, The Netherlands) for excellent assistance. We would also like to thank our colleagues at the Department of Health of NIZO food research and members of the Host-Microbe Interactomics group at Wageningen University for fruitful discussions. 


\section{REFERENCES}

1. Kaur, T.Ganguly, N. K. 2003. Modulation of gut physiology through enteric toxins. Mol Cell Biochem 253: 15-19.

2. (WHO), W. H. O. 2002.

Foodborne diseases, emerging.

3. Giannella, R. A., Broitman, S. A.Zamcheck, N. 1973. Influence of gastric acidity on bacterial and parasitic enteric infections. A perspective. Ann Intern Med 78: 271-276.

4. Gorden, J.Small, P. L. 1993. Acid resistance in enteric bacteria. Infect Immun 61: 364-367.

5. Sarker, S. A.Gyr, K. 1992. Non-immunological defence mechanisms of the gut. Gut 33: 987-993.

6. Duncan, H. E.Edberg, S. C. 1995. Host-microbe interaction in the gastrointestinal tract. Crit Rev Microbiol 21: 85-100.

7. Keilbaugh, S. A., Shin, M. E., Banchereau, R. F., McVay, L. D., Boyko, N., Artis, D., Cebra, J. J. et al. 2005. Activation of RegIIIbeta/gamma and interferon gamma expression in the intestinal tract of SCID mice: an innate response to bacterial colonisation of the gut. Gut 54: 623-629.
8. Cash, H. L., Whitham, C. V., Behrendt, C. L.Hooper,

L. V. 2006. Symbiotic bacteria direct expression of an intestinal bactericidal lectin. Science 313: 1126-1130.

9. van Ampting, M. T.,

Rodenburg, W., Vink, C., Kramer, E., Schonewille, A. J., Keijer, J., van der Meer, R. et al. 2009. Ileal Mucosal and Fecal Pancreatitis Associated Protein Levels Reflect Severity of Salmonella Infection in Rats. Dig Dis Sci 54: 2588-2597.

10. Rodenburg, W., BoveeOudenhoven, I. M., Kramer, E., van der Meer, R.Keijer, J. 2007. Gene expression response of the rat small intestine following oral Salmonella infection. Physiol Genomics 30: 123-133.

11. Lehotzky, R. E., Partch, C. L., Mukherjee, S., Cash, H. L., Goldman, W. E., Gardner, K. H.Hooper, L. V. 2010. Molecular basis for peptidoglycan recognition by a bactericidal lectin. PNAS 107: 7722-7727.

12. Brandl, K., Plitas, G., Schnabl, B., DeMatteo, R. P.Pamer, E. G. 2007. MyD88mediated signals induce the bactericidal lectin RegIII gamma and protect mice against intestinal Listeria monocytogenes infection. J Exp Med 204: 1891-1900.
13. Dessein, R., Gironella, M., Vignal, C., Peyrin-Biroulet, L., Sokol, H., Secher, T., Lacas-Gervais, S. et al. 2009. TLR2 is critical for induction of REG3\{beta\} expression and intestinal clearance of Yersinia pseudotuberculosis. Gut 58: 771-776.

14. Lieu, H. T., Simon, M. T., Nguyen-Khoa, T., Kebede, M., Cortes, A., Tebar, L., Smith, A. J. et al. 2006. Reg2 inactivation increases sensitivity to Fas hepatotoxicity and delays liver regeneration post-hepatectomy in mice. Hepatology 44: 1452-1464.

15. Reeves, P. G., Nielsen, F. H.Fahey, G. C., Jr. 1993. AIN93 purified diets for laboratory rodents: final report of the American Institute of Nutrition ad hoc writing committee on the reformulation of the AIN-76A rodent diet. J Nutr 123: 1939-1951.

\section{Oudenhoven, I. M.,} Klaasen, H. L., Lapre, J. A., Weerkamp, A. H.Van der Meer, R. 1994. Nitric oxidederived urinary nitrate as a marker of intestinal bacterial translocation in rats. Gastroenterology 107: 47-53.

17. van Netten, P., Perales, I., van de Moosdijk, A., Curtis, G. D.Mossel, D. A. 1989. Liquid and solid selective 
differential media for the detection and enumeration of L. monocytogenes and other Listeria spp. Int J Food Microbiol 8: 299-316.

18. Uhlar, C. M.Whitehead, A. S. 1999. Serum amyloid A, the major vertebrate acutephase reactant. Eur J Biochem 265: 501-523.

19. Vanasten, A. J. A. M., Koninkx, J. F. J. G.Vandijk, J. E. 2005. Salmonella entry: M cells versus absorptive enterocytes. Veterinary Microbiology 108: 149-152.

20. Grassl, G. A.Finlay, B. B. 2008. Pathogenesis of enteric Salmonella infections. Curr Opin Gastroenterol 24: 22-26.

21. Mukherjee, S., Partch, C. L., Lehotzky, R. E., Whitham, C. V., Chu, H., Bevins, C. L., Gardner, K. H. et al. 2009. Regulation of C-type Lectin Antimicrobial Activity by a Flexible N-terminal Prosegment. J Biol Chem 284: 48814888 .

22. Abreu, M. T., Fukata, M.Arditi, M. 2005. TLR signaling in the gut in health and disease. J Immunol 174: 4453-4460.

23. van Ampting, M. T., Schonewille, A. J., Vink, C., Brummer, R. J., van der Meer,
R.Bovee-Oudenhoven, I. M. 2009. Intestinal barrier function in response to abundant or depleted mucosal glutathione in Salmonella-infected rats. BMC Physiol 9: 6.

24. Raetz, C. R., Ulevitch, R. J., Wright, S. D., Sibley, C. H., Ding, A.Nathan, C. F. 1991. Gram-negative endotoxin: an extraordinary lipid with profound effects on eukaryotic signal transduction. FASEB J 5: 2652-2660.

25. Cossart, P.Sansonetti, P. J. 2004. Bacterial invasion: the paradigms of enteroinvasive pathogens. Science 304: 242248.

26. Pizarro-Cerda, J.Cossart, P. 2006. Bacterial adhesion and entry into host cells. Cell 124: 715-727.

27. Lecuit, M. 2007. Human listeriosis and animal models. Microbes Infect 9: 1216-1225.

28. Ly, K. T.Casanova, J. E. 2007. Mechanisms of Salmonella entry into host cells. Cell Microbiol 9: 2103-2111. 


\section{CHAPTER 4}

\section{FECAL PANCREATITIS- ASSOCIATED PROTEIN IS \\ INCREASED BY ESCHERICIA COLI INFECTION AND IN ULCERATIVE COLITIS BUT NOT IN CROHN'S DISEASE: AN EXPLORATORY STUDY}

Marleen T.J. van Ampting ${ }^{1,2}$, Carolien Vink ${ }^{1,2}$, Arjan J. Schonewille ${ }^{1,2}$, Henrike M. Hamer ${ }^{1,3}$, Gerard Dijkstra ${ }^{4}$, Robert Jan M Brummer ${ }^{1,3,5}$, Roelof van der Meer ${ }^{1,2}$, and Ingeborg M.J. Bovee-Oudenhoven ${ }^{1,2}$

${ }^{1}$ TI Food and Nutrition, Wageningen, the Netherlands

${ }^{2}$ Department of Health, NIZO food research, Ede, the Netherlands

${ }^{3}$ Department of Internal Medicine, Division of Gastroenterology-Hepatology, Nutrim, Maastricht University, the Netherlands

${ }^{4}$ Department of Gastroenterology and Hepatology, University Medical Center Groningen, University of Groningen, the Netherlands

${ }^{5}$ Present address: School of Health and Medical Sciences, Örebro University, Örebro, Sweden

Manuscript in preparation. 


\section{ABSTRACT}

Objective Pancreatitis-associated protein (PAP), also denoted regenerating protein III (RegIII), is highly expressed in the intestinal mucosa and detected in feces during intestinal infection and inflammation in rodents. The aim of the present study was to explore the human relevance of these findings and to compare PAP concentrations with calprotectin, a fecal biomarker of mucosal inflammation.

Methods PAP and calprotectin concentrations were determined by ELISA in feces of healthy subjects $(n=31)$ before and at various time points after oral infection with a live but attenuated enterotoxigenic Eschericia coli (ETEC) and in feces of patients with ulcerative colitis (UC; $\mathrm{n}=36$ ) or Crohn's disease (CD; $\mathrm{n}=22$ ).

Results Fecal PAP was present at low levels, $59 \pm 20 \mathrm{ng} / \mathrm{g}$ in healthy subjects, whereas calprotectin concentrations were $5 \pm 1 \mu \mathrm{g} / \mathrm{g}$. Oral ETEC infection was associated with increased PAP (by $76 \pm 31 \mathrm{ng} / \mathrm{g} ; \mathrm{p}<0.05$ ) from 3 days post infection. In contrast, fecal calprotectin increased instantaneously from the first day after infection. Both fecal PAP $(87 \pm 18 \mathrm{ng} / \mathrm{g})$ and calprotectin $(120 \pm 24 \mu \mathrm{g} / \mathrm{g})$ were significantly higher in UC patients in clinical remission than in healthy subjects $(\mathrm{p}<0.05)$. In $\mathrm{CD}$ patients, either with active disease or in remission, fecal PAP was not elevated despite significantly increased fecal calprotectin concentrations.

Conclusions This exploratory study indicates that PAP is detectable in human feces and levels increase upon intestinal infection and in UC but, interestingly, not in CD. The output kinetics of fecal PAP and calprotectin are not similar. Further studies are needed for validation of fecal PAP as a potential new biomarker to monitor or discriminate human intestinal disease. 


\section{INTRODUCTION}

There is great interest in identifying and validating new fecal biomarkers of intestinal health and disease, like gut infection and inflammation. Their implementation in clinical routine is attractive because these markers yield valuable information on intestinal health status by a non-invasive means. These markers could facilitate monitoring of intestinal disease activity with time, e.g. in response to therapeutic intervention, and may reduce the need for endoscopic investigations. At present a widely applied fecal marker for intestinal inflammation is the protein complex S100A8/S100A9 denoted 'calprotectin' (1). Application of these kinds of markers can also be considered in patients with mild symptoms of abdominal pain or diarrhea. Dependent on the sensitivity and specificity of fecal biomarkers, their analysis can be highly quantitative and even suitable for early detection of subclinical activity (2).

Recently, we have shown that the expression of pancreatitis associated protein (PAP), also known as regenerating protein III (RegIII), is increased in enterocytes of the ileal mucosa during Salmonella infection in rodents (3). Increased colonization and translocation of Salmonella coincided with higher ileal mucosal PAP/RegIII levels. The protein was shown to be excreted in rat feces at levels similar to mucosal levels and it was proposed as a potential new intestinal infection marker (3). Stimulated intestinal PAP expression is not specific for Salmonella infection as increased PAP transcript levels are found in the small intestine of pigs in a small intestinal perfusion model with Escherichia coli (4). The cellular origin of intestinal PAP and especially its functionality is still under investigation (5-8). Dessein et al. recently showed that the murine orthologue of PAP, alias RegIII $\beta$, plays a role in clearance of invasive Yersinia pseudotuberculosis in Peyer's patches of mice through a Toll-like receptor 2-mediated interaction (7). This suggests that PAP functions in a more complex manner than via the proposed direct antimicrobial activity (6). Concomitantly the above mentioned studies indicate that microbe-host interaction plays a crucial role in PAP expression and functionality.

Chronic inflammatory bowel disorders (IBD), such as ulcerative colitis (UC) and Crohn's disease (CD), are characterized by disturbed microbe-host interactions and an impaired gut barrier function (9). As many as 1.4 million subjects in the US and 2.2 million subjects in Europe suffer from these debilitating disorders (10). Most patients are subjected to invasive methods for diagnostics and monitoring disease activity and new non-invasive (fecal) surrogate markers of mucosal condition are needed. Several studies have reported that in IBD microbe-host interactions are crucial and PAP mRNA levels are increased in the intestinal mucosa of these IBD patients $(11,12)$. This suggests that fecal PAP levels could be used as a potential new biomarker.

To address human relevance of PAP as potential new biomarker of intestinal infectious disease and/or mucosal inflammation we first established its presence in human feces and subsequently studied whether levels changed upon 
intestinal bacterial infection and in established IBD. Fecal calprotectin was measured to quantify intestinal mucosal inflammation in the studied patient groups and to determine its association, if any, with fecal PAP. Our results indicate that fecal PAP is a marker dissimilar to the mucosal inflammation marker calprotectin and might aid in discriminating UC from CD.

\section{METHODS}

\section{Healthy and enterotoxigenic Escherichia coli infected subjects}

Post-hoc analyses was performed in stools collected in a human infection study, published previously (13). Feces from this healthy population, collected on two different but consecutive days per individual, were used as healthy subject samples in the present study. Briefly, thirty-one healthy men with the following characteristics were included: aged between 20-55 years, without reported use of antibiotics, immunosuppressive drugs, antacids, laxatives, or anti-diarrheal drugs in the last 3 months before the study, and no gastrointestinal illness or surgical operations in the past (13). All subjects gave their written informed consent before participation. The study was performed in accordance with the principles of the Helsinki Declaration and was approved by the Medical Ethics Committee of Wageningen University, the Netherlands. Before inclusion, serum and feces were screened for absence of enterotoxigenic Escherichia coli (ETEC) specific antibodies (CFAII epitope) and the presence of streptomycin resistant $E$. coli, respectively. The subjects ingested a live but attenuated ETEC strain as described (13). On several days after oral ETEC infection and on the above-mentioned pre-infection days $24 \mathrm{~h}$ stool was collected as described previously (13). These lyophilized-stool samples were used to determine baseline and infection-induced fecal PAP and calprotectin excretion as described below.

\section{Ulcerative colitis patients}

UC patients in remission were recruited from the South Limburg IBD registry (14). Thirty-six patients had a well-defined diagnosis of UC established by clinical, endoscopic, histological and/or radiological criteria. All patients were clinically in remission and had an Endoscopic Grading System (EGS) score below 5 at the first endoscopy (15). Disease location and medication at the time of fecal sampling are presented in Table 1. The left-sided colitis group included 15 patients with distal colitis. Patients were between 31 and 65 years of age and consumed a stable Western diet. Exclusion criteria comprised: proctitis only, pregnancy, lactation, changes in medication and/or prebiotic and probiotic intake less than two weeks prior to endoscopy, use of corticosteroids, enemas and suppositories within two weeks prior to endoscopy, use of antibiotics within the 3 months prior to or during endoscopy, other clinically significant systemic diseases, and previous radiotherapy or chemotherapy. All patients gave their written informed consent before participation. The study 
Table 1. Patient characteristics.

\begin{tabular}{|c|c|c|c|}
\hline & \multirow{2}{*}{$\begin{array}{c}\text { Ulcerative Colitis } \\
\text { Remission }\end{array}$} & \multicolumn{2}{|c|}{ Crohn's disease } \\
\hline & & Active & Remission \\
\hline Age (years): Mean (range) & $53(31-65)$ & $28(19-39)$ & $45(20-69)$ \\
\hline Number of patients & 36 & 8 & 14 \\
\hline Gender: Male & 21 & 5 & 4 \\
\hline \multirow[t]{4}{*}{ Localization of disease } & Left-sided colitis 27 & Ileum 4 & Ileum 8 \\
\hline & Pancolitis 7 & Ileocolonic 4 & Ileocolonic 3 \\
\hline & Unknown 2 & & Ileorectal 1 \\
\hline & & & Colon 2 \\
\hline \multicolumn{4}{|l|}{ Medication : } \\
\hline Biologicals & 0 & 0 & 3 \\
\hline Immunomodulators & 3 & 3 & 8 \\
\hline Oral 5-ASAs & 18 & 1 & 6 \\
\hline Topical corticosteroids & 0 & 1 & 3 \\
\hline None & 15 & 4 & 1 \\
\hline
\end{tabular}

was performed in accordance with the principles of the Helsinki Declaration and was approved by the Medical Ethics Committee of the University Hospital Maastricht, the Netherlands. Prior to endoscopy each patient collected $24 \mathrm{~h}$ stool, which was homogenized and lyophilized.

\section{Crohn's disease patients}

CD patients, aged 19-96 years, were either in remission $(n=14)$ or had active disease $(n=8)$. Remission was clinically determined by a physician global assessment (PGA), serum C-reactive protein $<5 \mathrm{mg} / \mathrm{L}$ and fecal calprotectin $<60 \mathrm{mg} /$ $\mathrm{kg}(60 \mu \mathrm{g} / \mathrm{g})$. Further subject characteristics are presented in Table 1. All patients gave their written informed consent before participation. The study was performed in accordance with the principles of the Helsinki Declaration and approved by the Medical Ethics Committee of the University Medical Centre Groningen, the Netherlands. From each patient stool was collected, homogenized and stored at $-80^{\circ} \mathrm{C}$.

\section{Fecal calprotectin analysis}

Fecal calprotectin was determined by a commercially available ELISA (Calpro AS, Oslo, Norway) following the manufacturer's instructions (16). Briefly, feces 
from healthy or infected subjects (13) or IBD patients were suspended and incubated at RT in the extraction buffer provided for $30 \mathrm{~min}$. After vigorous shaking the extracts were centrifuged for $20 \mathrm{~min}$ at $10,000 \mathrm{~g}$ at $4{ }^{\circ} \mathrm{C}$. The clear supernatants were diluted to fit the standard curve range and calprotectin levels were expressed as $\mu \mathrm{g}$ per $\mathrm{g}$ fecal wet weight. To monitor assay quality in each assay standard recovery and duplicates were included.

\section{Fecal PAP analysis}

A commercially available ELISA (Dynabio S.A., Marseille, France) for assaying human PAP in serum was used to determine PAP in feces. Fecal extracts were prepared as previously described (3). Control experiments on fecal extract residues showed that the method used extracted all PAP protein from (lyophilized) human feces. In each assay standard recovery was checked and duplicates were included to monitor assay quality. PAP output was expressed as ng per $\mathrm{g}$ fecal wet weight. From the two baseline samples intra-individual variation was calculated. To evaluate fecal PAP and calprotectin excretion kinetics during ETEC infection, the infection-induced change in these markers was calculated by subtracting the individuals' baseline (pre-infection) concentration from their postinfection concentrations.

In a separate control experiment, the stability of this protein in stool was investigated. For that purpose, fresh fecal samples from healthy subjects were homogenized and aliquots were stored either at RT or $4^{\circ} \mathrm{C}$ or at $-20^{\circ} \mathrm{C}$ for $24 \mathrm{~h}$ and $48 \mathrm{~h}$ and PAP levels were measured and compared with that of fresh feces. In addition, the effect of repeated freeze-thaw cycles and lyophillization on PAP stability was investigated.

\section{Statistics}

Statistical analysis was performed by using Prism 5.0 Software (GraphPad, San Diego, California, USA). All data was tested for normality by KolmogorovSmirnov normality test and Shapiro-Wilk normality test.

Absolute data from PAP and calprotectin excretion during ETEC infection were compared per time point to basal levels by Wilcoxon matched pairs test. Individual data from IBD patients versus healthy controls were tested by the nonparametric Kruskal-Wallis test, followed by Dunn's post-test for multiple comparisons. Statistical significance was set at $\mathrm{p}<0.05$. Numerical data are presented as mean \pm SE or median as indicated.

\section{RESULTS}

\section{Stability of fecal PAP}

To determine stability of fecal PAP various preservation methods were investigated. Fecal PAP was stable at $-20^{\circ} \mathrm{C}, 4^{\circ} \mathrm{C}$ and room temperature for at least 48 hrs and after repeated freeze-thaw cycles, as concentrations were similar to those observed in the fresh fecal samples (data not shown). In addition, fresh fecal 


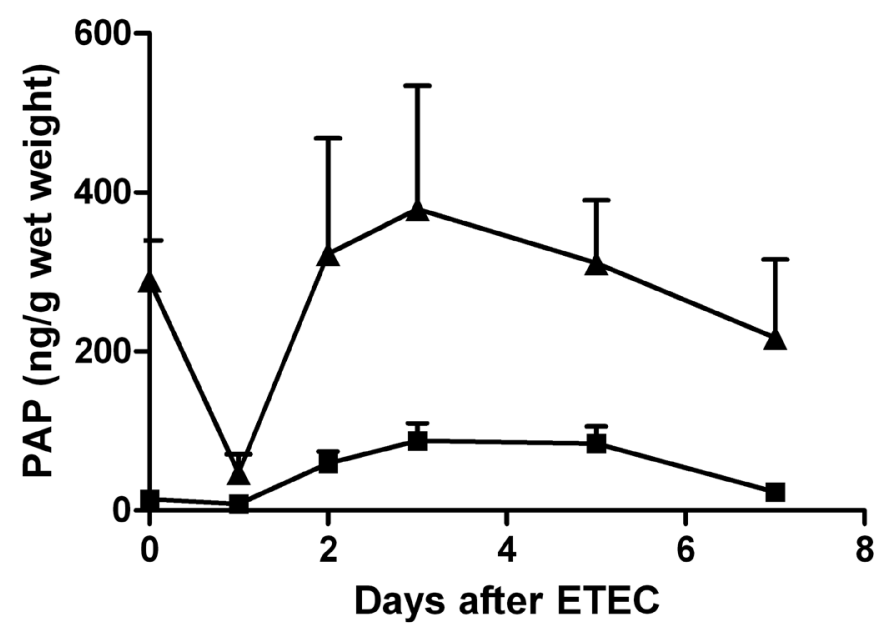

Figure 1. Fecal PAP excretion pattern in healthy subjects orally exposed to enterotoxigenic Escherichia coli (ETEC). Pancreatitis associated protein (PAP) concentrations in feces before (day 0) and after (days 1, 2, 3, 5 and 7) ingestion of a live but attenuated ETEC strain. Each line represents a categorical group based on basal PAP concentration: group 0-50 ng/g $(\boldsymbol{\square} ; \mathrm{n}=26)$, and those with basal levels $>100 \mathrm{ng} / \mathrm{g}(\boldsymbol{\Delta} ; \mathrm{n}=5)$. Basal (pre-infection) levels were based on two fecal samples of each subject, collected on different days. Fecal calprotectin was identical in both subgroups (data not shown). Data are expressed as mean \pm SE.

samples stored at $-20^{\circ} \mathrm{C}$ or the same samples lyophilized and stored at room temperature resulted in similar concentrations (data not shown). This indicated that lyophilization had no effect on fecal PAP concentrations.

\section{Fecal PAP and calprotectin in healthy subjects before and after ETEC infection}

To investigate fecal PAP and calprotectin levels in healthy subjects and after ETEC infection both proteins were analyzed in feces. In healthy subjects there was large variation in fecal PAP. The mean was $59 \pm 20 \mathrm{ng} / \mathrm{g}$ concentration (median 12 ng/g). Five subjects had a high basal PAP excretion (>100 ng/g; Fig. 1 and 3B) in comparison with other healthy subjects. Standard additions and identical results from multiple assays indicated that an analytical error was unlikely. As far as we know, these subjects had no other discriminating characteristic in common. Their fecal calprotectin concentration was as low as observed in other healthy subjects (total group mean $5 \pm 1 \mu \mathrm{g} / \mathrm{g}$; data not shown), total fecal output and relative fecal dry weight were also in the same range as those of other subjects. Also, fecal characteristics like $\mathrm{pH}$, cytotoxicity, ammonia levels, phosphate levels and the number of lactobacilli did not differ from other healthy subjects. Characteristics of the subjects such as age, BMI, habitual dietary intake, smoking 


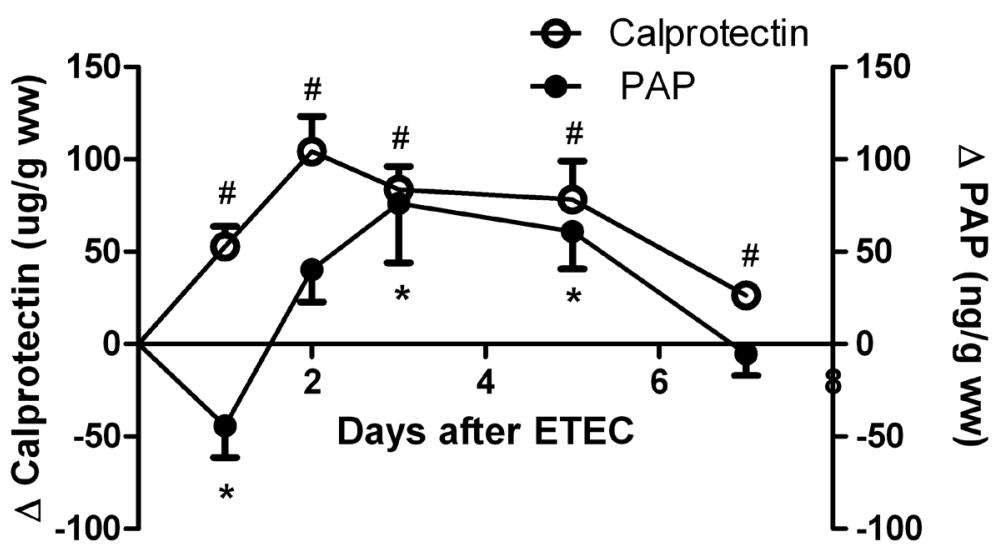

Figure 2. ETEC-induced excretion kinetics of PAP is not similar to calprotectin. Fecal PAP and calprotectin after ingestion of a live but attenuated ETEC strain on day 0 by healthy subjects $(n=31)$. $\Delta$ Concentration was calculated by correcting for baseline preinfection levels. Baseline levels were calculated from two fecal samples from each subject, collected on different days. Data are expressed as mean \pm SE per gram wet weight ( $g$ ww). Per time point absolute data were compared to basal levels by Wilcoxon matched pairs test for nonparametric paired data. ${ }^{*}<0.05$; \# $\mathrm{p}<0.01$

habits, and previous appendectomy were compared but revealed no differences between the five subjects and other healthy subjects. Aside from these five highPAP excretors, all other subjects had low basal PAP levels ( $\leq 50 \mathrm{ng} / \mathrm{g}$; Fig. 1). Follow-up of these two subgroups after oral ETEC infection showed that the infection-induced response in fecal PAP excretion was similar, although in the $>100 \mathrm{ng} / \mathrm{g}$-group an initial decrease of fecal PAP was shown on the first day after ETEC ingestion (Fig. 1). Overall the PAP output showed the same kinetics between the subgroups.

The absolute intra-individual variation was determined by analysis of two fecal samples collected prior to infection. As expected the intra-individual variation in PAP excretion including the five extreme subjects was much higher than without those subjects, namely $100 \mathrm{ng} / \mathrm{g}$ and $16 \mathrm{ng} / \mathrm{g}$, respectively.

On the first day after oral infection fecal PAP was significantly lower than baseline level (Fig. 2 ; by $44 \pm 17 \mathrm{ng} / \mathrm{g}$; $\mathrm{p}<0.05$ ), which was mainly caused by a decrease in fecal PAP in the five high-excretors as mentioned above. In contrast, at the same time fecal calprotectin was significantly elevated (by $53 \pm 11 \mu \mathrm{g} / \mathrm{g}$; $\mathrm{p}<0.05)$. On the second day after infection, calprotectin increased even more (by $104 \pm 20 \mu \mathrm{g} / \mathrm{g} ; \mathrm{p}<0.05)$. Only from day three did fecal PAP increase significantly, by $76 \pm 31 \mathrm{ng} / \mathrm{g}$, and concentrations returned to baseline levels at day seven post infection, whereas calprotectin levels were still elevated at that time (Fig. 2). Overall, fecal PAP and calprotectin were both increased by ETEC infection but their kinetics were different. 

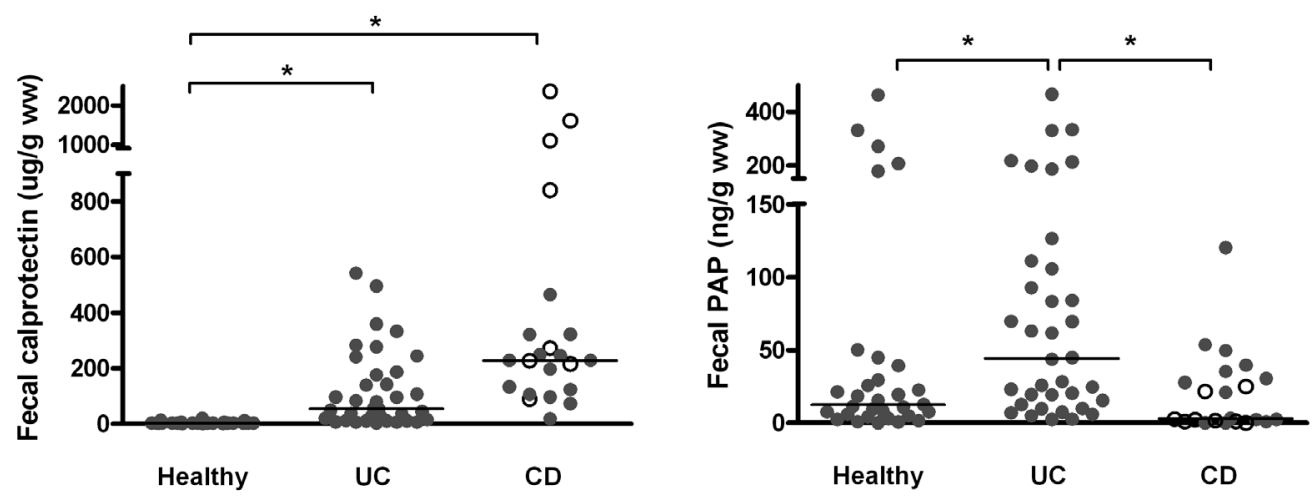

Figure 3. Fecal PAP and calprotectin in IBD patients. Calprotectin (A) and PAP (B) concentrations from healthy individuals $(n=31)$, ulcerative colitis $(U C ; n=36)$ and patients with Crohn's disease $(\mathrm{CD} ; \mathrm{n}=22)$. Inflammatory bowel disease patients were in remission $(\bullet)$ or had active disease $(O)$. Each individual is represented by a single dot and lines indicate the group's median. Data were tested by the nonparametric Kruskal-Wallis test, followed by Dunn's post test for multiple comparisons. Statistical significance was set at ${ }^{*} \mathrm{p}<0.05$.

\section{Stool analysis of IBD patients}

PAP en calprotectin were determined in feces from IBD patients to investigate and compare levels in UC and CD. Fecal calprotectin was higher in CD patients $(432 \pm 123 \mu \mathrm{g} / \mathrm{g})$ and in UC patients $(120 \pm 24 \mu \mathrm{g} / \mathrm{g}$; Fig. $3 \mathrm{~A})$ than in healthy subjects $(5 \pm 1 \mu \mathrm{g} / \mathrm{g})$. UC patients in remission had a significantly higher fecal PAP concentration $(87 \pm 18 \mathrm{ng} / \mathrm{g})$ than healthy subjects $(59 \pm 20 \mathrm{ng} / \mathrm{g} ; \mathrm{p}<0.05)$. In contrast, fecal PAP was not elevated in patients with active or non-active CD $(20 \pm 6$ ng/g; Fig. 3B). Interestingly, PAP was significantly lower in feces from this patient group compared to levels detected in feces from UC patients $(\mathrm{p}<0.05$; Fig. $3 \mathrm{~B})$. PAP levels were not associated with disease location or with medication (Table 1). In addition E2 and E3 location in UC patients, presented as one group termed "left-sided colitis", was not associated with PAP levels. Similarly, fecal calprotectin was not related to PAP levels.

\section{DISCUSSION}

This exploratory study shows that fecal PAP concentrations were associated with intestinal infection induced by oral ETEC infection in healthy volunteers. Furthermore, fecal PAP was increased in patients with UC in clinical remission, while in CD patients fecal PAP concentrations were not elevated despite significantly increased fecal calprotectin levels. 
Fecal biomarkers of intestinal inflammation are attractive in the clinical routine as they provide a non-invasive examination that can help the investigation of patients with mild symptoms such as abdominal pain and diarrhea. Measurement of such biomarkers can easily be repeated and enables non-invasive follow-up of mucosal inflammation, e.g. to monitor therapeutic efficacy (2). The most intensively investigated and currently applied fecal marker is the protein complex S100A8/S100A9 termed 'calprotectin'. This protein complex is mainly expressed by infiltrating granulocytes as well as monocytes and it is, to some extent, also inducible in epithelial cells $(1,17)$. The observed increase of fecal calprotectin in IBD patients we investigated is in concordance with results reported by others (18-20). High calprotectin levels are observed in active UC and CD (18-20), but even during a phase of (clinical) remission levels generally exceed those of healthy controls (20). The latter probably reflects the chronic nature of this disease.

To our knowledge, this is the first study showing that PAP is readily detectable in feces from healthy subjects. The protein is stable in feces for at least $48 \mathrm{hr}$ even at room temperature. Repeated measurements in multiple subjects indicated a rather high inter-individual variation but a relatively low intra-individual variation in fecal PAP. In most subjects, basal levels were below $50 \mathrm{ng} / \mathrm{g}$, but in a small subgroup relatively high levels were detected without any other discriminating health characteristic, including diet. Since there is no clear explanation for the higher levels identified in these subjects, we feel that there is no reason to exclude their data from the control group. The mechanism behind this high excretion of PAP requires further investigation.

The variation between individuals implies that PAP would not be suitable as a solitary biomarker, but more as a differentiating marker in addition to e.g. calprotectin. Irrespective of the basal level, fecal PAP increased with time after exposure of healthy subjects to an attenuated ETEC. Strikingly, similar to previous studies in rats, increased levels were not detected until day 3 post infection $(3,21)$. The course of an infection is characterized by different phases, from initial mucosal adherence and colonization of the pathogen, followed by activation of host defense and an inflammatory response, eventually resulting in inflammation suppression with mucosal repair and epithelial cell differentiation. Considering the delayed fecal PAP output in response to oral ETEC infection, a role for PAP in initial mucosa-pathogen contact seems less likely as intestinal ETEC colonization takes place within the first day after gastrointestinal entrance of this pathogen (13). Our results suggest that PAP plays a role in a more secondary defense or repair of the intestinal mucosa. Some studies indicate an antiinflammatory role of PAP in the immune response. Blocking of PAP in an animal model of acute pancreatitis increased pancreatic inflammation (22) and in human colonic HT29 cells PAP reduced inflammation by inhibiting TNF- $\alpha$ induced NFKB activation (23). 
The difference in excretion kinetics of PAP and calprotectin is not that surprising since the cellular origin of these proteins is different. Although still debated, human PAP and the rodent orthologue RegIII $\beta$ are predominantly present in intestinal epithelial cells $(3,5,24)$ whereas calprotectin is mainly present in infiltrating neutrophils (1).

We show that fecal PAP was elevated in UC patients in remission but not in CD patients (either active or in remission), suggesting increased intestinal mucosal levels of this protein in UC only. The latter seems in contrast with earlier studies describing increased PAP mRNA levels in inflamed colonic tissue of both UC and CD patients $(11,12)$. However, it was also reported that despite detectable RNA levels along all segments of the intestinal tract (25), in the healthy mucosa PAP protein detection was limited to the small intestine and the proximal colon (26). Studies on non-proximal parts of the colon failed to detect PAP protein (27), indicating that results depend on which part of the large intestine is investigated. It is not fully clear what part of the intestine is responsible for the increase in fecal PAP levels we observed. ETEC, used in our infection study, is known to attach mainly in the small intestine (28). This suggests that in this group the small intestine is mainly responsible for the fecal PAP elevation. Thorough investigation of the different disease locations of the IBD subjects and individual PAP levels did not indicate that a specific area was responsible for the increase in fecal PAP. UC patients with pancolitis or left-sided colitis (also E2 or E3) were represented in the complete range of fecal PAP concentrations. Similarly CD patients with active or inactive disease did not show relatively high or low levels of fecal PAP excretion but levels were equally distributed along the range. Therefore, we cannot state which part of the intestine is responsible for the increase of fecal PAP or whether disease activity plays a role. Further investigations using feces and biopsies from larger subgroups of UC and CD patients are needed to provide better insight. Monitoring PAP levels in feces from UC patients in active state also need to be investigated. This will tell us whether the increase of fecal PAP is specific for UC patients in remission or that levels are elevated further during active disease. These results will also provide a better insight in the possible function of this protein.

Our healthy population consisted of males only whereas the IBD groups were represented by males and females. However, the results from the IBD groups do not indicate that gender plays a role in fecal excretion of PAP and could have interfered with our results.

Our previous animal experiments $(3,21)$ and the present human infection study indicate that increased mucosal PAP excretion is a normal response to adherent Gram-negative enteropathogens, such as Salmonella and E. coli. An important role for E.coli in the pathogenesis of CD is suggested by clinical, experimental, and therapeutic studies (9). Functional alterations in the microbiota are most evident in adherent $E$. coli that colonizes the ileum of CD patients $(29,30)$. However, fecal PAP levels in CD patients in our study were 
low and not increased as in healthy subjects after E. coli infection. We speculate that CD patients have an impaired PAP response to enteropathogens and therefore lack a mucosal defense or repair which may contribute to CD pathology. Functionality studies of the mucosal response to enteropathogens in PAP knock-out mice are ongoing. These studies will tell us more about the role of PAP in mucosal defense or repair, and whether absence of PAP in the mucosa could contribute to CD pathology. Clarity on that point is highly essential for further validation of PAP as potential fecal biomarker to identify or monitor intestinal disease activity or recovery either induced by therapeutics or occurring spontaneously.

In conclusion, PAP is detectable in human feces and is increased upon intestinal bacterial infection. Moreover this protein is increased during UC in remission but not in $\mathrm{CD}$ patients, either in remission or with active disease. Fecal PAP excretion kinetics differs from that of the inflammation marker calprotectin, reflecting their different cellular origin and function. Neutrophil-derived proteins like calprotectin have already proved their value as biological markers to determine intestinal inflammation by non-invasive procedures. Markers derived from intestinal epithelial cells are far less well-developed but can be of high potential. This exploratory study in humans is an initial step and definitely needs confirmation and further investigation to determine the value of PAP to monitor intestinal disease activity and to discriminate between UC and CD.

\section{ACKNOWLEDGEMENTS}

We would like to acknowledge Jan Burema for critical guidance in study statistics. 


\section{REFERENCES}

1. Foell, D., Frosch, M., Sorg,

C.Roth, J. 2004. Phagocyte-

specific calcium-binding S100

proteins as clinical laboratory

markers of inflammation.

Clin Chim Acta 344: 37-51.

2. Pardi, D. S.Sandborn, W. J. 2005. Predicting relapse in patients with inflammatory bowel disease: what is the role of biomarkers? Gut 54: 321322.

3. van Ampting, M. T., Rodenburg, W., Vink, C., Kramer, E., Schonewille, A. J., Keijer, J., van der Meer, R. et al. 2009. Ileal Mucosal and Fecal Pancreatitis Associated Protein Levels Reflect Severity of Salmonella Infection in Rats. Dig Dis Sci 54: 25882597.

4. Niewold, T. A., Kerstens, $H$. H., van der Meulen, J., Smits, M. A.Hulst, M. M. 2005. Development of a porcine small intestinal cDNA microarray: characterization and functional analysis of the response to enterotoxigenic $\mathrm{E}$. coli. Vet Immunol Immunopathol 105: 317-329.

5. Ogawa, H., Fukushima, K., Naito, H., Funayama, Y., Unno, M., Takahashi, K., Kitayama, T. et al. 2003. Increased expression of HIP/
PAP and regenerating gene III in human inflammatory

bowel disease and a murine bacterial reconstitution model. Inflamm Bowel Dis 9: 162-170.

6. Cash, H. L., Whitham, C. V., Behrendt, C. L.Hooper, L.

V. 2006. Symbiotic bacteria direct expression of an intestinal bactericidal lectin. Science 313: 1126-1130.

7. Dessein, R., Gironella, M., Vignal, C., Peyrin-Biroulet, L., Sokol, H., Secher, T.,

Lacas-Gervais, S. et al. 2009. TLR2 is critical for induction of REG3\{beta\} expression and intestinal clearance of Yersinia pseudotuberculosis. Gut 58: 771-776.

\section{Medveczky, P., Szmola,} R.Sahin-Toth, M. 2009. Proteolytic activation of human

pancreatitis associated protein is required for peptidoglycan binding and bacterial aggregation. Biochem J 420: 335-343.

\section{Sartor, R. B. 2008. Micro-} bial influences in inflammatory bowel diseases. Gastroenterology 134: 577-594.

10. Loftus, E. V., Jr. 2004. Clinical epidemiology of inflammatory bowel disease: Incidence, prevalence, and environmental influences. Gastroenterology 126: 1504-1517.
11. Dieckgraefe, B. K., Stenson, W. F., Korzenik, J. R., Swanson, P. E.Harrington, C. A. 2000. Analysis of mucosal gene expression in inflammatory bowel disease by parallel oligonucleotide arrays.

Physiol Genomics 4: 1-11.

12. Lawrance, I. C., Fiocchi, C.Chakravarti, S. 2001. Ulcerative colitis and Crohn's disease: distinctive gene expression profiles and novel susceptibility candidate genes. Hum Mol Genet 10: 445-456.

\section{Bovee-Oudenhoven, I. M.,} Lettink-Wissink, M. L., Van Doesburg, W., Witteman, B. J.Van Der Meer, R. 2003. Diarrhea caused by enterotoxigenic Escherichia coli infection of humans is inhibited by dietary calcium. Gastroenterology 125: 469-476.

14. Russel, M. G., Dorant, E., Volovics, A., Brummer, R. J., Pop, P., Muris, J. W., Bos, L. P. et al. 1998. High incidence of inflammatory bowel disease in The Netherlands: results of a prospective study. The South Limburg IBD Study Group. Dis Colon Rectum 41: 33-40.

15. van der Heide, H., van den Brandt-Gradel, V., Tytgat, G. N., Endert, E., Wiltink, E. H., Schipper, M. E.Dekker, W. 1988. Comparison of 
beclomethasone dipropionate and prednisolone 21-phosphate enemas in the treatment of ulcerative proctitis. J Clin Gastroenterol 10: 169-172.

16. Roseth, A. G., Fagerhol, M. K., Aadland, E.Schjonsby, H. 1992. Assessment of the neutrophil dominating protein calprotectin in feces. A methodologic study. Scand J Gastroenterol 27: 793-798.

17. Frosch, M., Metze, D., Foell, D., Vogl, T., Sorg, C., Sunderkotter, C.Roth, J. 2005. Early activation of cutaneous vessels and epithelial cells is characteristic of acute systemic onset juvenile idiopathic arthritis. Exp Dermatol 14: 259-265.

18. von Roon, A. C., Karamountzos, L., Purkayastha, S., Reese, G. E., Darzi, A. W., Teare, J. P., Paraskeva, P. et al. 2007. Diagnostic precision of fecal calprotectin for inflammatory bowel disease and colorectal malignancy. Am J Gastroenterol 102: 803-813.

19. Sutherland, A. D., Gearry, R. B.Frizelle, F. A. 2008. Review of fecal biomarkers in inflammatory bowel disease. Dis Colon Rectum 51: 1283-1291.

20. Costa, F., Mumolo, M. G., Ceccarelli, L., Bellini, M.,
Romano, M. R., Sterpi, C., Ricchiuti, A. et al. 2005. Calprotectin is a stronger predictive marker of relapse in ulcerative colitis than in Crohn's disease. Gut 54: 364368.

21. Rodenburg, W., BoveeOudenhoven, I. M., Kramer, E., van der Meer, R.Keijer, J. 2007. Gene expression response of the rat small intestine following oral Salmonella infection. Physiol Genomics 30: 123-133.

22. Vasseur, S., Folch-Puy, E., Hlouschek, V., Garcia, S., Fiedler, F., Lerch, M. M., Dagorn, J. C. et al. 2004. p8 improves pancreatic response to acute pancreatitis by enhancing the expression of the anti-inflammatory protein pancreatitis-associated protein I. J Biol Chem 279: 7199-7207.

23. Gironella, M., Iovanna, J. L., Sans, M., Gil, F., Penalva, M., Closa, D., Miquel, R. et al. 2005. Anti-inflammatory effects of pancreatitis associated protein in inflammatory bowel disease. Gut 54: 12441253.

24. Iovanna, J. L., Keim, V., Bosshard, A., Orelle, B., Frigerio, J. M., Dusetti, N.Dagorn, J. C. 1993. PAP, a pancreatic secretory protein induced during acute pancreatitis, is expressed in rat intestine. Am J Physiol 265: G611-618.

25. Bartoli, C., Baeza, N., Figarella, C., Pellegrini, I.Figarella-Branger, D. 1998. Expression of peptide-23/ pancreatitis-associated protein and Reg genes in human pituitary and adenomas: comparison with other fetal and adult human tissues. J Clin Endocrinol Metab 83: 4041-4046.

26. Hervieu, V., Christa, L., Gouysse, G., Bouvier, R., Chayvialle, J. A., Brechot, C.Scoazec, J. Y. 2006. HIP/ PAP, a member of the reg family, is expressed in glucagonproducing enteropancreatic endocrine cells and tumors. Hum Pathol 37: 1066-1075.

27. Masciotra, L., Lechene de la Porte, P., Frigerio, J. M., Dusetti, N. J., Dagorn, J. C.Iovanna, J. L. 1995. Immunocytochemical localization of pancreatitis-associated protein in human small intestine. Dig Dis Sci 40: 519-524.

28. Levine, M. M. 1987. Escherichia coli that cause Diarrhea: Enterotoxigenic, Enteropathogenic, Enteroinvasive, Enterohemorrhagic, and Enteroadherent. The journal of infectious diseases 155: 377-389. 
29. Rolhion, N.Darfeuille-

Michaud, A. 2007. Adherent-

invasive Escherichia coli in

inflammatory bowel disease.

Inflamm Bowel Dis 13: $1277-$

1283.

30. Barnich, N.Darfeuille-

Michaud, A. 2007. Adherent-

invasive Escherichia coli and

Crohn's disease. Curr Opin

Gastroenterol 23: 16-20. 



\section{CHAPTER 5}

\section{INTESTINAL BARRIER FUNCTION IN RESPONSE TO ABUNDANT OR DEPLETED MUCOSAL GLUTATHIONE IN SALMONELLA-INFECTED RATS}

Marleen T.J. van Ampting ${ }^{1,2}$, Arjan J. Schonewille ${ }^{1,2}$, Carolien Vink ${ }^{1,2}$, Robert Jan M. Brummer ${ }^{1,3,4}$, Roelof van der Meer ${ }^{1,2}$, Ingeborg M.J. Bovee-Oudenhoven ${ }^{1,2}$

${ }^{1}$ TI Food and Nutrition, Wageningen, the Netherlands

${ }^{2}$ Department of Health and Safety, NIZO food research, Ede, the Netherlands

${ }^{3}$ Nutrition and Toxicology Research institute Maastricht, Maastricht University, Maastricht, the Netherlands

${ }^{4}$ Present address: School of Health and Medical Sciences, Örebro University, Örebro, Sweden

BMC Physiology 2009; 9: 6. 
ABSTRACT

Background: Glutathione, the main antioxidant of intestinal epithelial cells, is suggested to play an important role in gut barrier function and prevention of inflammation-related oxidative damage as induced by acute bacterial infection. Most studies on intestinal glutathione focus on oxidative stress reduction without considering functional disease outcome. Our aim was to determine whether depletion or maintenance of intestinal glutathione changes susceptibility of rats to Salmonella infection and associated inflammation.

Methods: Rats were fed a control diet or the same diet supplemented with buthionine sulfoximine (BSO; glutathione depletion) or cystine (glutathione maintenance). Inert chromium ethylenediamine-tetraacetic acid (CrEDTA) was added to the diets to quantify intestinal permeability. At day 4 after oral gavage with Salmonella enteritidis (or saline for non-infected controls), Salmonella translocation was determined by culturing extra-intestinal organs. Liver and ileal mucosa were collected for analyses of glutathione, inflammation markers and oxidative damage. Faeces was collected to quantify diarrhoea.

Results: Glutathione depletion aggravated ileal inflammation after infection as indicated by increased levels of mucosal myeloperoxidase and interleukin-1 $\beta$. Remarkably, intestinal permeability and Salmonella translocation were not increased. Cystine supplementation maintained glutathione in the intestinal mucosa but inflammation and oxidative damage were not diminished. Nevertheless, cystine reduced intestinal permeability and Salmonella translocation.

Conclusions: Despite increased infection-induced mucosal inflammation upon glutathione depletion, this tripeptide does not play a role in intestinal permeability, bacterial translocation and diarrhoea. On the other hand, cystine enhances gut barrier function by a mechanism unlikely to be related to glutathione. 


\section{BACKGROUND}

During foodborne Salmonella enteritidis infection pathogens can pass the gut epithelial cell lining and translocate to extra-intestinal organs like the spleen and liver (1). In response to mucosal invasion of pathogens, epithelial cells and macrophages express pro-inflammatory cytokines, e.g. interleukin-1 $\beta$ (IL-1 $\beta$ ), to recruit neutrophils $(2,3)$. These efficient killers of translocating microbes (4) contain high concentrations of the enzyme myeloperoxidase (MPO) $(4,5)$, which participates in the innate immune defence through formation of powerful reactive oxidants $(4,5)$. An unfortunate side-effect of this defence machinery is that the anti-bacterial reactive oxygen species produced also react with cellular organic molecules and have the potential to induce oxidative tissue damage (4-6). For example, MPO is associated with oxidative stress-related damage (protein nitration) in the inflamed mucosa of ulcerative colitis patients (7). To reduce this damage, inhibition of MPO has even become a possible target of new drug development (8).

Glutathione, a tripeptide composed of $\gamma$-glutamic acid, cysteine and glycine is quantitatively the most important low-molecular-weight (non-protein) thiol in tissues $(6,9,10)$. Glutathione, synthesised by most mammalian cells but mainly in the liver $(9,11)$, is an active free-radical-scavenging compound found in virtually all animal cells $(6,9,11)$. In comparison with a number of other tissues the liver has a particularly high content of glutathione (9). A relatively high concentration of glutathione is also detected in the intestinal epithelium (12). Here glutathione has been shown to play an important role in the protection of the intestinal mucosa against oxidative stress both in vitro $(13,14)$ and in vivo $(12,15)$. For example, glutathione depletion in newborn rats leads to increased nitrosative stress during necrotising enterocolitis (15). Furthermore, Salmonella infection decreases enterocyte glutathione levels in mouse ileal loops and this reduction increases the susceptibility of epithelial cells to oxidative damage (16). This oxidative damage in its turn might impair barrier function. As well as the gut microbiota (17), mucus (18) and the immune system $(19,20)$, intestinal glutathione is suggested to be important for intestinal barrier function (15). Many studies on the role of glutathione in prevention of oxidative damage in the intestinal mucosa have been performed (13-15). However, actual in vivo proof that intestinal glutathione is important for gut barrier function is lacking. We therefore investigated the role of glutathione in intestinal barrier function and infection-induced mucosal inflammation.

Buthionine sulfoximine (BSO) is a specific inhibitor of $\gamma$-glutamylcysteine synthetase (gamma-GCS), which is the rate-limiting enzyme of glutathione synthesis (21). This chemical causes glutathione-deficiency in animals (22) and enables us to investigate the role of this tripeptide in animal models. Besides glutathione depletion, stimulation of synthesis is interesting for that purpose as well. Cysteine is known to stimulate glutathione synthesis (23), and cysteine availability is often the limiting factor for intracellular glutathione 
synthesis (24). For example, intraperitoneally administered $\mathrm{N}$-acetylcysteine was shown to increase hepatic and intestinal glutathione levels in bile-duct ligated rats (25). Therefore, dietary supplementation with cysteine, or the more stable variant cystine, can potentially maintain or increase hepatic and intestinal glutathione levels during oxidative stress.

Our aim was to determine whether depletion of glutathione by BSO affects gut barrier function and increases susceptibility of rats to Salmonella infection and the associated inflammation. In addition, the effect of dietary cystine on glutathione levels in the intestinal mucosa and consequences for the resistance to infection were investigated.

\section{METHODS}

\section{Diets, infection and dissection of the rats}

The animal experiments were approved by the animal welfare committee of Wageningen University (Wageningen, the Netherlands). Specific-pathogen-free male Wistar rats (WU, Harlan, Horst, the Netherlands), 8 weeks old at the start of the dietary intervention, were housed individually in metabolic cages. Rooms were temperature $\left(20-21^{\circ} \mathrm{C}\right)$ and humidity-controlled (50-60\%) with a $12: 12$ hour light/dark cycle. Rats were fed purified diets containing per kg: $200 \mathrm{~g}$ acid casein, $326 \mathrm{~g}$ cornstarch, $174 \mathrm{~g}$ glucose, $160 \mathrm{~g}$ palm oil, $40 \mathrm{~g}$ corn oil, $50 \mathrm{~g}$ cellulose and vitamin and mineral mix (without calcium) according to AIN-93 (26). To mimic the composition of a Western human diet, the prepared diets were relatively low in calcium $(30 \mathrm{mmol} / \mathrm{kg})$ and high in fat content $(200 \mathrm{~g} / \mathrm{kg})$ in comparison with recommendations for rodent diets by AIN-93. This control diet was supplemented with DL-buthionine $(S, R)$-sulfoximine (BSO) or L-cystine (both purchased from Sigma-Aldrich, St. Louis, Missouri, USA), at the expense of glucose, to a final concentration of $7.5 \mathrm{mmol} / \mathrm{kg}$ and $12.3 \mathrm{mmol} / \mathrm{kg}$, respectively. Nitrogen correction of the diets was considered unnecessary, since the contribution of cystine was marginal $(0.035 \%)$. In addition, the inert intestinal permeability marker CrEDTA was added to the diets $(27,28)$. Preparation and purity control of CrEDTA was performed as described (29-31). The CrEDTA solution was lyophilised in a manifold freeze dryer (FD5515; Ilshin Laboratory Co Ltd, Seoul, South Korea) and the dry material obtained was added to the diets to a final concentration of $2 \mathrm{~g} / \mathrm{kg}$.

Food and demineralised drinking water were supplied ad libitum. Body weight and food intake were recorded twice a week before infection and daily after infection. One group was fed the control diet and another group was fed the cystine-supplemented diet $(n=14$ per diet). The third group $(n=14)$ was fed the control diet for one week, followed by the BSO diet for the remaining study period.

Animals were acclimatised to housing and dietary conditions for 21 days, after which 8 animals per diet group were orally infected with $1 \mathrm{ml}$ of saline containing $1.10^{9} \mathrm{CFU}$ of Salmonella enteritidis (clinical isolate, phage type 4; strain B1214 NIZO food research, Ede, the Netherlands) as described elsewhere 
(32). The other 6 animals per diet group were not infected and received $1 \mathrm{ml}$ saline orally.

In previous Salmonella infection studies in rats we have found that levels of ileal mucosal glutathione change with time (unpublished). After an initial decrease, total glutathione levels start to recover at day 4 post infection. Furthermore, for monitoring functional infection outcomes like Salmonella colonization, translocation and infection-induced permeability changes, follow-up of infected rats for at least 3 to 4 days is needed. Therefore section was performed at day 4 after infection (or sham treatment). Rats were randomly selected and killed by carbon dioxide inhalation. During the dissection, the distal $12 \mathrm{~cm}$ of the ileum was excised and cut open longitudinally. After flushing rapidly with saline, the mucosa was scraped off with a spatula and immediately frozen in liquid nitrogen for protein analyses. Furthermore, the spleen and liver were aseptically excised and after homogenisation in sterile saline directly used for Salmonella quantification, as described elsewhere (33). Another part of the liver was immediately frozen in liquid nitrogen for further preparation and analyses as described below.

Fresh faecal samples were collected to quantify Salmonella colonization prior to infection and 1 and 3 days post infection, as described elsewhere (34). In addition, $24 \mathrm{~h}$ faeces (pooled per animal in both the pre-infection and post-infection period) and urines were collected from 2 days before infection until 4 days after oral Salmonella administration. All faeces and urine samples were stored at $-20^{\circ} \mathrm{C}$ until further analysis. Oxytetracycline (Sigma-Aldrich) was added to the urine collection vessels of the metabolic cages to prevent bacterial deterioration.

\section{Salmonella colonization and diarrhoea}

Faecal Salmonella was determined in fresh faecal samples collected with time as described elsewhere (34). Total $24 \mathrm{~h}$ faeces were lyophilized in a manifold freeze dryer (FD5515; Ilshin Laboratory Co Ltd). Faecal water was prepared as described previously and osmolarity was measured (Osmomat 030-D, Gonotec, Berlin, Germany) to calculate the percentage wet weight (35). Direct determination of faecal wet weight by lyophilisation was considered inappropriate because this underestimates relative faecal wet weight due to evaporation of water from the faecal pellets in the collection vessels of the metabolic cages.

\section{Intestinal permeability analysis}

CrEDTA excreted in $24 \mathrm{~h}$ urine samples was determined by inductively coupled plasma atomic emission spectroscopy (ICP-AES; Varian, Mulgrave, Australia) as described elsewhere (30). Urinary CrEDTA output was expressed as percentage of dietary intake. Infection-induced urinary excretion of CrEDTA was corrected for baseline (pre-infection) levels. Urine was tested negative for faecal contamination by checking the absorption spectrum 400-600 $\mathrm{nm}$ for bile pigments. These pigments are present in faeces but absent in urine. 


\section{Tissue sample preparation}

Frozen liver tissue and ileal mucosa were pulverised under liquid nitrogen. Frozen pulverised tissue was suspended in a $0.2 \mathrm{M}$ sucrose buffer of $\mathrm{pH} 7.4$ containing $20 \mathrm{mM}$ trishydroxymethylaminomethane (Tris), $1 \mathrm{mM}$ dithiothreitol (DTT; Sigma Aldrich) and Complete Protease Inhibitor Cocktail (Roche Diagnostics, Basel, Switzerland) and sonicated on ice for 20-30 s at level 2-3 (Sonicator XL2020, Heat Systems, Farmingdale, NY, USA). The protein concentration of the samples was determined using biocinchoninic acid (BC) Assay (Omnilabo, Veenendaal, the Netherlands).

\section{Total glutathione and cysteine analyses}

Total glutathione in liver and ileum was measured using a slightly modified assay described by Mansoor et al. (36). This method determines the total of reduced, oxidized, and protein-bound forms of glutathione by HPLC without discrimination of the individual forms. As a result, total glutathione levels are presented and indicated in the text by 'glutathione'. Compared to the original method, twice the sample volumes and reagents were used. Briefly, samples of $25 \mu$ were injected into a $150 \times 4.6 \mathrm{~mm}, 3 \mu \mathrm{m}$ PLRP-S column, equipped with a PLRP-S guard column (Polymer Laboratories, Amherst, MA, USA). Flow rate was $1 \mathrm{ml} /$ min at $30^{\circ} \mathrm{C}$ with elution solvent $\mathrm{A}(0.1 \%$ trifluoric acid (TFA), 5\% acetonitrile) and solvent B $(0.1 \%$ TFA, $80 \%$ acetonitrile), both diluted with distilled water. Chemicals were purchased from Sigma-Aldrich. The elution profile was as follows: $0-20 \mathrm{~min}, 0 \% \mathrm{~B} ; 20-25 \mathrm{~min}, 16 \% \mathrm{~B} ; 25-30 \mathrm{~min} 50 \% \mathrm{~B}$, with retention time of bimane derivatives of glutathione of $23 \mathrm{~min}$. A Spectra Systems FL2000 fluorometer (Spectra Physics, Mountain View, CA, USA) was used for detection, with excitation and emission at 394 and $480 \mathrm{~nm}$, respectively. Plotting and integration of peaks were performed by Chromeleon software 6.6 (Dionex, Sunnyvale, CA, USA). Total glutathione results are expressed as $\mu \mathrm{mol} / \mathrm{g}$ tissue protein.

In the samples described above cysteine, identified as a separated peak in chromatograms, was determined identically and simultaneously with the glutathione analysis.

\section{Mucosal antioxidant capacity}

Mucosal antioxidant capacity of non-thiols, thus excluding glutathione, was determined using the ferric reducing ability method as described for plasma (37). Briefly, to $33 \mu \mathrm{l}$ ileum sample $1 \mathrm{ml}$ of ferric reducing ability reagent was added (37). Antioxidant capacity is expressed as $\mathrm{nmol} \mathrm{Fe}^{2+}$ formed per $\mathrm{mg}$ protein.

\section{Mucosal inflammation and oxidative damage}

A mouse MPO ELISA test kit (Hycult biotechnology, Uden, the Netherlands), which is cross-reactive with rat MPO, was used to determine the concentration of MPO in mucosal scrapings. IL-1 $\beta$ levels were determined using an ELISA kit (Biosource, Nivilles, Belgium). 
To evaluate lipid peroxidation, TBARS in the mucosal samples were determined according to Ohkawa (38), using $100 \mu \mathrm{l}$ of undiluted sample (35). Control experiments with reference samples, known to have TBARS, were analysed positive. In addition, spiking of ileal mucosal samples of the present study with the reference material showed good recovery of TBARS.

Ileal protein carbonyls, as marker of protein oxidation, were measured by an ELISA according to the method of Buss et al. (39). Briefly, standards and samples were diluted in phosphate-buffered saline to a protein concentration of $4 \mathrm{mg} / \mathrm{ml}$. Carbonyls were derivatised with 2,4-dinitrophenyl hydrazine (SigmaAldrich) and coated on an ELISA plate (Nunc-Immuno plate maxisorp, Nunc, Roskilde, Denmark). After probing with biotinylated anti-2,4-dinitrophenyl hydrazine antibody (Molecular Probes Inc, Eugene, OR, USA), streptavidin-biotinylated horseradish peroxidase (Amersham Biosciences, Piscataway, NJ, USA) was incubated in the wells. Staining was performed with $o$-phenylenediamine (Sigma-Aldrich). Absorbance was read at $490 \mathrm{~nm}$ in a ThermoMax microplate reader (Molecular Devices Corp, Sunnyvale, CA, USA).

\section{S. enteritidis lipopolysaccharide experiment}

To study the effect of dietary cystine on the capacity of rats to generate NO in response to systemic bacterial stimuli, rats ( $n=8$ per group) fed the control or cystine diet (dietary acclimatisation of 14 days) were intraperitoneally injected with $0.5 \mathrm{mg} / \mathrm{kg}$ LPS, as described elsewhere (33). The LPS used was derived from $S$. enterica Serovar enteritidis, which is identical to the strain used in the oral infection study. Animals were monitored until 3 days after challenge and $24 \mathrm{~h}$ urines were collected. The NO response was quantified by measuring urinary $\mathrm{NO}_{\mathrm{x}}$ (sum of nitrate and nitrite) excretion by using a colorimetric enzymatic kit (Roche Diagnostics), as described elsewhere (40).

\section{Statistical analysis}

All data are expressed as means \pm SE. Data were tested for normality by the Kolmogorov-Smirnov test. If normally distributed, differences between the control and dietary intervention groups (cystine or BSO) were tested for significance using one-way ANOVA, followed by Bonferroni's multiple-comparison test. Our aim was to investigate dietary effects in the non-infection and the infection period separately. Therefore, differences between non-infected and infected groups were not tested. When data of groups showed unequal variances, the Kruskal-Wallis test was used, followed by Dunn's post test for multiple comparisons. Statistical significance was set at $\mathrm{p}<0.05$.

\section{RESULTS}

\section{Animals and food intake}

At the start of the study, mean body weight of the animals was $243 \mathrm{~g}$. Average food intake before infection was $19 \mathrm{~g} / \mathrm{d}$ in the control and cystine group, and 17 
A

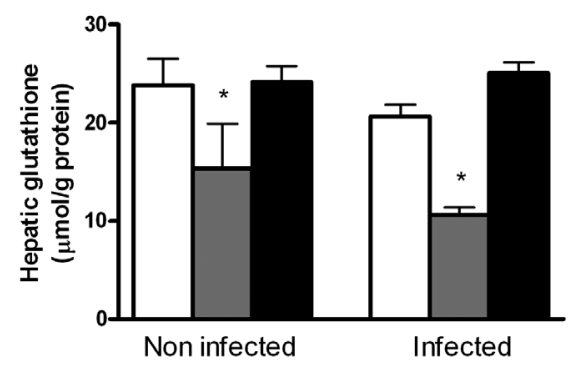

$\mathrm{B}$

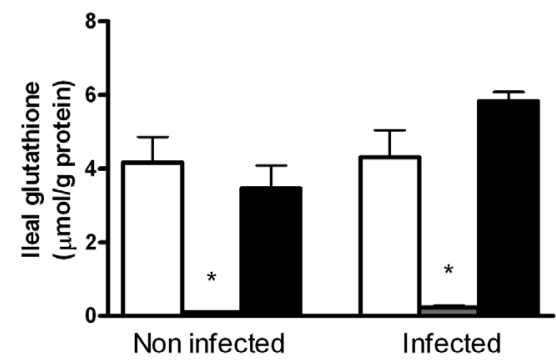

Figure 1. Total glutathione in liver and ileum mucosa. Total glutathione in liver (A) and ileum mucosa (B) of rats fed the control diet (white bars) or the same diet supplemented with buthionine sulfoximine (BSO; grey bars) or cystine (black bars). Rats were orally infected with $1.10^{9}$ colony-forming units $S$. enteritidis ( $\mathrm{n}=8$ per diet) or received saline only (non-infected animals; $\mathrm{n}=6$ per diet). Results are expressed as means \pm SE. An asterisk indicates a significant difference from the control diet group (either non-infected or infected rats; $\mathrm{p}<0.05)$.

$\mathrm{g} / \mathrm{d}$ in the BSO group $(\mathrm{p}<0.05)$. Post infection, food intake was $16 \mathrm{~g} / \mathrm{d}$ in all groups. Mean body weight gain prior to infection was $5 \mathrm{~g} / \mathrm{d}$. After infection, average body weight gain was $3 \mathrm{~g} / \mathrm{d}$ in all groups.

\section{BSO decreases the glutathione content in liver and ileum mucosa}

BSO decreased hepatic glutathione by $48 \%$ in the infected animals in comparison with the control group (Figure $1 \mathrm{~A} ; \mathrm{p}<0.05$ ). Cystine supplementation did not significantly affect liver glutathione of non-infected rats. Post-infection levels were $21 \%$ higher in cystine-fed animals, although this increase did not reach statistical significance. BSO decreased ileal mucosal glutathione by $\geq 98 \%$ in non-infected and infected rats (Figure 1B; $\mathrm{p}<0.05$ ). Dietary cystine did not increase ileal glutathione in non-infected or infected rats.

BSO is a competitive inhibitor of gamma-GCS and could possibly cause an accumulation of cysteine in the ileum mucosa. However, mucosal cysteine levels were decreased in BSO treated animals (data not shown).

\section{Diarrhoea, faecal excretion and translocation of Salmonella}

Glutathione depletion increased relative faecal wet weight in non-infected animals whereas cystine had no effect (Figure 2A). After infection, there was no difference in diarrhoea between the control and BSO group or between the control and cystine group.

Faecal Salmonella excretion was similar in all diet groups on the first and third day after Salmonella infection $\left(10^{7}\right.$ and $10^{6}$ colony-forming units (CFU)/g faeces, respectively), indicating identical intestinal colonization levels in all groups. Furthermore, depletion of mucosal glutathione did not affect 
A

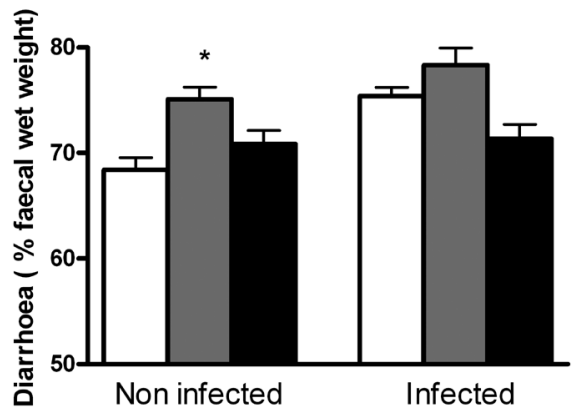

B

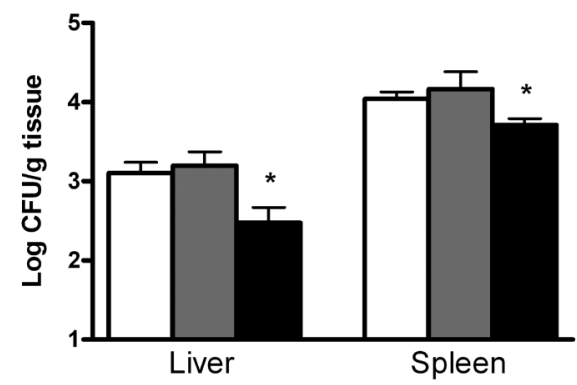

Figure 2. Relative faecal wet weight and Salmonella translocation. Relative faecal wet weight (A) before ( $\mathrm{n}=6$ per diet group) and after oral $S$. enteritidis infection ( $\mathrm{n}=8$ per diet group) of rats fed the control diet (white bars) or the same diet supplemented with BSO (grey bars) or cystine (black bars). Translocation of $S$. enteritidis as determined by viable pathogen counts (B) in liver and spleen. Results are expressed as means \pm SE. CFU means colony-forming units. An asterisk indicates a significant difference from the control diet group (either non-infected or infected rats; $\mathrm{p}<0.05$ ).

Salmonella translocation to liver and spleen (Figure 2B). In contrast, cystine decreased the number of Salmonella in both tissues (Figure 2B), pointing to a protective effect of cystine on Salmonella translocation to extra-intestinal organs.

\section{Mucosal antioxidant capacity}

In response to a serious decrease of glutathione, the body could compensate by increasing other (non-thiol) antioxidants. Therefore we investigated the total mucosal antioxidant capacity of non-thiols by determining the ferric reducing ability of mucosal tissue. Neither BSO nor cystine changed the mucosal nonthiol antioxidant capacity before infection. The same results were found in infected rats (Figure 3).

\section{Mucosal inflammation and oxidative damage}

Despite identical colonization levels, the glutathione-depleted rats, presumably with lower antioxidant capacity, had increased ileal mucosal IL- $1 \beta$ levels (Figure 4A). This coincided with a more intensive inflammatory response in this group as measured by ileal MPO (Figure 4B). However, this did not increase oxidative-stress related mucosal damage like protein carbonyls (Figure 4C) and mucosal lipid peroxidation, measured by thiobarbituric acid reactive substances (TBARS; results not shown). Despite protective effects of cystine on Salmonella translocation and maintenance of glutathione levels, intestinal inflammation and oxidative damage markers were not decreased in this group (Figure 4). 


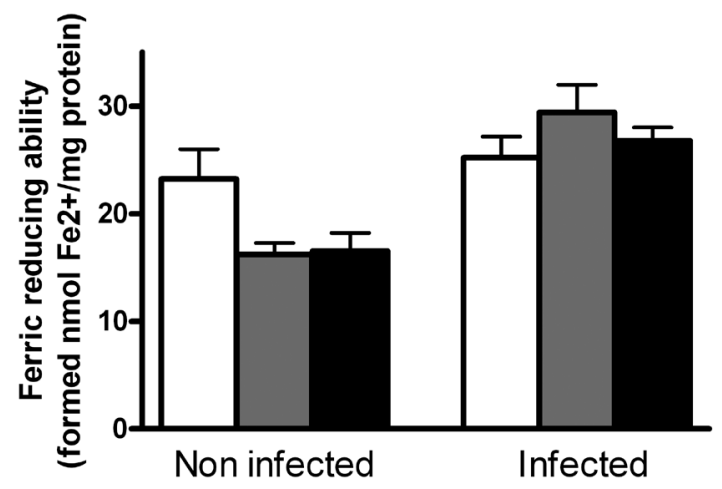

Figure 3. Ferric reducing ability of non-thiols in the ileum mucosa. Ferric reducing ability of non-thiols in the ileum mucosa of non-infected rats $(\mathrm{n}=6$ per diet) and $S$. enteritidis infected rats ( $\mathrm{n}=8$ per diet) fed the control diet (white bars) or the same diet supplemented with BSO (grey bars) or cystine (black bars). All results are expressed as means \pm SE. No significant differences were detected between the control diet group and the BSO or cystine-supplemented group.

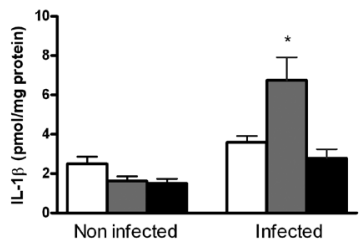

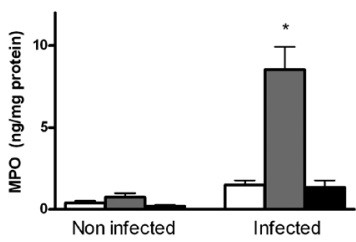

C

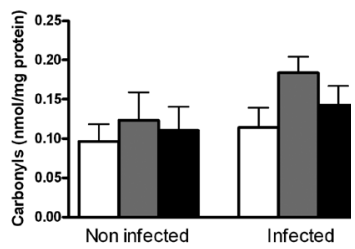

Figure 4. Inflammation and oxidative damage in the ileum mucosa. BSO increased inflammation in the ileum mucosa of $S$. enteritidis infected rats. S. enteritidis infected ( $\mathrm{n}=8$ per diet) and non-infected ( $n=6$ per diet) rats were fed the control diet (white bars) or the same diet supplemented with BSO (grey bars) or cystine (black bars). Mucosal levels of the pro-inflammatory cytokine interleukin-1 $\beta$ (IL-1 $\beta$ ) and myeloperoxidase (MPO) are shown in panels $A$ and B, respectively. Recovery experiments with purified IL- $1 \beta$ and MPO, added to the mucosal samples, were included in each assay and confirmed the absence of inhibiting factors in the ileal samples. Oxidative damage to ileal proteins was determined by measurement of protein carbonyls (C). All results are expressed as means \pm SE. An asterisk indicates a significant difference from the control diet group (either non-infected or infected rats; $\mathrm{p}<0.05)$.

\section{Intestinal permeability}

In general, the Salmonella infection increased paracellular intestinal permeability with time (Figure 5). Despite increased mucosal inflammation in BSO treated animals, intestinal permeability was not aggravated. In contrast, the results suggest a decrease in comparison with the control group (Figure 5). Moreover, cystine partially restored infection-induced intestinal permeability to basal (pre-infection) levels, suggesting a beneficial effect of cystine on gut 


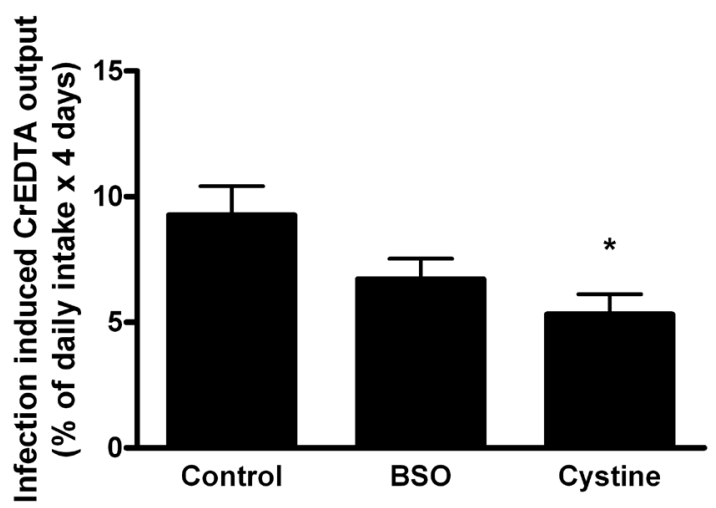

Figure 5. Infection-induced urinary excretion of dietary CrEDTA. Infection-induced urinary excretion of dietary CrEDTA after oral $S$. enteritidis infection ( $\mathrm{n}=8$ per diet) in rats fed the control diet or the same diet supplemented with BSO or cystine. Results, expressed as means \pm SE, were corrected for baseline (pre infection) permeability. Baseline CrEDTA output was identical in all groups. The asterisk indicates a significant difference from the control group $(\mathrm{p}<0.05)$.

barrier function. Neither BSO nor cystine supplementation affected intestinal permeability in non-infected rats (data not shown).

\section{Nitric oxide response is not affected by the cystine diet}

Since diet composition can affect the inducible nitric oxide (NO) production capacity in response to microbial stimuli, the effect of dietary cystine was investigated in an LPS experiment. Urinary $\mathrm{NO}_{\mathrm{x}}$ (sum of nitrate and nitrite) excretion in response to intraperitoneally administered lipopolysaccharide (LPS) was identical in the control and cystine group (data not shown), demonstrating equal host capacity to produce NO.

\section{DISCUSSION}

The present study shows that depletion of glutathione during Salmonella infection results in increased mucosal inflammation. However, as Salmonella translocation was not affected by BSO treatment, glutathione depletion obviously does not affect mucosal barrier function. Also, urinary excretion of the paracellular permeability marker chromium ethylenediamine-tetraacetic acid (CrEDTA) was not increased in comparison with infected rats fed the control diet. On the other hand, cystine supplementation resulted in improved barrier function and decreased Salmonella counts in extra-intestinal organs. However, the subsequent ileal inflammation was not reduced. Since cystine did not significantly increase glutathione and inflammation was not reduced the results suggest that the protective mechanism of cystine supplementation is not related to mucosal glutathione levels. Most likely other host defences than glutathione are strengthened by cystine. 
In line with other studies, oral administration of BSO, a selective inhibitor of glutathione synthesis, decreased hepatic glutathione levels $(41,42)$. Nearly complete depletion was observed in ileal mucosa of both infected and non-infected animals. A decrease of intestinal glutathione is shown during necrotising enterocolitis in rats (15) and in mouse ileal loops exposed to Salmonella typhimurium (16). This decrease is suggested to contribute to pathogenesis of disease and subsequent failure of barrier integrity $(15,16)$. Our results now show that depletion of glutathione does not necessarily lead to impaired intestinal barrier function. A study with mice indicated that glutathione-depletion by BSO caused mucosal damage in the jejunum and colon (43). However, a much higher dose of BSO was applied, increasing the risk of pharmacological side-effects of BSO in that study. The lower dose used in our study, nearly depleted intestinal mucosal glutathione but hardly affected body weight gain and did not result in histological mucosal damage in haematoxylin- and eosin-stained ileum sections (data not shown).

The oral Salmonella infection in our experiment had no or little effect on liver and ileal mucosal glutathione at 4 days post infection, indicating that the organ-specific capacity to synthesise glutathione was adequate or that infectioninduced oxidative stress was absent in normally fed rats (diet adequate in antioxidants). In previous studies we (unpublished results) and others (15) detected a temporarily decrease of intestinal glutathione after an intestinal insult. So, intestinal glutathione levels may differ depending on the time point studied, which may result in seemingly contrasting results. For example, in our in-vivo study, glutathione was determined at 4 days after infection and levels were not (or no longer) decreased. However, a reduction in glutathione was reported in an ileal loop study at $18 \mathrm{hrs}$ after Salmonella introduction (16). Furthermore, studies limited to specific cell types, for example enterocytes isolated from infected animals (16), may show different results from in vivo studies investigating complete mucosa. Specifically, during infection $\mathrm{T}$ lymphocytes and macrophages migrate into the intestinal mucosa and these cells are also able to synthesise glutathione and thus contribute to mucosal glutathione $(23,44)$. In our study, oxidative damage in the form of intestinal protein carbonyls or TBARS was not detected when intestinal glutathione was depleted (BSO treated rats). Oxidative damage induced by glutathione depletion has been shown in plasma lipids (45) and liver (DNA adducts) (41), however those studies did not investigate the intestine.

Supplementation of cystine maintained intestinal glutathione levels similar to the control diet group. Surprisingly, inflammation was not reduced despite a decrease in intestinal permeability and significant inhibition of Salmonella translocation. Improvement of gut barrier function has also been described for intraperitoneally administered $\mathrm{N}$-acetylcysteine in partially hepatectomised rats (46). The reduced viable Salmonella counts in liver and spleen of the cystine-fed rats in our study may have resulted from decreased Salmonella translocation from the gut or from enhanced killing of translocated pathogens by the innate immune system, e.g. by increased production of nitric oxide (NO) $(47,48)$. N-acetylcysteine can 
enhance this NO defence (49), but the effect of cystine was unknown. Our LPS experiment revealed that rats fed the control and cystine diet responded identically to an intraperitoneal LPS challenge, excluding differences in the NO-based capacity of the host to kill bacterial invaders. Therefore, the lower Salmonella counts in liver and spleen observed here probably reflect reduced translocation of this pathogen from the gut lumen.

Surprisingly, infection-induced intestinal permeability of BSO-treated animals seemed lower than that of the control group (Figure 5) but the effect was not significant. One could hypothesize that competitive inhibition of gamma-GCS may cause accumulation of cysteine in the mucosa, resulting in protective effects as seen on the cystine diet. However, mucosal cysteine levels were decreased in BSO treated animals. Furthermore, in contrast to the cystine fed rats, no protective effect against Salmonella translocation was observed in these animals.

The mucosal barrier enhancing effect of cystine requires further investigation. Results need to be reproduced and the mechanism behind the protective effect should be explored. Cysteine can play a role in various host defences. For instance, trefoil peptides, which stabilise mucosal glycoproteins and protect the mucosa from various insults, e g bacterial toxins (50), contain several cysteine-rich domains $(50,51)$. In addition, defensins, which are antimicrobial peptides secreted by human and rodent ileal Paneth cells, contain 6 conserved cysteines (52) and are important for intestinal resistance to Salmonella infection (53). Although, cysteine is not an essential amino acid and can be synthesised from methionine, it might be conditionally essential like suggested for glutamine $(54,55)$.

In conclusion, intestinal depletion of glutathione is not as detrimental for maintenance of the gut barrier as often presumed. Neither paracellular intestinal permeability nor Salmonella translocation were promoted at very low mucosal glutathione levels, despite increased infection-induced ileal inflammation. On the other hand, dietary cystine did not reduce infection-associated inflammation but decreased intestinal permeability and Salmonella translocation to extra-intestinal organs by a mechanism unlikely related to glutathione. Follow-up studies are needed to elucidate the molecular mechanism(s) underlying the protective effect of cystine supplementation on gut barrier function and to address human relevance.

\section{ACKNOWLEDGEMENTS}

The authors would like to thank the biotechnicians at the Small Animal Centre of Wageningen University (Wageningen, The Netherlands) for excellent assistance. We also thank our colleagues of the department of Health and Safety at NIZO food research and Professor Aalt Bast (Maastricht University, The Netherlands) for fruitful discussions. 


\section{REFERENCES}

1. Finlay, B. B.Brumell, J. H. 2000. Salmonella interactions with host cells: in vitro to in vivo. Philos Trans R Soc Lond B Biol Sci 355: 623-631.

2. Jung, H. C., Eckmann, L., Yang, S. K., Panja, A., Fierer, J., Morzycka-Wroblewska, E.Kagnoff, M. F. 1995. A distinct array of proinflammatory cytokines is expressed in human colon epithelial cells in response to bacterial invasion. J Clin Invest 95: 55-65.

3. Eckmann, L., Kagnoff, M. F.Fierer, J. 1993. Epithelial cells secrete the chemokine interleukin-8 in response to bacterial entry. Infect Immun 61: 4569-4574.

4. Segal, A. W. 2005. How neutrophils kill microbes. Annu Rev Immunol 23: 197 223.

5. Klebanoff, S. J. 1999. Myeloperoxidase. Proc Assoc Am Physicians 111: 383-389.

6. Meister, A. 1988. Glutathione metabolism and its selective modification. J Biol Chem 263: 17205-17208.

7. Kruidenier, L., Kuiper, I., Lamers, C. B.Verspaget, $H$. W. 2003. Intestinal oxidative damage in inflammatory bowel disease: semi-quantification, localization, and association with mucosal antioxidants. J Pathol 201: 28-36.

8. Malle, E., Furtmuller, P. G., Sattler, W.Obinger, C. 2007. Myeloperoxidase: a target for new drug development? Br J Pharmacol 152: 838-854.

\section{Kosower, N. S.Kosower,} E. M. 1978. The glutathione status of cells. Int Rev Cytol 54: 109-160.

10. Meister, A. 1984. New aspects of glutathione biochemistry and transport--selective alteration of glutathione metabolism. Nutr Rev 42: 397-410.

11. Meister, A. 1988. On the discovery of glutathione. Trends Biochem Sci 13: 185188.

12. Kelly, F. J. 1993. Glutathione content of the small intestine: regulation and function. Br J Nutr 69: 589-596.

\section{Lash, L. H., Hagen, T.} M.Jones, D. P. 1986. Exogenous glutathione protects intestinal epithelial cells from oxidative injury. Proc Natl Acad Sci U S A 83: 4641-4645.

14. Rao, R. K., Li, L., Baker, R. D., Baker, S. S.Gupta, A.
2000. Glutathione oxidation and PTPase inhibition by hydrogen peroxide in Caco-2 cell monolayer. Am J Physiol Gastrointest Liver Physiol 279: G332-340.

15. Kelly, N., Friend, K., Boyle, P., Zhang, X. R., Wong, C., Hackam, D. J., Zamora, R. et al. 2004. The role of the glutathione antioxidant system in gut barrier failure in a rodent model of experimental necrotizing enterocolitis. Surgery 136: 557-566.

16. Mehta, A., Singh, S.Ganguly, N. K. 1998. Impairment of intestinal mucosal antioxidant defense system during Salmonella typhimurium infection. Dig Dis Sci 43: 646-651.

17. Lievin-Le Moal, V.Servin, A. L. 2006. The front line of enteric host defense against unwelcome intrusion of harmful microorganisms: mucins, antimicrobial peptides, and microbiota. Clin Microbiol Rev 19: 315-337.

18. Dommett, R., Zilbauer, M., George, J. T.Bajajelliott, M. 2005. Innate immune defence in the human gastrointestinal tract. Molecular Immunology 42: 903-912.

19. Mowat, A. M. 2003. Anatomical basis of tolerance 
and immunity to intestinal antigens. Nat Rev Immunol 3: 331-341.

20. Muller, C. A., Autenrieth, I. B.Peschel, A. 2005. Innate defenses of the intestinal epithelial barrier. Cell Mol Life Sci 62: 1297-1307.

21. Griffith, O. W.Meister, A. 1979. Potent and specific inhibition of glutathione synthesis by buthionine sulfoximine (S-n-butyl homocysteine sulfoximine). J Biol Chem 254: 7558-7560.

22. Watanabe, T., Sagisaka, H., Arakawa, S., Shibaya, Y., Watanabe, M., Igarashi, I., Tanaka, K. et al. 2003. A novel model of continuous depletion of glutathione in mice treated with L-buthionine (S,R)-sulfoximine. J Toxicol Sci 28: 455-469.

23. Meister, A. 1998. The Liver biology and pathobiology: Glutathione, Second edition ed. Raven Press, Ltd., New York.

24. Meister, A. 1991. Glutathione deficiency produced by inhibition of its synthesis, and its reversal; applications in research and therapy. Pharmacol Ther 51: 155-194.

\section{Assimakopoulos, S. F.,} Maroulis, I., Patsoukis, N., Vagenas, K., Scopa, C. D.,
Georgiou, C. D.Vagianos, C. E. 2007. Effect of antioxidant treatments on the gut-liver axis oxidative status and function in bile duct-ligated rats. World J Surg 31: 2023-2032.

26. Reeves, P. G., Nielsen, F. H.Fahey, G. C., Jr. 1993. AIN93 purified diets for laboratory rodents: final report of the American Institute of Nutrition ad hoc writing committee on the reformulation of the AIN-76A rodent diet. J Nutr 123: 1939-1951.

27. Bjarnason, I., Maxton, D., Reynolds, A. P., Catt, S., Peters, T. J.Menzies, I. S. 1994. Comparison of four markers of intestinal permeability in control subjects and patients with coeliac disease. Scand J Gastroenterol 29: 630-639.

28. Oman, H., Blomquist, L., Henriksson, A. E.Johansson, S. G. 1995. Comparison of polysucrose $15000,51 \mathrm{Cr}$ labelled ethylenediaminetetraacetic acid, and 14C-mannitol as markers of intestinal permeability in man. Scand J Gastroenterol 30: 1172-1177.

\section{Binnerts, W. T., van 't} Klooster, A. T.Frens, A. M. 1968. Soluble chromium indicator measured by atomic absorbtion in digestion experiments. The veterinaty record 82: 470 .
30. Ten Bruggencate, S. J., Bovee-Oudenhoven, I. M., Lettink-Wissink, M. L.Van der Meer, R. 2005. Dietary fructooligosaccharides increase intestinal permeability in rats. J Nutr 135: 837-842.

\section{Ten Bruggencate, S. J.,} Bovee-Oudenhoven, I. M., Lettink-Wissink, M. L., Katan, M. B.van der Meer, R. 2006. Dietary fructooligosaccharides affect intestinal barrier function in healthy men. J Nutr 136: 70-74.

\section{Bovee-Oudenhoven, I.} M., ten Bruggencate, S. J., Lettink-Wissink, M. L. van der Meer, R. 2003. Dietary fructo-oligosaccharides and lactulose inhibit intestinal colonization but stimulate translocation of salmonella in rats. Gut 52: 1572-1578.

\section{Oudenhoven, I. M., Klaa-} sen, H. L., Lapre, J. A., Weerkamp, A. H.Van der Meer, R. 1994. Nitric oxide-derived urinary nitrate as a marker of intestinal bacterial translocation in rats. Gastroenterology 107: 47-53.

\section{Bovee-Oudenhoven, I.} M., Wissink, M. L., Wouters, J. T.Van der Meer, R. 1999. Dietary calcium phosphate stimulates intestinal lactobacilli and decreases the severity of a salmonella infection in rats. J Nutr 129: 607-612. 
35. Sesink, A. L., Termont, D. S., Kleibeuker, J. H.Van der Meer, R. 1999. Red meat and colon cancer: the cytotoxic and hyperproliferative effects of dietary heme. Cancer Res 59: 5704-5709.

36. Mansoor, M. A., Svardal, A. M.Ueland, P. M. 1992. Determination of the in vivo redox status of cysteine, cysteinylglycine, homocysteine, and glutathione in human plasma. Anal Biochem 200: 218-229.

37. Benzie, I. F.Strain, J. J. 1996. The ferric reducing ability of plasma (FRAP) as a measure of "antioxidant power": the FRAP assay. Anal Biochem 239: 70-76.

\section{Ohkawa, H., Ohishi,} N.Yagi, K. 1979. Assay for lipid peroxides in animal tissues by thiobarbituric acid reaction. Anal Biochem 95: 351-358.

39. Buss, H., Chan, T. P., Sluis, K. B., Domigan, N. M.Winterbourn, C. C. 1997. Protein carbonyl measurement by a sensitive ELISA method. Free Radic Biol Med 23: 361-366.

40. Ten Bruggencate, S. J., Bovee-Oudenhoven, I. M., Lettink-Wissink, M. L., Katan, M. B.Van Der Meer, R.
2004. Dietary fructo-oligosaccharides and inulin decrease resistance of rats to salmonella: protective role of calcium. Gut 53: 530-535.

\section{Chung, F. L., Komni-} nou, D., Zhang, L., Nath, R., Pan, J., Amin, S.Richie, J. 2005. Glutathione depletion enhances the formation of endogenous cyclic DNA adducts derived from t-4-hydroxy2 -nonenal in rat liver. Chem Res Toxicol 18: 24-27.

42. Kiyosawa, N., Ito, K., Sakuma, K., Niino, N., Kanbori, M., Yamoto, T., Manabe, S. et al. 2004. Evaluation of glutathione deficiency in rat livers by microarray analysis. Biochem Pharmacol 68: 14651475.

\section{Martensson, J., Jain,} A.Meister, A. 1990. Glutathione is required for intestinal function. Proc Natl Acad Sci U S A 87: 1715-1719.

44. Sido, B., Lasitschka, F., Giese, T., Gassler, N., Funke, B., Schroder-Braunstein, J., Brunnemer, U. et al. 2008. A prominent role for mucosal cystine/cysteine metabolism in intestinal immunoregulation. Gastroenterology 134: 179-191.

45. Rajasekaran, N. S., Sathyanarayanan, S., Devaraj, N.
S.Devaraj, H. 2005. Chronic depletion of glutathione (GSH) and minimal modification of LDL in vivo: its prevention by glutathione mono ester (GME) therapy. Biochim Biophys Acta 1741: 103-112.

46. Okay, E., Karadenizli, A., Muezzinoglu, B., Zeybek, U., Arzu Ergen, H.Isbir, T. 2005. $\mathrm{N}$-acetylcysteine attenuates bacterial translocation after partial hepatectomy in rats. J Surg Res 127: 164-170.

47. Cerquetti, M. C., Goren, N. B., Ropolo, A. J., Grasso, D., Giacomodonato, $M$. N.Vaccaro, M. I. 2002. Nitric oxide and apoptosis induced in Peyer's patches by attenuated strains of Salmonella enterica serovar Enteritidis. Infect Immun 70: 964-969.

48. Iovine, N. M., Pursnani, S., Voldman, A., Wasserman, G., Blaser, M. J.Weinrauch, Y. 2008. Reactive nitrogen species contribute to innate host defense against Campylobacter jejuni. Infect Immun 76: 986-993.

49. Bergamini, S., Rota, C., Canali, R., Staffieri, M., Daneri, F., Bini, A., Giovannini, F. et al. 2001. N-acetylcysteine inhibits in vivo nitric oxide production by inducible nitric oxide synthase. Nitric Oxide 5: 349-360. 
50. Kindon, H., Pothoulakis, C., Thim, L., Lynch-Devaney, K.Podolsky, D. K. 1995.

Trefoil peptide protection of intestinal epithelial barrier function: cooperative interaction with mucin glycoprotein. Gastroenterology 109: 516-523.

51. Sands, B. E.Podolsky, D. K. 1996. The trefoil peptide family. Annu Rev Physiol 58: 253-273.

52. Cunliffe, R. N.Mahida, Y. R. 2004. Expression and regulation of antimicrobial peptides in the gastrointestinal tract. J Leukoc Biol 75: 49-58.

53. Salzman, N. H., Ghosh, D., Huttner, K. M., Paterson, Y.Bevins, C. L. 2003. Protection against enteric salmonellosis in transgenic mice expressing a human intestinal defensin. Nature 422: 522526.

54. Ziegler, T. R., Evans, M. E., Fernandez-Estivariz, C.Jones, D. P. 2003. Trophic and cytoprotective nutrition for intestinal adaptation, mucosal repair, and barrier function. Annu Rev Nutr 23: 229-261.

55. Furst, P. 1998. Old and new substrates in clinical nutrition. J Nutr 128: 789-796. 



\section{CHAPTER 6}

\section{DAMAGE TO THE INTESTINAL EPITHELIAL BARRIER BY ANTIBIOTIC PRETREATMENT OF SALMONELLA-INFECTED RATS IS LESSENED BY DIETARY CALCIUM OR TANNIC ACID}

Marleen T.J. van Ampting ${ }^{1,2}$, Arjan J. Schonewille ${ }^{1,2}$, Carolien Vink ${ }^{1,2}$, Robert Jan M. Brummer ${ }^{1,3}$, Roelof van der Meer ${ }^{1,2,4}$, Ingeborg M.J. Bovee-Oudenhoven ${ }^{1,2}$

${ }^{1}$ TI Food and Nutrition, Wageningen, the Netherlands

${ }^{2}$ Department of Health, NIZO food research, Ede, the Netherlands

${ }^{3}$ Present address: School of Health and Medical Sciences, Örebro University, Örebro, Sweden

${ }^{4}$ Present address: Department of Human Nutrition, Wageningen University, Wageningen, the Netherlands

J. Nut. 2010, in press. 
ABSTRACT

Perturbation of the intestinal microbiota by antibiotics predisposes the host to foodborne pathogens like Salmonella. Effects of antibiotic treatment on intestinal permeability during infection and the efficacy of dietary components to improve resistance to infection have not been studied. Therefore, we investigated the effect of clindamycin on intestinal barrier function in Salmonella-infected rats. We also studied the ability of dietary calcium and tannic acid to protect against infection and concomitant diarrhea and we assessed intestinal barrier function. Rats were fed a purified control diet including the permeability marker CrEDTA $(2 \mathrm{~g} / \mathrm{kg})$, or the same diet supplemented with calcium $(4.8 \mathrm{~g} / \mathrm{kg})$ or tannic acid $(3.75 \mathrm{~g} / \mathrm{kg})$. After adaptation, rats were orally treated with clindamycin for $4 \mathrm{~d}$, followed by oral infection with Salmonella enteritidis. Two additional control groups were not treated with antibiotics and received either saline or Salmonella. Urine and feces were collected to quantify intestinal permeability, diarrhea, cytotoxicity of fecal water, and Salmonella excretion. In addition, Salmonella translocation was determined. Diarrhea, CrEDTA excretion, and cytotoxicity of fecal water were higher in the clindamycin-treated infected rats compared with the non-clindamycin treated infected control group. Intestinal barrier function was less in Salmonella-infected rats pretreated with antibiotics compared with non-clindamycin treated rats. Both calcium and tannic acid reduced infection-associated diarrhea and inhibited the adverse intestinal permeability changes, but did not decrease Salmonella colonization and translocation. Our results indicate that calcium protects against intestinal changes due to Salmonella infection by reducing luminal cytotoxicity whereas tannic acid offers protection by improving the mucosal resistance. 


\section{INTRODUCTION}

The use of antibiotics is ubiquitous in our present society. The use of broad-spectrum antibiotics like clindamycin disturbs the indigenous microbiota in the intestine. This perturbation of the intestinal microbiota predisposes the host to enteric pathogens such as Salmonella (1). Eradication or suppression of parts of the indigenous microbiota can decrease the colonization resistance of the host (2). For example, competition for mucosal adhesion sites (3) and growth substrates (4) can decrease and thus facilitate intestinal colonization of bacterial pathogens. Invasive species, like certain types of Salmonella, are able to translocate from the intestinal lumen to extra-intestinal organs $(5,6)$, a phenomenon which is often accompanied by increased mucosal paracellular permeability and diarrhea (7). The magnitude of these latter events not only depends on the amount of pathogens present, but is also strongly determined by the intestinal defense status of the host (7).

Diet may be a tool to strengthen this intestinal defense or resistance to infection and infectious diarrhea. We have shown earlier that dietary calcium enhances intestinal resistance to infectious disease and protects rats (8-11) and humans (11) against Salmonella and enterotoxigenic Escherichia coli (ETEC) associated disease. The protective effects of calcium are associated with an increase of lactobacilli in the microbiota $(8,10)$. Whether this increase is causally related to the protective effect of calcium is not known yet, but can be studied by using antibiotics that lower indigenous lactobacilli.

A group of dietary compounds with potential to inhibit intestinal infections are the polyphenols. For example, complex (hydrolysable) tannins, which are widespread in some vegetable foods, e.g. grapes, berries and wines produced from them (12), have antimicrobial effects against Gram-negative bacteria (13). The polyphenol tannic acid is a complex hydrolysable tannin. It is composed of six to nine gallic acid molecules esterified with glucose, and is used as a preservative by the food industry $(14,15)$.

In this study we investigated the effect of clindamycin on Salmonella infection, translocation and intestinal permeability using a rat model. Second, we examined whether dietary calcium is still able to protect against intestinal infection when the indigenous microbiota is temporarily crippled. Third, protective effects of tannic acid were investigated in the same model.

\section{METHODS}

\section{Experiment approval and rats}

The animal experiment was approved by the animal welfare committee of Wageningen University (Wageningen, the Netherlands). Specific pathogen-free male Wistar rats (WU, Harlan, Horst, the Netherlands), $8 \mathrm{wk}$ old at the start of the dietary intervention, were housed individually in metabolic cages. The animal room was temperature $\left(20-21^{\circ} \mathrm{C}\right)$ and humidity-controlled (50-60\%) with a 12:12-hour light/dark cycle. 


\section{Diets, clindamycin treatment and infection}

Rats were fed a purified control diet as described previously (7), containing, per $\mathrm{kg}, 200 \mathrm{~g}$ acid casein, $326 \mathrm{~g}$ cornstarch, $174 \mathrm{~g}$ glucose, $160 \mathrm{~g}$ palm oil, $40 \mathrm{~g}$ corn oil, $50 \mathrm{~g}$ cellulose, and vitamin and mineral mix according to AIN-93 (except for calcium) (16). To mimic the composition of a Western human diet the calcium concentration was lowered (to $1.2 \mathrm{~g} / \mathrm{kg}$ ) and the fat concentration increased (to $200 \mathrm{~g} / \mathrm{kg}$ ) in comparison with the AIN-93 recommendations. The control diet was supplemented with either calcium phosphate $\left(\mathrm{CaHPO}_{4} \cdot 2 \mathrm{H}_{2} \mathrm{O}\right)$ or tannic acid (both purchased from Sigma-Aldrich, St. Louis, Missouri, USA), at the expense of glucose. The final concentrations of calcium and tannic acid were 4.8 $\mathrm{g} / \mathrm{kg}$ and $3.75 \mathrm{~g} / \mathrm{kg}$, respectively. In addition, the inert intestinal permeability marker chromium ethylenediamine-tetraacetic acid (CrEDTA) was added to the diets $(2 \mathrm{~g} / \mathrm{kg})$. Preparation, purity control and addition of lyophilized CrEDTA to the diets was performed as described previously (7). Rats consumed food and demineralized drinking water ad libitum. Body weight and food intake were recorded twice a week before clindamycin treatment. Body weight and food intake were measured daily after the clindamycin treatment to record possible day-to-day fluctuation in intake. Three groups were fed the control diet; one of these groups $(n=5)$ served as a non-clindamycin treated, uninfected control (UC, uninfected rats fed the control diet). The second control-diet group $(n=8)$ was not pre-treated with clindamycin and received Salmonella (IC, infected rats fed the control diet). The third control-diet group $(n=8)$ was pre-treated with clindamycin and received Salmonella (AIC, antibiotic-treated infected rats fed the control diet). Two additional groups ( $\mathrm{n}=8$ per diet) that received clindamycin plus Salmonella were fed either the calcium (AICa, antibiotic-treated infected rats fed the calcium diet) or tannic acid (AITa, antibiotic-treated infected rats fed the tannic acid diet) supplemented diet (Table 1).

Rats were acclimatized to housing and dietary conditions for $12 \mathrm{~d}$, after which they received $15 \mathrm{mg} / \mathrm{kg}$ clindamycin or saline, the latter as sham treatment, by oral gavage for four consecutive days depending on treatment group. After a day of rest, the rats were orally infected with $10^{9}$ colony-forming units (CFU) of Salmonella enteritidis (clinical isolate, phage type 4; strain B1214 NIZO

Table 1. Overview of different treatment groups of Wistar rats used in the study.

\begin{tabular}{lccccc}
\hline Group & UC & IC & AIC & AICa & AITa \\
\hline Diet & Control & Control & Control & Calcium & Tannic acid \\
Antibiotic & - & - & + & + & + \\
Infection & - & + & + & + & + \\
n & 5 & 8 & 8 & 8 & 8
\end{tabular}


food research, Ede, the Netherlands) suspended in $1 \mathrm{~mL}$ saline as described elsewhere (10) or received $1 \mathrm{~mL}$ saline only.

\section{Collection of biological samples and bacterial quantification}

On $\mathrm{d} 7$ after oral infection or sham treatment, rats were randomly selected and killed by carbon dioxide inhalation. Blood was obtained by orbital puncture for the preparation of serum. Mesenteric lymph nodes (MLN), spleen and liver were aseptically excised and after homogenization in sterile saline directly used for Salmonella quantification, as described elsewhere (17).

Fresh fecal samples were collected to quantify Salmonella colonization pre- and at various days post-infection, as described elsewhere (10). The numbers of lactobacilli and enterobacteria were determined only in feces collected prior to infection both pre- and post-clindamycin treatment, as described elsewhere (10), with the slight modification that Rogosa plates, to quantify lactobacilli, were incubated at $37{ }^{\circ} \mathrm{C}$ in anaerobic jars (Anoxomat ${ }^{\mathrm{Tm}}$-system, MART Microbiology, Drachten, The Netherlands) for 2 days.

In addition, feces were collected for $24 \mathrm{~h}$ and pooled per rat in the following periods: post-clindamycin but pre-infection, and post-infection $\mathrm{d}$ 4-7. Urine was collected each $24 \mathrm{~h}$ from d 2 before clindamycin treatment until d 7 after oral Salmonella administration. All feces and urine samples were stored at $-20^{\circ} \mathrm{C}$ until further analysis. Oxytetracycline (Sigma-Aldrich) was added to the urine collection vessels of the metabolic cages to prevent bacterial deterioration. Salmonella translocation was quantified by measuring urinary $\mathrm{NO}_{\mathrm{x}}$ (sum of nitrate and nitrite) excretion by using a colorimetric enzymatic kit (Roche Diagnostics, Basel, Switzerland), as described and validated earlier $(17,18)$. The area under the curve (AUC) for infection-induced urinary $\mathrm{NO}_{\mathrm{x}}$ excretion was calculated and corrected for baseline (pre-infection) levels.

\section{Quantification of diarrhea and cytotoxicity of fecal water}

Total $24 \mathrm{~h}$ feces were lyophilized in a manifold freeze-dryer (FD5515; Ilshin Laboratory Co Ltd). Fecal water was prepared as described previously and osmolarity was measured (Osmomat 030-D, Gonotec, Berlin, Germany) to calculate the percentage wet weight (19). Direct determination of relative fecal wet weight by lyophilization was considered inappropriate because it underestimates the true water content of feces due to evaporation of water from the fecal pellets in the collection vessels of the metabolic cages of the rats.

Cytotoxicity of fecal water was determined by using an erythrocyte assay as described previously (20). Results were calculated as described (20) and are expressed as AUC of \% lysis from a $40 \mu \mathrm{L}$ and $80 \mu \mathrm{L}$ sample of each fecal water.

\section{CrEDTA excretion in urine}

CrEDTA excreted in $24 \mathrm{~h}$ urine samples was determined by inductively coupled plasma atomic emission spectroscopy (Varian, Mulgrave, Australia), as described 
previously (7). The output was expressed as percentage of dietary intake to correct for day-to-day and inter-individual variability in intake of this marker.

\section{Serum immunoglobulin M (IgM) to Salmonella and core endotoxin}

Detection of IgM instead of IgG was preferred because sera were obtained at $\mathrm{d} 7$ post infection. In general, full development of a serum IgG response takes almost $2 \mathrm{wk}$, whereas IgM already peaks at earlier time points, as these are the earliest antibodies in the humoral immune response (21). The determination of serum IgM to core endotoxin, present in most Gram-negative microorganisms, was performed using the EndoCab ELISA kit (Hycult biotechnology b.v., Uden, The Netherlands) according to the manufacturer's protocol. The IgM tracer was replaced by 1:1000 diluted horseradish peroxidase (HRP) conjugated mouse anti-rat IgM (Invitrogen, Carlsbad, USA).

To investigate serum IgM specific to Salmonella a maxisorp 96 well plate (Nunc, Roskilde, Denmark) was coated with $135 \mu \mathrm{L}$ of a heat-killed S. enteriditis suspension. This suspension originally contained $10^{10} \mathrm{CFU} / \mathrm{L}$ S. enteritidis, iden-

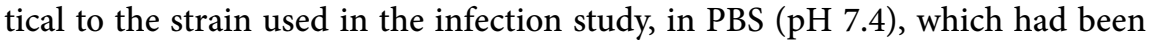
incubated at $60^{\circ} \mathrm{C}$ for $90 \mathrm{~min}$. After incubating the plates for $20 \mathrm{~h}$ at $4^{\circ} \mathrm{C}$ the wells were blocked with $4 \%$ Protifar plus (Nutricia, Cuijk, The Netherlands) in PBS for $1 \mathrm{~h}$. Plates were incubated with $100 \mu \mathrm{L}$ of diluted serum for $2 \mathrm{~h}$ and with $100 \mu \mathrm{L}$ HRP-Mouse Anti-Rat IgM (Invitrogen, Carlsbad, USA) for $1.5 \mathrm{~h}$ at room temperature. Between all incubations the plates were washed thoroughly with PBS$0.05 \%$ Tween-20. Finally, $100 \mu \mathrm{L}$ of a reaction mixture containing hydrogen peroxide and $o$-phenylenediamine was added. The reaction was discontinued after $20 \mathrm{~min}$ by adding $100 \mu \mathrm{L} 1 \mathrm{~mol} / \mathrm{L} \mathrm{H}_{2} \mathrm{SO}_{4}$ and the absorbance was read at $490 \mathrm{~nm}$ on an automated ELISA plate reader (Dynatech MR7000; Trade Tek, Rotterdam, The Netherlands). Negative controls showed that the HRP-Mouse Anti-Rat IgM did not bind to wells coated with the blocking-solution only.

\section{Statistical analysis}

All data are expressed as means \pm SEM and statistics were performed using Graphpad Prism 5 software (GraphPad Software, Inc. La Jolla, CA, USA). Our aim was to investigate 1) the effect of clindamycin on infection 2) the dietary effects in clindamycin pre-treated infected rats. Therefore, the pre-defined comparisons of interest were: UC and IC versus AIC, and AICa and AITa versus AIC. In addition, the effect of clindamycin on the fecal microbiota in rats on the different diets was investigated prior to infection.

Data were tested for normality by Kolmogorov-Smirnov and ShapiroWilk tests. If normally distributed, differences were tested for significance using one-way ANOVA, and when needed followed by Dunett's test for comparisons to the AIC group. Data with unequal variances were tested by using the KruskalWallis test, and when appropriate, followed by Dunn's post hoc test for comparisons to the AIC group. Within group comparison of the microbiota data before 
and after clindamycin treatment was tested by a paired t-test or Wilcoxon matched paired test for data with equal and unequal variances, respectively. Salmonella output in feces was determined at multiple time points and therefore these data were analyzed by repeated-measures two-way ANOVA (mixedmodel) followed by Bonferroni post testing for comparisons to the AIC group. Differences were considered statistically significant when $P<0.05$.

\section{RESULTS}

\section{Growth and food intake}

At the start of the study, body weight of the rats was $279 \pm 1.3 \mathrm{~g}$. Food intake prior to clindamycin treatment was $20 \pm 0.3 \mathrm{~g} / \mathrm{d}$ in all groups (data not shown). Daily food intake post-infection or sham treatment was higher in the IC and UC groups $(17 \pm 0.3 \mathrm{~g} / \mathrm{d})$ than in the AIC group $(14 \pm 0.3 \mathrm{~g} / \mathrm{d} ; P<0.05)$. Daily food intake did not differ from the AIC group in the AICa, and AITa groups (data not shown).

Prior to infection, body weight gain was $4 \pm 0.1 \mathrm{~g} / \mathrm{d}$ in all groups. Postinfection, body weight gain in all clindamycin-treated groups was $1 \pm 0.3 \mathrm{~g} / \mathrm{d}$ whereas non-clindamycin-treated rats gained more weight $(3 \pm 0.2 \mathrm{~g} / \mathrm{d} ; P<0.05)$. Body weight gain did not differ from the AIC group in either the AICa or the AITa group (data not shown).

\section{Lactobacilli and enterobacteria in feces.}

The effects of clindamycin and the diets on the intestinal microbiota were determined prior to infection. In line with our earlier studies (10), fecal lactobacilli

Table 2. Effect of dietary calcium, tannic acid and clindamycin on viable lactobacilli and enterobacteria in the indigenous microbiota of rats before and after clindamycin treatment and prior to infection ${ }^{1}$

\begin{tabular}{llclll}
\hline \hline & \multicolumn{2}{c}{ Before } & & \multicolumn{2}{c}{ After } \\
\cline { 2 - 3 } \cline { 5 - 6 } Group & Lactobacilli & Enterobacteria & & Lactobacilli & Enterobacteria \\
& & & \multicolumn{2}{c}{$\log$ CFU/g feces } & \\
\hline AIC & $7.40 \pm 0.13$ & $8.58 \pm 0.28$ & & $4.28 \pm 0.47^{\#}$ & $9.15 \pm 0.05$ \\
AICa & $8.05 \pm 0.09^{*}$ & $6.82 \pm 0.15^{*}$ & & $5.51 \pm 0.28^{* \#}$ & $9.12 \pm 0.16^{\#}$ \\
AITa & $7.79 \pm 0.16$ & $7.67 \pm 0.27^{*}$ & & $4.63 \pm 0.28^{\#}$ & $9.38 \pm 0.15^{\#}$ \\
\hline \hline
\end{tabular}

${ }^{1}$ Values are means \pm SEM, $\mathrm{n}=8$.

$*$ Different from AIC, $P<0.05$.

${ }^{\#}$ Different from the before-clindamycin period, $P<0.05$. 
were higher and enterobacteria were lower in the AICa group than in the AIC group (Table $2 ; P<0.05$ ). The enterobacteria were also lower in the AITa group than in the AIC group prior to clindamycin treatment (Table $2 ; P<0.05$ ).

Clindamycin drastically reduced the number of lactobacilli in all groups (Table 2; $P<0.05$ ) whereas enterobacteria increased in AICa and AITa groups compared with pre-clindamycin levels, resulting in levels that were identical to the AIC group. This showed that dietary effects on the gut microbiota were abolished after clindamycin treatment, except for slightly more lactobacilli in the AICa group compared with the AIC group (Table 2; $P<0.05$ ).

\section{Salmonella colonization}

Clindamycin treatment clearly decreased colonization resistance of the intestine, as fecal Salmonella excretion was 100-fold higher in the AIC group than in the IC group (Fig $1 ; P<0.05$ ). Fecal Salmonella excretion was higher in the AIC compared to the IC group at each day after infection. Colonization levels were not lower in the AICa and AITa groups compared with the AIC group. At d 3 the AITa group was higher than the AIC group (Fig $1 ; P<0.05$ ).

\section{Salmonella translocation}

Salmonella translocation to MLN, liver and spleen was lower in the IC group than in the AIC group (Table $3 ; P<0.05$ ) and neither the AICa group nor the AITa group was different from the AIC group. Results of Salmonella culture of extra-intestinal organs were confirmed by analysis of urinary $\mathrm{NO}_{\mathrm{x}}$ excretion.

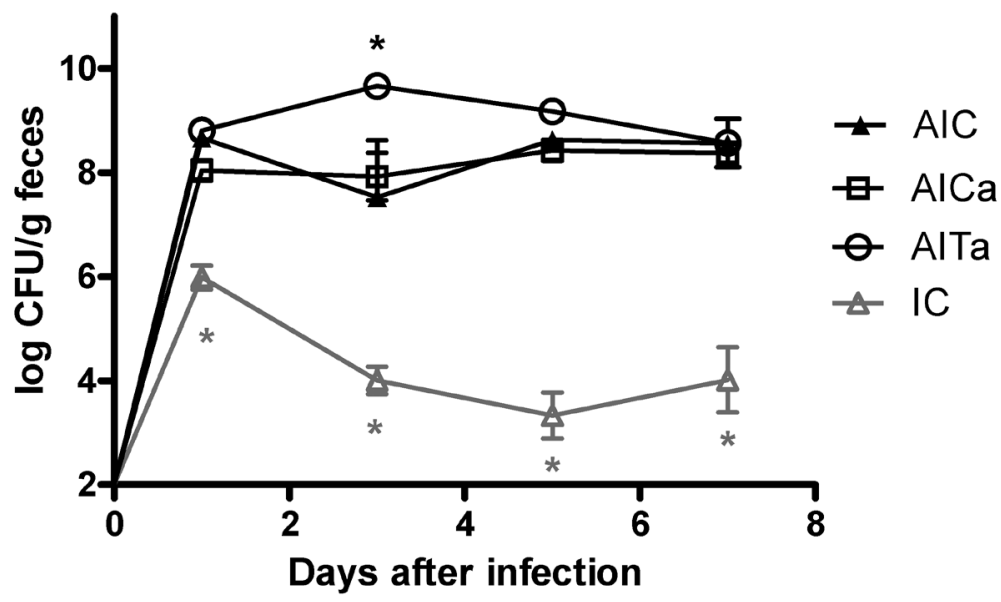

Figure 1. Fecal S. enteritidis excretion in orally infected rats pre-treated with clindamycin. Values are means $\pm S E M, n=8$. All error bars are shown, however, some error bars are smaller than figure symbols and therefore not visible. ${ }^{*}$ Different from AIC, $\mathrm{P}<0.05$. 
Table 3. Effect of dietary calcium, tannic acid or antibiotic on infection-induced urinary $\mathrm{NO}_{\mathrm{x}}$ excretion and viable Salmonella counts in extra-intestinal organs in rats ${ }^{1}$

\begin{tabular}{|c|c|c|c|c|}
\hline \multirow[b]{3}{*}{ Group } & \multicolumn{3}{|c|}{ Salmonella } & \multirow{2}{*}{$\begin{array}{r}\text { Urinary } \mathbf{N O x} \\
A U C^{3}\end{array}$} \\
\hline & MLN & Spleen & Liver & \\
\hline & & $\log C F U / g$ tissue & & $\mu \mathrm{mol}^{*} 7 \mathrm{~d}$ \\
\hline$\overline{\mathbf{U C}}$ & $\mathrm{nd}^{2}$ & nd & nd & $0 \pm 2 *$ \\
\hline IC & $4.66 \pm 0.11 *$ & $3.20 \pm 0.10$ & $2.13 \pm 0.12 *$ & $61 \pm 11^{*}$ \\
\hline AIC & $5.01 \pm 0.09$ & $3.28 \pm 0.14$ & $3.23 \pm 0.19$ & $350 \pm 36$ \\
\hline AICa & $5.05 \pm 0.13$ & $3.37 \pm 0.13$ & $2.85 \pm 0.15$ & $300 \pm 34$ \\
\hline AITa & $4.97 \pm 0.11$ & $3.39 \pm 0.11$ & $3.00 \pm 0.16$ & $295 \pm 35$ \\
\hline
\end{tabular}

\footnotetext{
${ }^{1}$ Values are means \pm SEM, $\mathrm{n}=8$ except $\mathrm{UC} \mathrm{n}=5$.

*Different from AIC, $P<0.05$.

${ }^{2}$ Not determined.

${ }^{3}$ Data were corrected for baseline values.
}

The AUC for infection induced urinary $\mathrm{NO}_{\mathrm{x}}$ was higher in the AIC group than in the UC and IC groups (Table 3; $P<0.05$ ). The levels in the AICa and AITa groups did not differ from the AIC group. Urinary $\mathrm{NO}_{\mathrm{x}}$ did not differ among the 5 groups before or after clindamycin treatment (data not shown), indicating that neither the diets nor a drastic change in the microbiota by clindamycin treatment affected $\mathrm{NO}_{\mathrm{x}}$ excretion.

\section{Diarrhea}

Fecal relative wet weight was determined to quantify possible treatment effects on diarrhea. Clindamycin did not significantly affect fecal wet weight in the period prior to infection (data not shown). In contrast, fecal wet weight was greater in the AIC group than the IC group (Table 4; $P<0.05$ ). Infectioninduced diarrhea was less in the AICa and AITa groups than the AIC group (Table 4). This indicated that despite similar Salmonella-colonization and translocation levels, the normal functioning of the surface epithelium was better maintained in the rats fed the calcium or tannic acid diet. Cytotoxicity of fecal water, which can affect the surface epithelium, was significantly higher in the AIC group than in the UC and IC groups (Table $4 ; P<0.05$ ). This cytotoxicity in the AITa group did not differ from the AIC group, but was much lower in the AICa group compared with the AIC group (Table $4 ; P<0.05$ ). 
Table 4. Effect of dietary calcium, tannic acid or antibiotic on fecal wet weight, luminal cytotoxicity, urinary CrEDTA excretion, and the serum IgM response to core endotoxin in rats ${ }^{1}$

\begin{tabular}{|c|c|c|c|c|}
\hline & Relative fecal wet weight & Cytotoxicity & Urinary CrEDTA & IgM to core endotoxin \\
\hline Group & $\mathrm{g} / 100 \mathrm{~g}$ feces & $\%$ lysis & $\%$ of intake & $A_{450}$ \\
\hline $\mathbf{U C}$ & $68.5 \pm 2.2 *$ & $22.2 \pm 4.2 *$ & $3.6 \pm 0.3 *$ & $0.37 \pm 0.11^{*}$ \\
\hline IC & $72.7 \pm 1.8 *$ & $27.6 \pm 2.9^{*}$ & $4.2 \pm 0.4 *$ & $0.33 \pm 0.04 *$ \\
\hline AIC & $78.5 \pm 0.7$ & $81.9 \pm 5.7$ & $7.2 \pm 0.9$ & $1.05 \pm 0.13$ \\
\hline AICa & $71.9 \pm 1.0 *$ & $40.7 \pm 7.8^{*}$ & $4.1 \pm 0.4 *$ & $0.60 \pm 0.10 *$ \\
\hline AITa & $71.2 \pm 1.0 *$ & $93.9 \pm 3.5$ & $3.8 \pm 0.4^{*}$ & $0.67 \pm 0.07 *$ \\
\hline
\end{tabular}

${ }^{1}$ Values are means \pm SEM, $\mathrm{n}=8$ except $\mathrm{UC} \mathrm{n}=5$

$*$ Different from AIC, $P<0.05$.

\section{Intestinal permeability}

The barrier function of the epithelial monolayer was investigated by measuring urinary recovery of oral CrEDTA, which is a marker of paracellular permeability in gut epithelium (7). CrEDTA recovery almost doubled in the AIC group compared with the UC and IC group (Table 4). However, this permeability was significantly lower in the AICa and AITa groups compared with the AIC group (Table $4 ; P<0.05$ ).

Whether differences in intestinal permeability affected the leakage of noxious luminal compounds was studied by measuring the antibody response to core endotoxin. The IgM response to core endotoxin was significantly higher in the AIC group compared to the IC group (Table $4 ; P<0.05$ ). Both AICa and AITa groups had less of an IgM response compared with the AIC group $(P<0.05)$. The difference in these IgM levels could be caused by modulation of the immune response by calcium and tannic acid. Therefore, we also measured serum levels of IgM directed against Salmonella. This IgM response did not differ significantly among the AICa and AITa groups compared with the AIC group (data not shown), a result in line with the comparable translocation levels of this bacterium. Thus, these results indicated that the effects of calcium and tannic acid on core endotoxin IgM levels (Table 4) were not due to a generic modulation of the immune response.

\section{DISCUSSION}

This study corroborates earlier findings that antibiotic treatment predisposes the host to Salmonella infection $(1,2)$. We now show that this phenomenon is accompanied by diarrhea, increased intestinal permeability and an increased IgM response to core endotoxin in serum. These symptoms are associated with a major increase in the cytotoxicity of fecal water, indicating increased irritating effects of the luminal content on the surface epithelium. 
The present study indicates that Salmonella colonization levels were not lower in the AICa group than in the AIC group. This is in contrast to results in a conventional infection model, in which reduced colonization by dietary calcium is associated with an increase in fecal lactobacilli and a decrease in the number of enterobacteria (10). These effects of dietary calcium were present in the AICa group compared with the AIC group prior to clindamycin treatment. After clindamycin treatment these presumed beneficial changes of the intestinal microbiota were almost completely abrogated. Except for slightly more lactobacilli in the AICa group, levels from all groups were identical to the AIC group. The suppression of enterobacteria in the AICa group compared with the AIC group was abolished by clindamycin, which can be explained by the fact that clindamycin favors growth of these bacteria (22). These results support our hypothesis (10) that calcium improves the resistance to Salmonella via stimulation of the competitive microbiota. They falsify, however, our alternative hypothesis (11) that protection is due to binding of Salmonella to amorphous calcium phosphate in the intestinal lumen. This proposed binding should not be affected by the clindamycin treatment and then colonization levels in the AICa group would have been lower than in the AIC group.

Despite the absence of an inhibitory effect on Salmonella colonization and translocation, the infection-related diarrhea was less in the AICa group than in the AIC group. This indicated that, despite similar Salmonella colonization and translocation levels, the normal functioning of the surface epithelium was better maintained in AICa group than in the AIC group. The surface epithelium is highly affected by the cytotoxicity of fecal water (23). The present study provides evidence that clindamycin greatly increased the cytotoxicity of fecal water, as levels were much higher in the AIC group than in the IC group. Previous animal $(9)$ and human $(20,24)$ studies have shown that calcium precipitates irritating bile acids and other cytotoxic surfactants and thus reduces cytotoxicity of luminal contents, which prevents epitheliolysis and likely preserves intestinal barrier function. These human studies used a dietary calcium dosage within the same concentration range as in the present study. Therefore the proposed protective mechanism of calcium in rats is likely to be of relevance to humans.

Here we present the novel finding that dietary calcium preserved the barrier function in a sensitized Salmonella-infection model as leakage of CrEDTA from the intestinal lumen was lower in the AICa group compared with the AIC group. Increased paracellular permeability can facilitate translocation of noxious bacterial components such as (lipopolysaccharide) LPS, the outer-membrane component of Gram-negative bacteria. Bacterial translocation of Salmonella bacteria itself occurs via a transcellular route. This transport is facilitated by a mechanism which involves binding to epithelial cells by the type III secretory system (TTSS), which is present on the bacterium $(25,26)$. This TTSS allows direct activation of components of the host cytoskeleton by dedicated bacterial effectors (5). Translocation of Salmonella is not affected by the difference in 
cytotoxicity. Colonization levels were identical in the AIC and AICa groups, but cytotoxicity was clearly higher in the AIC group. Despite the difference in cytotoxicity translocation levels of Salmonella were identical in both groups. This shows that increased luminal cytotoxicity did not affect Salmonella translocation in our study. Furthermore, we investigated the antibody response directed to core endotoxin, which is the conserved part of bacterial LPS. Increased serum LPS is associated with increased paracellular permeability, for example induced by non-steroidal anti-inflammatory compounds $(27,28)$. The IgM response to core endotoxin was significantly lower in the AICa group than in the AIC group, a result in line with intestinal permeability differences between these groups. This indicated that dietary calcium inhibited the leakage of LPS. We speculate that this is due to the observed inhibition of luminal cytotoxicity (Table 4). Thus calcium lowers the concentration of cytotoxic surfactants to which the mucosa is exposed and this may inhibit paracellular permeability, as discussed above. This protective effect of calcium on leakage of noxious luminal components is further supported by our recent finding that dietary calcium ameliorates colitis in a transgenic rat model of inflammatory bowel disease (29).

On the other hand, the observed difference in the luminal calcium concentration due to our dietary intervention might affect gut barrier function more directly. Obviously, alterations in tight junction proteins as the primary regulators of intestinal permeability are expected. Recent studies indicate that calcium did not induce changes in gene expression of tight junction proteins (e.g. claudins, occludin, zona occludens, and myosin IXb) (29), although morphological and structural alterations in tight junctions might exist. For example, internalization into the cellular cytoplasm and phosphorylation of tight junction proteins are suggested to be important for leakiness of the mucosal barrier (30). Extracellular (luminal) calcium is crucial for maintenance of intestinal tight junction function in cell studies. However, these effects seem to occur at free calcium concentrations up to $0.1 \mathrm{mmol} / \mathrm{L}(31)$, which is at least 50 times lower than the luminal calcium levels of rats fed the control or calcium diet (29). Therefore direct effects of luminal calcium on tight junction proteins in vivo seem less likely.

Despite antimicrobial effects of (hydrolysable) tannins like tannic acid in vitro $(13,15)$, neither intestinal Salmonella colonization nor translocation was lower in the AITa group than in the AIC group. This indicated that possible antimicrobial effects of tannic acid were overruled by the clindamycin pretreatment, as shown by our culture data (Table 2 and Fig 1). Notwithstanding that, tannic acid, although chemically unrelated to calcium, had similar effects on diarrhea and epithelial permeability in the AITa group compared with the AIC group. As cytotoxicity of fecal water was not lower in the AITa group than in the AIC group, this polyphenol apparently maintained the proper functioning of the mucosa by increasing its resistance to luminal cytotoxicity. 
At present, we can only speculate about the mechanism of this unexpected barrier-strengthening effect of tannic acid. As a first hypothesis we propose that protection is due to direct binding of tannic acid to the outer leaflet of the apical membrane of the surface epithelium, as is shown for ligated intestinal segments of rats (32). We conjecture that a surface layer of bound tannic acid polymers prevents the interaction of hydrophobic, and thus cytotoxic, surfactants with the apical membrane. This is supported by the finding that topically applied tannic acid protects human skin epithelium against hydrophobic surfactants such as lauryl sulfate (33). As an additional mechanism, we propose that gallic acid, taken up by enterocytes, may have additional protective effects. This phenolic monomer is released from the polymeric tannic acid by hydrolysis and fermentation by intestinal bacteria (34). A recent in-vitro study (35) shows that gallic acid, taken up by mast cells, lowers cytosolic calcium and inhibits stress signaling via protein kinases by preventing NF-kB activation. This is in line with another study (36), which shows that gallic acid inhibits several protein kinases by competitive inhibition of the ATP binding site. Decreasing cytosolic calcium and protein kinase activity lowers fluid and ion secretion, such as chloride secretion regulated by the cystic fibrosis transmembrane conductance regulator (CFTR), by enterocytes (37). As activation of myosin light-chain kinase increases tight-junction permeability (38), we speculate that this can be counteracted by gallic acid. These two hypothetical mechanisms are difficult, if not impossible, to study in vivo. Therefore, we plan further in-vitro studies in which enterocytes, cultured in a Transwell system, are apically exposed to cytotoxic surfactants in the absence and presence of tannic acid or gallic acid. It should be noted that the suggested mechanism by changes in cytosolic calcium is not relevant to our calcium intervention. A diet high in calcium does increase luminal calcium levels but it does not increase intracellular calcium levels. Systemic (serum) calcium concentrations are tightly regulated, and thus stable, and are not influenced by dietary calcium supplementation (39). Therefore, the effects of an increase of intracellular calcium differ from effects of increased luminal calcium.

It is important to extrapolate our dietary interventions to the human situation. The calcium content of the calcium-supplemented diet was $4.8 \mathrm{~g} / \mathrm{kg}$ dry food, which corresponds to a daily calcium intake of $2.4 \mathrm{~g}$ in humans, assuming that humans have a daily dry food intake of approximately $500 \mathrm{~g}$. In general, human dietary calcium intake in the Western world is approximately $1.4 \mathrm{~g}$ daily (24). This indicates that the calcium-supplemented diet provided more than the general habitual dietary calcium intake. However, this is not an unrealistic intake when using calcium supplements. Similarly, it can be calculated that the used tannic acid diet of $3.75 \mathrm{~g} / \mathrm{kg}$ dry food corresponds to a daily tannic acid intake of $1.9 \mathrm{~g}$ in humans. The estimated daily tannic acid intake in humans (in the US) is $1 \mathrm{~g}$ (40). Therefore, the applied tannic acid diet can also be extrapolated to humans using tannic acid supplements. 
In conclusion, clindamycin resulted in increased diarrhea, intestinal permeability and elevated IgM levels to core endotoxin in a Salmonella-infection model. These symptoms were associated with increased cytotoxicity of fecal water. Both calcium and tannic acid lessened these effects, but without decreasing Salmonella colonization and translocation. Further investigations should focus on the mechanisms by which these dietary components maintain proper barrier function of the surface epithelium in this mucosal-stress model. Our results indicate that calcium protects by reducing luminal cytotoxicity and that tannic acid functions by improving the mucosal resistance to luminal cytotoxicity. Verification of the human relevance of our findings in exploratory studies, e.g. in antibiotic-treated humans, are also needed.

\section{ACKNOWLEDGEMENTS}

The authors would like to thank D.S. Jonker-Termont for performing and analyzing the cytotoxicity experiments. 


\section{REFERENCES}

1. Sekirov, I., Tam, N. M., Jogova, M., Robertson, $M$. L., Li, Y., Lupp, C.Finlay, B. B. 2008. Antibiotic-induced perturbations of the intestinal microbiota alter host susceptibility to enteric infection. Infect Immun 76: 47264736.

2. Croswell, A., Amir, E., Teggatz, P., Barman, M. Salzman, N. H. 2009. Prolonged impact of antibiotics on intestinal microbial ecology and susceptibility to enteric Salmonella infection. Infect Immun 77: 2741-2753.

\section{Lee, Y. K., Puong, K. Y.,} Ouwehand, A. C.Salminen, S. 2003. Displacement of bacterial pathogens from mucus and Caco- 2 cell surface by lactobacilli. J Med Microbiol 52: 925-930.

\section{Freter, R., Brickner, H.,} Botney, M., Cleven, D.Aranki, A. 1983. Mechanisms that control bacterial populations in continuous-flow culture models of mouse large intestinal flora. Infect Immun 39: 676-685.

\section{Cossart, P.Sansonetti, P. J.} 2004. Bacterial invasion: the paradigms of enteroinvasive pathogens. Science 304: 242248.
6. Salyers, A. A.Whitt, D. D. 1994. Salmonella infections. In: Bacterial pathogenesis; A molecular approach. ASM Press, Washington, D.C.

7. van Ampting, M. T., Schonewille, A. J., Vink, C., Brummer, R. J., van der Meer, R.Bovee-Oudenhoven, I. $M$. 2009. Intestinal barrier function in response to abundant or depleted mucosal glutathione in Salmonella-infected rats. BMC Physiol 9: 6.

8. Bovee-Oudenhoven, I. M., Termont, D. S., Heidt, P. J.Van der Meer, R. 1997. Increasing the intestinal resistance of rats to the invasive pathogen Salmonella enteritidis: additive effects of dietary lactulose and calcium. Gut 40: 497-504.

\section{Bovee-Oudenhoven, I. M.,} Termont, D. S., Weerkamp, A. H., Faassen-Peters, M. A.Van der Meer, R. 1997. Dietary calcium inhibits the intestinal colonization and translocation of Salmonella in rats. Gastroenterology 113: 550557.

\section{Bovee-Oudenhoven, I.} M., Wissink, M. L., Wouters, J. T.Van der Meer, R. 1999.

Dietary calcium phosphate stimulates intestinal lactobacilli and decreases the severity of a salmonella infection in rats. J Nutr 129: 607-612.
11. Bovee-Oudenhoven, I. M., Lettink-Wissink, M. L., Van Doesburg, W., Witteman, B. J.Van Der Meer, R. 2003. Diarrhea caused by enterotoxigenic Escherichia coli infection of humans is inhibited by dietary calcium. Gastroenterology 125: 469-476.

12. Beecher, G. R. 2003. Overview of dietary flavonoids: nomenclature, occurrence and intake. J Nutr 133: 3248S-3254S.

13. Puupponen-Pimia, R., Nohynek, L., Meier, C., Kahkonen, M., Heinonen, M., Hopia, A.Oksman-Caldentey, K. M. 2001. Antimicrobial properties of phenolic compounds from berries. J Appl Microbiol 90: 494-507.

\section{Okuda, T., Yoshida,}

T.Hatano, T. 1995. Hydrolyzable tannins and related polyphenols. Fortschritte der chemie organischer naturstoffe 66: 1-117.

15. Chung, K. T., Wong, T. Y., Wei, C. I., Huang, Y. W.Lin, Y. 1998. Tannins and human health: a review. Crit Rev Food Sci Nutr 38: 421-464.

16. Reeves, P. G., Nielsen, F. H.Fahey, G. C., Jr. 1993. AIN93 purified diets for laboratory rodents: final report of the American Institute of 
Nutrition ad hoc writing committee on the reformulation of the AIN-76A rodent diet. J

Nutr 123: 1939-1951.

\section{Oudenhoven, I. M.,} Klaasen, H. L., Lapre, J. A., Weerkamp, A. H.Van der Meer, R. 1994. Nitric oxidederived urinary nitrate as a marker of intestinal bacterial translocation in rats. Gastroenterology 107: 47-53.

\section{Ten Bruggencate, S. J.,} Bovee-Oudenhoven, I. M., Lettink-Wissink, M. L., Katan, M. B.Van Der Meer, R. 2004. Dietary fructo-oligosaccharides and inulin decrease resistance of rats to salmonella: protective role of calcium. Gut 53: 530-535.

19. Sesink, A. L., Termont, D. S., Kleibeuker, J. H.Van der Meer, R. 1999. Red meat and colon cancer: the cytotoxic and hyperproliferative effects of dietary heme. Cancer Res 59: 5704-5709.

\section{Govers, M. J., Termont,} D. S., Lapre, J. A., Kleibeuker, J. H., Vonk, R. J.Van der Meer, R. 1996. Calcium in milk products precipitates intestinal fatty acids and secondary bile acids and thus inhibits colonic cytotoxicity in humans. Cancer Res 56: 32703275.
21. Janeway, C. A., Travers, P., Walport, M.Shlomchik, M. J. 2005. The humoral immune response. In: Immuno Biology; the immunesystem in health and disease (E., L., ed.), pp. 367408. Garland Science publishing, New York.

22. Nyberg, S. D., Österblad, M., Hakanen, A. J., Löfmark, S., Edlund, C., Huovinen, P.Jalava, J. 2007. Long-term antimicrobial resistance en Escherichia coli from human intestinal microbiota after administration of clindamycin. Scandinavian Journal of Infectious Diseases 39: 514520 .

23. de Vogel, J., van-Eck, W. B., Sesink, A. L., Jonker-

Termont, D. S., Kleibeuker, J.van der Meer, R. 2008. Dietary heme injures surface eptithelium resulting in hyperproliferation, inhibition of apoptosis and crypt hyperplasia in rat colon. Carcinogenesis 29: 398-403.

\section{4. van der Meer, R., Wel-} berg, J. W. M., Kuipers, F., Kleibeuker, J. H., Mulder, N. H., De Vries, H. T.De Vries, E. G. E. 1990. Effects of supplemental dietary calcium on the intestinal association of calcium, phosphate, and bile acids. Gastroenterology 99: 1653-1659.
25. Grassl, G. A.Finlay, B. B. 2008. Pathogenesis of enteric Salmonella infections. Curr Opin Gastroenterol 24: 22-26.

26. Ly, K. T.Casanova, J. E. 2007. Mechanisms of Salmonella entry into host cells. Cell Microbiol 9: 2103-2111.

27. Tugendreich, S., Pearson, C. I., Sagartz, J., Jarnagin, K.Kolaja, K. 2006. NSAIDInduced Acute Phase Response is Due to Increased Intestinal Permeability and Characterized by Early and Consistent Alterations in Hepatic Gene Expression. Toxicologic Pathology 34: 168-179.

28. Oshima, T., Miwa, H.Joh, T. 2008. Aspirin induces gastric epithelial barrier dysfunction by activating p38 MAPK via claudin-7

Am J Physiol Cell Physiol 295: C800-C806.

29. Schepens, M. A., Schonewille, A. J., Vink, C., van Schothorst, E. M., Kramer, E., Hendriks, T., Brummer, R. J. et al. 2009. Supplemental Calcium Attenuates the Colitis-Related Increase in Diarrhea, Intestinal Permeability, and Extracellular Matrix Breakdown in HLA-B27 Transgenic Rats. J Nutr. 
30. Bruewer, M., Samarin, S.Nusrat, A. 2006. Inflammatory bowel disease and the apical junctional complex. Ann N Y Acad Sci 1072: 242252.

31. Gonzalez-Mariscal, L., Contreras, R. G., Bolivar, J. J., Ponce, A., Chavez De Ramirez, B.Cereijido, $M$. 1990. Role of calcium in tight junction formation between epithelial cells. Am J Physiol Cell Physiol 259: C978-986.

\section{Carbonaro, M., Grant,} G.Pusztai, A. 2001. Evaluation of polyphenol bioavailability in rat small intestine. Eur J Nutrition 40: 84-90.

33. Shimizu, T.Maibach, H. I. 1999. Squamometry: an evaluation method for a barrier protectant (tannic acid). Contact Dermatitis 40: 189-191.

34. Bravo, L., Abia, R., Eastwood, M. A.Saura-Calixto, F. 1994. Degradation of polyphenols (catechin and tannic acid) in the rat intestinal tract. Effect on colonic fermentation and faecal output. Br J Nutr 71: 933-946.

\section{Kim, S. H., Jun, C. D.,} Suk, K., Choi, B. J., Lim, H., Park, S., Lee, S. H. et al. 2006. Gallic acid inhibits histamine release and pro-inflammatory cytokine production in mast cells. Toxicol Sci 91: 123-131.

36. Yang, E. B., Wei, L., Zhang, K., Chen, Y. Z.Chen, W. N. 2006. Tannic acid, a potent inhibitor of epidermal growth factor receptor tyrosine kinase. J Biochem 139: 495-502.

37. Schiller, L. R. 1995.

Review article: anti-diarrhoeal pharmacology and therapeutics. Aliment Pharmacol Ther 9: 87-106.

38. Turner, J. R. 2006. Molecular basis of epithelial barrier regulation: from basic mechanisms to clinical application. Am J Pathol 169: 1901-1909.

39. Appleton, G. V., Owen, R. W., Wheeler, E. E., Challacombe, D. N.Williamson, $R$. C. 1991. Effect of dietary calcium on the colonic luminal environment. Gut 32: 13741377.

40. Sanyal, R., Darroudi, F., Parzefall, W., Nagao, M.Knasmuller, S. 1997. Inhibition of the genotoxic effects of heterocyclic amines in human derived hepatoma cells by dietary bioantimutagens. Mutagenesis 12: 297303. 



\section{CHAPTER 7}

\section{GENERAL DISCUSSION AND CONCLUDING REMARKS}




\section{INTRODUCTION}

Gastrointestinal infections are a major health problem and growing resistance of bacterial pathogens, including Salmonella species, to generally applied antibiotics is a concern (1-5). Therefore alternative methods to increase host resistance to intestinal infection are crucial for society in general and specifically those subpopulations prone to intestinal infections and its complications, like young children and the elderly.

This thesis focuses on dietary modulation of intestinal Salmonella infection and its sequelae. The over-arching question of this thesis is "How can diet modulate intestinal Salmonella infection?". The studies contributing to the thesis aimed to answer more specific questions like "Which host defence mechanisms are important during Salmonella infection?" and "What dietary components can modulate intestinal Salmonella infection?". This final chapter summarizes and discusses the main findings of our research (schematically depicted in Fig 1 and summarized in Table 1) in the perspective of the current state-of-the-art knowledge in this area. Attention is paid to extrapolating findings of the rat studies to the human situation. In addition, suggestions for future research are addressed.

\section{Oral Salmonella infection}
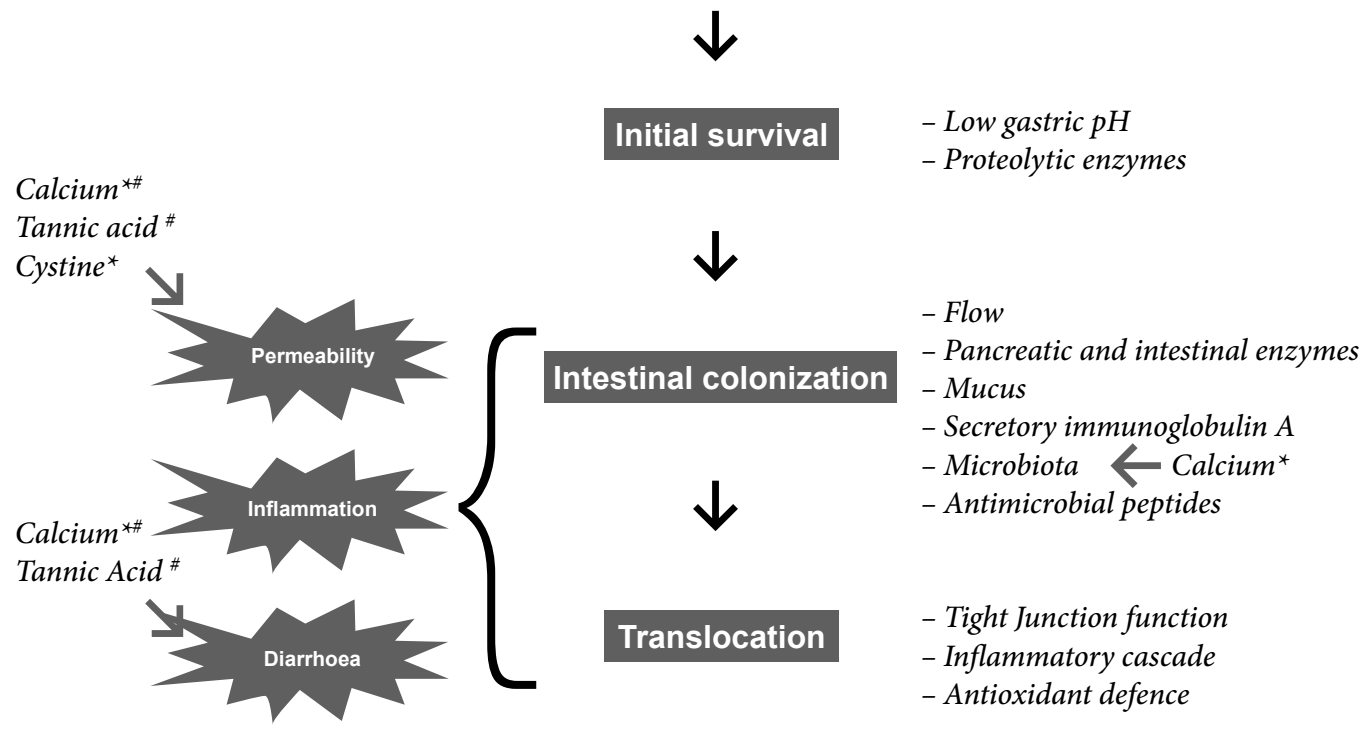

Figure 1. Cascade of Salmonella infection in rats (stages shown in boxes). Pathophysiological consequences known to occur or increase upon infection are depicted in random order and involved host defence mechanisms in italics. Grey arrows indicate specific host mechanisms or pathophysiological consequences that are directly or indirectly modulated by dietary components in regular infected $\left(^{*}\right)$ or antibiotic-pretreated infected $(\#)$ rats described in this thesis. 
The acute Salmonella infection model in rats, which is the basis of the investigations presented in this thesis, can be used as a model for gastro-intestinal infections in general. Findings can be extrapolated depending on the affected host defence mechanisms and (patho)physiological consequences. When these defence mechanisms or sequelae are known to be relevant for other infections, such as e.g. diarrhoea during non-invasive enterotoxigenic Eschericia coli (ETEC) infection, dietary components might also affect resistance to these other pathogens.

\section{MODELS TO INVESTIGATE DEFENCE MECHANISMS DURING SALMONELLA INFECTION}

The necessity to identify and select appropriate models is a pivotal issue in investigating dietary modulation of intestinal infection and finding new dietary components to improve intestinal defence. Traditionally, dietary interventions are initially performed in animal models. The Salmonella enteritidis infection model in rats, which was used in the studies presented in this thesis, is a relatively mild infection model associated with relatively low mucosal inflammation, infectious diarrhoea, and undetectable mucosal oxidative protein or lipid damage. Moreover, S. enteritidis is a highly relevant human bacterial pathogen based on its incidence rates (1). The mild infection symptoms make the model appropriate for elucidating the presumably subtle protective effects of dietary components. The putative action of nutritional modulation should be aligned with the specific characteristics of the model applied. For example, this model is not suitable for investigating antioxidative properties of dietary components because oxidative damage is not detectable.

The rats in all our studies were fed "Western" purified diets in order to mimic the human situation. It is known that diet affects the composition, gene abundance, and gene expression of the intestinal microbiota in rodents and a humanized diet results in a more human-like microbiota than a standard rodent diet (6). In this way we optimized our studies for extrapolating results to the human situation. It should be kept in mind, however, that $S$. enteritidis might behave differently in humans compared with rats. Especially the occurrence of microbial translocation is much more frequent and severe in animal models than in the healthy human. In humans, especially in infants and in immunocompromised adults, the infection can become systemic, which is associated with substantial morbidity and even mortality $(7,8)$.

This thesis describes, in addition to the above mentioned regular Salmonella infection model in rats, other animal models that can be used in this field of research. These models concern compromised host defence mechanisms in order to reveal the role of a specific nutrient-gut interaction in the course of infection and enable us to: 1) identify what pathophysiological mechanisms could be improved during infection, 2) deliver proof-of-concept that a specific dietary compound has beneficial effects, and 3) identify specific host defence 
mechanisms involved in protective effects of a specific dietary component, and therefore indicate if the component can be used to combat also other disorders than Salmonella infection. In addition, the compromised host defence mechanism, or more sensitive, infection model can be used for development of new biomarkers that can be used in intervention research.

\section{Clindamycin model}

This host compromised model concerns a situation in which the intestinal microbiota is temporarily disturbed by clindamycin administration before the rats receive the oral Salmonella infection (Chapter 6). Such a disturbance increases susceptibility to infection and increases bacterial colonization, translocation and mucosal inflammation $(9,10)$. Our studies showed that the epithelial barrier was negatively affected by clindamycin administration prior to infection, and that luminal lipopolysaccharide (LPS), possibly microbiota-derived, leaked to the systemic circulation. This phenomenon was associated with increased luminal cytotoxicity, which showed that the epithelial lining was exposed to more noxious compounds.

A future area of research is to establish human relevance, thus whether the results found in this animal model would have been similar in the human situation. This would include non-invasive studies, such as monitoring gut permeability by urinary CrEDTA excretion in humans that receive antibiotics. It is necessary to know whether this gut barrier impairment generally occurs during (oral) antibiotic treatments and whether non-infected individuals also show these symptoms. This could be investigated for example in relatively healthy humans that receive oral clindamycin for acne treatment. Investigation of serum LPS or antibodies against LPS can be used to determine whether LPS increases systemically upon antibiotic treatment, even in non-infected humans. Appropriate (dietary) measures against these symptoms then might reduce the antibiotic treatment related symptoms such as diarrhoea and may reduce secondary infection risks.

\section{Glutathione depletion model}

The glutathione depletion model (Chapter 5) is a second compromised host defence model presented in this thesis. Glutathione is an important compound in the natural antioxidant defence of the host. Our study showed that this defence mechanism was not substantially involved in colonization and translocation of Salmonella. It did, however, play an important role in the magnitude of the immune response. Mucosal myeloperoxidase (MPO) levels were extremely high in glutathione-depleted rats during infection. This highly increased mucosal inflammatory activity was, however, not associated with paracellular permeability defects.

The role of glutathione in infection has been studied mainly in ex-vivo models. Salmonella infection, for example, decreases enterocyte glutathione 
levels in mouse ileal loops and this reduction increases the susceptibility of epithelial cells to oxidative damage (11). Studies in this thesis clearly showed that decreased glutathione levels in the intestinal mucosa of 'healthy' or infected rats fed an adequate diet did not result in oxidative damage and subsequent intestinal barrier defects. This underlines that one should be cautious to extrapolate conclusions from ex-vivo experiments to in vivo situations. Apparently, during relatively mild intestinal inflammation, such as in the Salmonella infection model, glutathione is not such an important antioxidant as often presumed. The study described in Chapter 5 actually showed that the healthy gut has a good antioxidant defence system, even when one player is eliminated. This may indicate the importance of studying antioxidative networking rather than that of specific anti-oxidative compounds. In situations in which the gut is chronically compromised, as seen in inflammatory bowel disease (IBD), glutathione depletion could have different outcomes and might have detrimental effects. In fact, in animal models (Schepens et al. submitted for publication) and in humans $(12,13)$ IBD has been associated with extremely low glutathione levels. IBD is a chronic disorder and the inflammatory process there cannot simply be compared with inflammation in an acute infection model as used in the studies of this thesis. However, the hyper-immune response of the intestinal epithelium that was observed in the acute situation might resemble the situation that occurs chronically during IBD. Some studies have suggested that thiol-mediated redox regulation of intestinal lamina propria $\mathrm{T}$ lymphocytes is involved in the pathogenesis of $\operatorname{IBD}(14,15)$. Our study might support this hypothesis.

Several questions remain to be answered. What is the pathophysiology of the increased inflammatory activity of the intestinal mucosa in glutathionedepleted rats? What is the role of the above mentioned hyperresponse of propria T lymphocytes? Do these phenomena also occur in chronic intestinal disorders like IBD? Answers revealing these pathophysiologic mechanisms may offer solutions to disorders associated with glutathione deficiency.

\section{BIOMARKERS}

There is great scientific and medical interest in identifying and validating new and non-invasive biomarkers of intestinal health and disease, such as gut infection and inflammation. Their implementation in clinical routine in humans is attractive because these markers yield valuable information on intestinal health status by non-invasive means, reducing the need for invasive endoscopy. Therefore, and besides studying nutritional effects on host defence against intestinal infectious disease, there was keen interest in new potential biomarker identification using the Salmonella infection model.

Expression of rat pancreatitis-associated protein 1 (PAP) and its murine homologue RegIII $\beta$ protein increased in the ileal mucosa as well as faeces of infected rodents (Chapters 2 and 3). The amount of protein found in faeces well reflected the infection severity in rats (Chapter 2). Moreover, the human 
homologue, designated PAP, was also detected in human faeces (Chapter 4) and its levels were higher after ETEC infection. Faecal PAP levels were also elevated in faeces from ulcerative colitis (UC) patients, but not in those from Crohn's disease (CD) patients (Chapter 4). Human faecal PAP concentrations were not proportional to those of calprotectin, a commonly used faecal biomarker of intestinal inflammation. Our data suggested that faecal PAP levels possibly provide information about the defence status of intestinal epithelial cells, rather than being an inflammation marker. Mechanistic studies in mice revealed that RegIII $\beta$ protein plays a protective role against infection with the Gram-negative S. enteritidis but not against the Gram-postive Listeria moncytogenes (Chapter 3). Its function was associated with binding of RegIII $\beta$ to this Gram-negative bacterium and thereby possibly inhibiting bacterial translocation.

Faecal PAP might be a new non-invasive biomarker for intestinal epthelial defence status in humans, and might have added value in combination with calprotectin measurement, which reflects the mucosal inflammatory response. Currently, we can not describe the specific properties of the biomarker. Increased faecal PAP concentrations in UC patients (Chapter 4), do not support PAP as a biomarker of intestinal infection.

This family of RegIII proteins exists in many species and the mice and human isoforms are very similar at the amino acid level, which indicates that this protein is well preserved during evolution. This underlines that RegIII function might be crucial for host survival. The murine isoform RegIII $\gamma$ and human PAP have antimicrobial activity against Gram-positive bacteria but not the Gramnegative E. coli. (16). Studies published in this thesis contribute to elucidating the biological function of RegIII $\beta$.

The exploratory study in humans described in this thesis (Chapter 4 ) is an initial step and definitely needs confirmation and further investigation to determine the value of PAP for monitoring intestinal disease activity and discriminating between UC and CD. Larger follow-up studies including well-defined IBD patients and healthy volunteers are needed. Investigations concerning faecal PAP concentrations in healthy volunteers are needed to address our questions concerning a small group of 'outliers' at baseline level (Chapter 4). If the range of faecal PAP concentrations in healthy individuals really is that wide, a clinical application of the biomarker might not be feasible. Biopsies of IBD patients are needed to indicate whether ileal or colonic tissues (or both) are the specific source areas causing an increase of faecal PAP. Also PAP concentrations in serum should be investigated, as studies describe elevated serum PAP in IBD patients with active disease (17). Although those studies suggest intestinal epithelial expression as the cause of increased serum levels, the question how this protein is secreted to the serosal side remains to be answered. It would be remarkable that an epithelial expressed protein is secreted into the systemic circulation as well as into the intestinal lumen. Therefore a more comprehensive investigation in epithelial tissues, faeces and serum is needed to address all these 
issues simultaneously. Ultimately, faecal PAP levels should be correlated with severity of disease or recovery in order to fine-tune the function of this protein as biomarker or even to separate CD from UC.

Further studies to reveal the exact function of murine RegIII $\beta$ (PAP) can tell us whether this protein is involved in all Gram-negative infections. It might also have impact on bacteria from the indigenous microbiota and thereby modulate its composition or functionality. Binding competition experiments, for example with anti-RegIII $\beta$ antibodies, may reveal whether binding of the protein to bacteria is crucial for its protective function.

\section{DIETARY MODULATION OF INTESTINAL INFECTION Cystine}

Dietary cystine supplementation preserved (paracellular) gut barrier function and inhibited Salmonella translocation in infected rats (Chapter 5). Studies on the protective function of this dietary component have mainly focussed on glutathione-related aspects. Our study showed that a cystine supplemented diet did not increase hepatic or ileal glutathione levels compared to rats fed a control diet adequate in sulphur-containing amino acids. This indicated that dietary cystine has protective properties on the intestinal barrier function due to mechanisms unrelated to glutathione.

Further studies are needed to reveal the mechanism by which cystine supplementation affects the intestinal barrier and how it may inhibit Salmonella translocation. It still remains unsolved whether the cystine-associated effects are due to its absorbtion by the intestinal mucosa and whether subsequent circulation of cystine is required. Amino acids like cystine are absorbed in the small intestine and, as has been shown for glutamine, cystine probably affects the epithelial barrier via systemic effects. Depending on the results of future studies, cystine might be a suitable nutritional supplement in enteral and/or parenteral nutrition in other application areas and more chronic disorders than investigated in this thesis.

\section{Calcium}

Dietary calcium supplementation was shown to have protective properties with regard to intestinal Salmonella infection as it decreased Salmonella colonization and translocation (Chapter 2). This thesis presents results which showed that disturbance of the composition of the endogenous microbiota, by antibiotic treatment before Salmonella infection, influenced these protective effects of calcium. In this compromised host model calcium beneficially affected the epithelial barrier function (urinary CrEDTA excretion and LPS antibody response in serum) and diarrhoea. Both functional effects were associated with lowered cytotoxicity of faecal water. In the same infection model, however, calcium supplementation was not able to inhibit colonization and translocation of Salmonella in contrast to the regular infection situation when rats were not pretreated with antibiotics 
(Chapters 6 and 1, respectively). This suggests that the microbiota play a pivotal role in some, but not all of the protective effects of calcium against intestinal infectious disease.

Animal (18) and human $(19,20)$ studies have shown that calcium precipitates irritating bile acids and other cytotoxic surfactants and thus reduces cytotoxicity of luminal contents, preventing epitheliolysis. This seems to be a prominent mechanism in calcium-associated protection of epithelial function. Other protective mechanisms, such as shown in the regular infection model including reduced colonization and translocation of Salmonella, probably act via stimulation of competitive microbiota (lactobacilli) (21). Previous studies suggested an alternative hypothesis of epithelial protection by dietary calcium. Calcium binds to phosphate in the intestinal lumen and this complex has been suggested to bind Salmonella and thereby inhibiting epithelial binding and translocation of this bacterium (22). Calcium should still have these properties in the calcium intervention in antibiotic-pretreated infected rats (Chapters 6) and consequently colonization and translocation should be reduced. However, these protective effects were not shown in the antibiotic-pretreated infection model. Hence, this hypothesis is ruled out by the data presented in this thesis.

The study presented in this thesis (Chapter 6) underlined the usefulness of the clindamycin-pretreated infection model in dietary interventions. It provided better insight into how calcium may enforce the intestinal barrier against S. enteritidis infection and its sequelae. The data in this thesis showed that calcium has a dual protective function. This phenomenon of providing protective effects via more than one (defence) mechanism can be hypothesized for other dietary components as well.

The major questions which remain to be answered concern the pathophysiological mechanism or route by which the intestinal epithelial layer is protected by the calcium supplementation and the severity of diarrhoea is diminished. More specifically, what generic mechanisms in the intestinal epithelium are affected by reduction of the luminal cytotoxicity. These questions are presumably also relevant to explain the previously shown beneficial effects of calcium in amelioration of intestinal inflammation and related symptoms observed in a rat IBD model (23). It is also important to elucidate quantitative and qualitative microbial factors responsible for the protective effects of calcium supplementation on Salmonella colonization and translocation. The proposed role for endogenous lactobacilli (21) could be verified by e.g. by varying the level of lactobacilli colonization in rats and subsequent determination of its influence on Salmonella colonization. Unpublished results from a Salmonella-infection study in rats with variable levels of lactobacilli by oral bile acid supplementation, however, showed that a reduced number of lactobacilli did not affect Salmonella colonization or translocation. An alternative approach is to study the efficacy of oral probiotics to improve intestinal resistance to Salmonella infection. For selection of bacterial species, particularly able to compete with $S$. enteritidis for adhesion to epithelial 
cells, in vitro competition assays might be included in the screening phase. However, predictive power of these particular in vitro experiments for in vivo efficacy is speculative, as these assays do not reflect the complex multi-factorial interactions that occur in vivo where heterogeneous multi-cellular systems mutually interact with microorganisms.

Human studies have shown similar luminal cytotoxicity reducing properties of calcium supplementation $(19,20)$ as found in the rat studies presented in this theses. Hence, the proposed protective mechanism of calcium in rats is likely to be of relevance to humans too and should be further investigated. Especially, studies addressing the effect of dietary calcium on intestinal permeability, diarrhoea, and intestinal microbial composition are welcomed as these generic functionalities are presumed relevant for several intestinal disorders, especially resistance to infectious disease and intestinal inflammation.

\section{Tannic acid}

Tannic acid reduced diarrhoea as well as epithelial permeability in clindamycinpretreated infected rats (Chapter 6). We can only speculate about the mechanism of these protective effects on epithelial function. The results presented in this thesis suggest that the observed protective effects of tannic acid are not related to the composition of the microbiota since antibiotic pretreatment of rats did not abolish these effects. Moreover, the protective effects were not associated with changes in luminal cytotoxicity and therefore also this mechanism possibly is not involved in terms of the observed protection.

Up to now polyphenols have been suggested to strengthen the intestinal epithelial barrier by their possible antioxidative and scavanging or immunmodulatory properties $(24,25)$. The research presented in this thesis opens up a more differentiated avenue of bioactivity in infection-related barrier dysfunctioning. Polyphenol research related to intestinal defence against infection predominantly concerns in vitro research, and mainly focusses on the antimicrobial properties of these compounds $(26,27)$. As the study presented in this thesis (Chapter 6) could not reproduce the antibacterial effects, shown in vitro $(26,27)$, of hydrolysable tannins like tannic acid in vivo, this indicated that these antimicrobial effects might not be applicable to the in vivo situation and should be interpreted and extrapolated carefully.

Mechanistic studies on the epithelial barrier strengthening properties of tannic acid and other polyphenolic compounds are needed. An initial approach would be to expose enterocytes, cultured in an in vitro transwell system, apically to cytotoxic surfactants in the absence or presence of tannic acid or gallic acid. It would also be of interest to determine structure-function effects of polyphenols on the tight junction function or cystic fibrosis transmembrane conductance regulator (CFTR) inhibition in vivo or ex vivo in these tissues.

The concentration of tannic acid used in our rat study can be extrapolated to the human intake. Therefore it would be interesting to perform a 
controlled tannic acid or gallic acid dietary intervention in humans that use antibiotics in order to investigate whether these compounds reduce infection severity and diarrhoea in humans.

\section{CONCLUSION}

The question how diet can modulate intestinal Salmonella infection cannot be answered in a simple way. This thesis shows that protection by a single dietary component can affect multiple pathophysiological consequences of a gastrointestinal disorder (Fig 1, Table 1). As multiple sequelae are affected this also suggests that multiple mechanisms are involved in dietary modulation of host defence, which may be interrelated with other defence or pathophysiological mechanisms. The protective properties of dietary calcium supplementation on Salmonella infection and its sequelae involve at least two (patho)physiological routes related to infection. One of these routes can be modulated depending on microbiota-associated host defence status (Table 1). The 'second route' is independent of the microbiota as functional protective properties on diarrhoea and intestinal permeability are maintained after use of antibiotics. Understanding the underlying mechanisms of protective effects is very important, especially in order to judge whether dietary effects observed in the acute infection model can be extrapolated to more chronic disorders.

Table 1. Overview of the observed protective effects of dietary components investigated in either the regular or clindamycin-pretreated Salmonella enteritidis-infection model in rats.

\begin{tabular}{|l|l|l|l|l|l|l|}
\hline Infection model & $\begin{array}{l}\text { Supplemented } \\
\text { dietary compound } \\
(\mathrm{mmol} / \mathrm{kg})\end{array}$ & Diarrhoea & $\begin{array}{l}\text { Intestinal } \\
\text { Salmonella } \\
\text { colonization }\end{array}$ & $\begin{array}{l}\text { Salmonella } \\
\text { translocation }\end{array}$ & $\begin{array}{l}\text { Infection- } \\
\text { induced } \\
\text { increase of } \\
\text { intestinal } \\
\text { permeability }\end{array}$ & $\begin{array}{l}\text { Ileal } \\
\text { inflammation }\end{array}$ \\
\hline \multirow{2}{*}{ Regular } & Calcium (120) & Yes $^{1}$ & Yes & Yes & Yes & No \\
\cline { 2 - 7 } & Cystine (12.3) & No $^{2}$ & No & Yes & Yes & No \\
\hline \multirow{2}{*}{ Clindamycin preteated } & Calcium (120) & Yes & No & No & Yes & nd $^{3}$ \\
\cline { 2 - 7 } & Tannic acid (2.2) & Yes & No & No & Yes & $\mathrm{nd}$ \\
\hline
\end{tabular}

\footnotetext{
${ }^{1}$ Protective effect

${ }^{2}$ No protective effect

${ }^{3}$ Not determined
}

This thesis provides new insight into which nutrient-sensitive host defence mechanisms are important in Salmonella infection. The indigenous microbiota is very important with respect to colonization resistance and prevention of translocation of pathogens. Currently, there is keen scientific and commercial interest in nutritional modulation of the gut microbiota, e.g. by 
probiotics and prebiotics, and progress can be achieved if microbiota profiling data are linked to clinically relevant functional effects in the same studies. Also other dietary components, like we showed in the case of calcium, can modulate gut microbial composition or function. Intestinal glutathione levels do not seem to modulate protection against intestinal infection, although they play a role in the magnitude of the inflammatory response. As a disproportionate inflammatory response is also a key factor of chronic inflammation in IBD, it is worthwhile to further explore the role of mucosal glutathione in the orchestration of the inflammatory response as it might identify new targets for therapeutic intervention even by dietary means.

Part of this thesis is dedicated to biomarker discovery and we identified PAP protein as a potential candidate useful in animal and human disease. Further studies are needed to fully understand its function and its role as a noninvasive biomarker. Moreover, this thesis provides intervention models in which (dietary) investigations can be refined by using more sensitive infection models in rats with a compromised host defence mechanism.

To conclude, the research presented in this thesis showed that broadening the scope for other types of nutrients or food components than pre- and probiotics is worthwhile. Candidates like cystine and tannic acid showed promising results and indicated that there are many options for future research in dietary modulation of intestinal infection. This research area is important because of the growing resistance of bacterial pathogens to generally applied antibiotics and, therefore, the increasing demand to rely on well functioning host defences. 


\section{REFERENCES}

1. (WHO), W. H. O. 2002.

Foodborne diseases, emerging.

2. (WHO), W. H. O. 2005.

Drug-resistant Salmonella.

3. Tenover, F. C.Hughes, J.

M. 1996. The challenge of emerging infectious diseases

- Development and spread of multiply-resistant bacterial pathogens. JAMA 275: 300304.

\section{Lee, L. A., Puhr, N. D., Maloney, E. K., Bean, N. H.Tauxe, R. V. 1994. Increase in antimicrobial-resistant Salmonella infections in the United States, 1989-1990. J Infect Dis 170: 128-134.}

5. Ramos, J. M., Alés, J. M., Cuenca-Estrella, M., Fernandez-Roblas, R.Soriano, F. 1996. Changes in susceptibility of Salmonella enteritidis, Salmonella typhimurium, and Salmonella virchow to six antimicrobial agents in a Spanish hospital. Eur J Clin Microbiol Infect Dis 15: 85-88.

\section{Turnbaugh, P. J., Rid-} aura, V. K., Faith, J. J., Rey, F. E., Knight, R.Gordon, J. I. 2009. The effect of diet on the human gut microbiome: A metagenomic analysis in humanized gnotobiotic mice. Sci Transl Med 11.
7. Salyers, A. A.Whitt, D. D. 1994. Salmonella infections. In: Bacterial pathogenesis; A molecular approach. ASM Press, Washington, D.C.

8. Brooks, S. G., May, J., Sedman, P., Tring, I., Johnstone, D., Mitchell, C. J.MacFie, J. 1993. Translocation of enteric bacteria in humans. Br J Surg 80: 901-902.

\section{Sekirov, I., Tam, N. M.,} Jogova, M., Robertson, $M$. L., Li, Y., Lupp, C.Finlay, B. B. 2008. Antibiotic-induced perturbations of the intestinal microbiota alter host susceptibility to enteric infection. Infect Immun 76: 4726-4736.

10. Croswell, A., Amir, E., Teggatz, P., Barman, M.Salzman, N. H. 2009. Prolonged impact of antibiotics on intestinal microbial ecology and susceptibility to enteric Salmonella infection. Infect Immun 77: 2741-2753.

11. Mehta, A., Singh,

S.Ganguly, N. K. 1998. Impairment of intestinal mucosal antioxidant defense system during Salmonella typhimurium infection. Dig Dis Sci 43: 646-651.

12. Sido, B., Hack, V., Hochlehnert, A., Lipps, H., Herfarth, C.Dröge, W. 1998. Impairment of intestinal glutathione synthesis in patients with inflammatory bowel disease. gut 42: 485492.

\section{Geerling, B. J., v Hou-} welingen, A., BadartSmook, A., Stockbrügger, R. W.Brummer, R. J. 1999. The relation between antioxidant status and alterations in fatty acid profile in patients with Crohn disease and controls. Scand J Gastroenterol 34: 1108-1116.

\section{Sido, B., Braunstein, J.,} Breitkreutz, R., Herfarth, C.Meuer, S. C. 2000. Thiolmediated redox regulation of intestinal lamina propria $\mathrm{T}$ lymphocytes. J Exp Med 192: 907-912.

15. Sido, B., Lasitschka, F., Giese, T., Gassler, N., Funke, B., Schroder-Braunstein, J., Brunnemer, U. et al. 2008. A prominent role for mucosal cystine/cysteine metabolism in intestinal immunoregulation. Gastroenterology 134: 179-191.

16. Cash, H. L., Whitham, C. V., Behrendt, C. L.Hooper, L. V. 2006. Symbiotic bacteria direct expression of an intestinal bactericidal lectin. Science 313: 1126-1130.

17. Gironella, M., Iovanna, J. L., Sans, M., Gil, F., Penalva, 
M., Closa, D., Miquel, R. et al. 2005. Anti-inflammatory effects of pancreatitis associated protein in inflammatory bowel disease. Gut 54: 12441253.

\section{Bovee-Oudenhoven,} I. M., Termont, D. S., Weerkamp, A. H., FaassenPeters, M. A.Van der Meer, R. 1997. Dietary calcium inhibits the intestinal colonization and translocation of Salmonella in rats. Gastroenterology 113: 550-557.

19. van der Meer, R., Welberg, J. W. M., Kuipers, F., Kleibeuker, J. H., Mulder, N. H., De Vries, H. T.De Vries, E. G. E. 1990. Effects of supplemental dietary calcium on the intestinal association of calcium, phosphate, and bile acids. Gastroenterology 99: 1653-1659.

20. Govers, M. J., Termont, D. S., Lapre, J. A., Kleibeuker, J. H., Vonk, R. J.Van der Meer, R. 1996. Calcium in milk products precipitates intestinal fatty acids and secondary bile acids and thus inhibits colonic cytotoxicity in humans. Cancer Res 56: 3270-3275.

21. Bovee-Oudenhoven, I. M., Wissink, M. L., Wouters, J. T.Van der Meer, R. 1999. Dietary calcium phosphate stimulates intestinal lactobacilli and decreases the severity of a salmonella infection in rats. J Nutr 129: 607-612.

\section{Bovee-Oudenhoven, I.} M., Lettink-Wissink, M. L., Van Doesburg, W., Witteman, B. J.Van Der Meer, R. 2003. Diarrhea caused by enterotoxigenic Escherichia coli infection of humans is inhibited by dietary calcium. Gastroenterology 125: 469476.

23. Schepens, M. A., Schonewille, A. J., Vink, C., van Schothorst, E. M., Kramer, E., Hendriks, T., Brummer, R. J. et al. 2009. Supplemental Calcium Attenuates the Colitis-Related Increase in Diarrhea, Intestinal Permeability, and Extracellular Matrix Breakdown in HLAB27 Transgenic Rats. J Nutr.

24. Ergün, O., Ergün, G., Oktem, G., Selvi, N., Dogan, H., Tunçyürek, M., Saydam, G. et al. 2007. Enteral resveratrol supplementation attenuates intestinal epithelial inducible nitric oxide synthase activity and mucosal damage in experimental necrotizing enterocolitis. J Pediatr Surg 42: 1687-1694.

25. Watson, J. L., Asari, S., Cameron, H., Wang, A., Akhtar, M.McKay, D. M.
2004. Green tea polyphenol (-)-epigallocatechin gallate blocks epithelial barrier dysfunction provoked by IFNgamma but not by IL-4. Am J Physiol Gastrointest Liver Physiol 287: G954-961.

26. Puupponen-Pimia, R., Nohynek, L., Meier, C., Kahkonen, M., Heinonen, M., Hopia, A.Oksman-Caldentey, K. M. 2001. Antimicrobial properties of phenolic compounds from berries. J Appl Microbiol 90: 494-507.

27. Chung, K. T., Wong, T. Y., Wei, C. I., Huang, Y. W.Lin, Y. 1998. Tannins and human health: a review. Crit Rev Food Sci Nutr 38: 421-464. 



\section{SUMMARY}


Intestinal infections are widespread and still an emerging public health problem. The growing resistance of bacterial pathogens, including Salmonella species, to generally applied antibiotics makes diet an attractive tool to increase intestinal defence against these threats. In Chapter 1 the current knowledge about defence mechanisms to protect against intestinal foodborne infections has been reviewed, including dietary components that might improve resistance against Salmonella infection. From this review it can be concluded that there are, besides pre- and probiotics, dietary components that may increase resistance to Salmonella infection and its sequelae. Dietary interventions in the established S. enteritidis infection model in rats are essential to first evaluate the potential of these dietary components to ultimately improve resistance to intestinal infection in humans. In addition to studying the efficacy of diet in improving infection resistance, investigations using the Salmonella infection model can also be used to identify new potential biomarkers of intestinal health.

In Chapter 2 pancreatitis associated protein (PAP), also known as RegIII $\beta$ in mice, was evaluated as potential new biomarker. Ileal and faecal protein levels were associated with infection severity in rats. Also in mice levels increased in the ileal mucosa after intestinal infection (Chapter 3). Mechanistic studies in mice described in Chapter 3 revealed that RegIII $\beta$ protein plays a protective role against infection with the Gram-negative S. enteritidis but not against the Grampositive Listeria monocytogenes. The protective effect is associated with binding of this protein to the bacterium. Future studies are needed to reveal if and how this association might determine its protective function. In addition to the mechanistic rodent studies it is important for biomarker validation to show human relevance. Therefore, faecal PAP levels were investigated in human faeces. In Chapter 4 it is described that PAP levels were increased in human faeces after oral infection with enterotoxigenic Escherichia coli (ETEC), as shown in rodents that were infected with other pathogenic bacteria. Faecal PAP levels were also elevated in faeces of ulcerative colitis (UC) patients, but not in those of Crohn's disease (CD) patients. In these human studies faecal PAP levels were not proportional to faecal calprotectin, which is an established marker for intestinal inflammation. Taken together, these results indicate that faecal PAP probably has potential as a new non-invasive biomarker of intestinal infectious and/or inflammatory conditions in humans; however more research is needed on its exact function and specificity, preferably in combination with other gut biomarkers e.g. calprotectin. Our preliminary results suggest that it is neither a biomarker for intestinal inflammation nor for intestinal infection only. Follow-up studies are needed to determine the value of PAP for monitoring intestinal disease activity and/or its response to therapeutic or dietary interventions, and discriminating between UC and CD.

Some of the intestinal defence mechanisms are suggested to be crucial for the course of Salmonella infection; however in vivo evidence is often lacking. Therefore to answer part of the question "which host defence mechanisms are 
important during Salmonella infection?", the effects of glutathione depletion during Salmonella infection and its relevance for gut barrier function were studied as described in Chapter 5. This in vivo study showed that this defence mechanism is not substantially involved in colonization and translocation of Salmonella. It does, however, play an important role in the magnitude of the immune response. The latter association and the underlying mechanism need to be further investigated, especially in the context of hyper-immune responses during intestinal diseases, such as inflammatory bowel disease, which is associated with deceased glutathione levels. Dietary cysteine is known to be essential for gluthathione synthesis and might be involved in various host defence mechanisms. To answer the question "what dietary components can modulate intestinal Salmonella infection?" the protective effect of dietary cystine, which is the more stable variant of cysteine, on Salmonella infection was investigated in rats (Chapter 5). Dietary cystine did not increase hepatic or ileal glutathione levels compared to rats fed a control diet adequate in sulphur-containing amino acids. However, dietary cystine preserved (paracellular) gut barrier function and inhibited Salmonella translocation in infected rats. These studies reveal a protective function of dietary cystine that seems unrelated to glutathione levels and definitely has potential for further human research to improve gut health.

In Chapter 6 the role of the microbiota-related host defence during Salmonella infection was investigated in Salmonella infected rats that were pretreated with oral clindamycin. It has been shown previously that such a pretreatment disturbs the gut microbiota ecosystem and leads to increased pathogen colonization. The study described in Chapter 6 shows that the epithelial barrier is negatively affected by clindamycin pretreatment, which results in barrier defects, and these defects are associated with high luminal cytotoxicity. Therefore, it is an interesting new insight that some of the negative effects of antibiotic treatment may be counteracted by focussing on the luminal cytotoxicity. Further studies are needed to confirm whether these symptoms also occur in humans.

The infection model with a compromised microbiota-related host defence was also used to investigate protective properties of dietary calcium and tannic acid. Dietary calcium inhibits Salmonella colonization and translocation in rats with a normal defence status (Chapter 2). Due to the study described in Chapter 6 we now know that these effects of dietary calcium crucially depend on the intestinal microbiota. In contrast, reduction of the luminal cytotoxicity associated with a preserved paracellular epithelial barrier and reduced diarrhoea are protective properties of dietary calcium that are maintained in the antibiotic pretreated infection model. Therefore these protective effects are possibly not maintained via the microbiota, but probably arise via reduction of luminal cytotoxicity. Similarly, tannic acid reduces diarrhoea and preserves epithelial permeability in clindamycin pretreated infected rats. These effects were not associated with reduced luminal cytotoxicity and the mode of action of tannic acid points to 
improvement or enforcement of the intestinal epithelial lining. Currently we can only speculate about the mechanism of protection by tannic acid; future studies, e.g. with epithelial cells exposed to tannic acid, should provide more information. Antimicrobial activity that has been described for polyphenols like tannic acid in vitro seemed not to be present in vivo; therefore this study underlines the importance of evaluation of such effects in an in vivo model.

In conclusion, the studies described in this thesis indicate that nutrients or food components other than pre- and probiotics can improve resistance to intestinal infection. Candidates like cystine and tannic acid showed promising results and indicated that there are many options for future research in dietary modulation to improve defence to intestinal infectious disease. This research area is of growing importance, because of the increasing resistance of bacterial pathogens to generally applied antibiotics and, therefore, the increasing demand to rely on a well functioning host defence. 


\section{SAMENVATTING}

\section{(DUTCH SUMMARY)}


Darminfecties komen wereldwijd voor en zijn nog steeds een groeiend probleem voor de volksgezondheid. Een belangrijk probleem is de toenemende resistentie van bacteriële pathogenen, zoals Salmonella, tegen de doorgaans gebruikte antibiotica. Het verbeteren van de darmweerstand tegen deze bedreigingen met behulp van voeding is daarom een aantrekkelijke methode. In Hoofdstuk 1 wordt de huidige kennis met betrekking tot de weerstandsmechanismen ter bescherming tegen darminfecties (veroorzaakt door bacteriële voedselinfecties) besproken, inclusief voedingscomponenten die mogelijk de weerstand van de gastheer tegen een Salmonella infectie kunnen verhogen. Uit dit literatuuroverzicht kunnen we concluderen dat er, naast pre- en probiotica, voedingscomponenten zijn die de weerstand kunnen verhogen tegen een Salmonella infectie en/of de bijbehorende gevolgen kunnen verminderen. Om de potentie van voedingcomponenten, die uiteindelijk infectieweerstand in de mens kunnen vergroten, te evalueren is het essentieel om eerst voedingsinterventies in een diermodel uit te voeren. In dit proefschrift is dat het gevestigde Salmonella infectiemodel in ratten. Naast het bestuderen van de werkzaamheid van voeding om de weerstand van de gastheer te verhogen tegen infectie, kan het onderzoek met behulp van het Salmonella infectiemodel ook worden gebuikt om nieuwe potentiële biomarkers van darmgezondheid te identificeren.

In Hoofdstuk 2 werd het eiwit pancreatitis associated protein(PAP) geëvalueerd als mogelijke nieuwe biomarker. In ratten zijn de eiwitconcentraties in het ileum en feces geassocieerd met de mate van infectie. De homoloog van dit eiwit in muizen, genaamd $\operatorname{RegIII} \beta$, nam ook toe in hoeveelheid eiwit in de ileummucosa na darminfectie (Hoofdstuk 3). Studies in muizen naar het werkingsmechanisme van dit eiwit, beschreven in Hoofdstuk 3, onthulden dat RegIII $\beta$ een beschermende rol speelt tegen Gram-negatieve $S$. enterititdis infectie, maar niet tegen Gram-positieve Listeria monocytogenes infectie. Het beschermende effect is geassocieerd met de binding van het eiwit aan de bacterie. Verdere studies zijn nodig om te achterhalen hoe deze associatie de beschermende functie bepaald. Naast de mechanistische studies in knaagdieren is het voor biomarkervalidatie van belang om humane relevantie aan te tonen. Daarom werd in humane feces de PAP concentratie onderzocht. In Hoofdstuk 4 staat beschreven dat de PAP concentraties toenamen in humane feces na orale infectie met enterotoxigenic Escherichia coli (ETEC), hetzelfde fenomeen dat werd geconstateerd in knaagdieren die werden geïnfecteerd met andere pathogene bacteriën. Fecale PAP concentraties namen ook toe in feces van patiënten met colitis ulcerosa (UC), maar niet in feces van patiënten met de ziekte van Crohn (CD). In deze humane studies nam fecale PAP niet proportioneel toe met fecale calprotectine, hetgeen een gevestigde marker voor darmontsteking is. Samenvattend geven deze resultaten aan dat fecale PAP potentie heeft als nieuwe biomarker voor darminfectie en/of darmontsteking gerelateerde condities in de mens; hoewel meer onderzoek moet worden gedaan om de exacte functie en specificiteit te bepalen, bij voorkeur in combinatie met andere darmbiomarkers zoals 
bijvoorbeeld calprotectine. Onze preliminaire resultaten suggereren dat het geen biomarker voor darmontsteking is en ook niet voor een op zich staande darminfectie. Vervolgstudies zijn nodig om de waarde van PAP als biomarker te bepalen in het kader van 1) de activiteit van darmaandoeningen en/of de respons op medische of voedings interventies te monitoren en 2 ) het onderscheid te maken tussen UC en CD.

In de literatuur wordt gesuggereerd dat sommige weerstandsmechanismen een cruciale rol te spelen tijdens een Salmonella infectie hoewel hier vaak geen in vivo bewijs voor is. Om een deel van de vraag "Welke weersstandsmechanismen zijn belangrijk tijdens Salmonella infectie?" te beantwoorden, werden in Hoofdstuk 5 de effecten van glutathiondepletie tijdens een Salmonella infectie en de relevantie voor de darmbarrière functie bestudeerd. Deze in vivo studie liet zien dat dit weerstandsmechanisme geen substantiële rol speelt in colonisatie en translocatie van Salmonella. Het speelt echter wel een belangrijke rol bij de reactie van het immuunsysteem. Deze associatie en het onderliggende mechanisme moeten verder worden onderzocht, met name in de context van de hyperimmuunreactie tijdens darmziekten zoals chronische darmontsteking (inflammatory bowel disease;IBD), hetgeen ook wordt geassocieerd met verlaagde glutathion gehaltes. Cysteïne uit voeding is essentieel voor glutathion synthese en zou een belangrijke rol kunnen spelen in verschillende weerstandsmechanismen van de gastheer. Om de vraag "Welke voedingscomponenten kunnen een Salmonella geassocieerde darminfectie moduleren?" deels te beantwoorden, werd het beschermende effect van cystine (stabiele variant van cysteïne) tegen Salmonella infectie onderzocht (Hoofdstuk 5). Cystine in voeding van ratten was niet in staat glutathion te verhogen in de lever of het ileum vergeleken met ratten die een controle dieet kregen dat adequaat was in zwavelhoudende aminozuren. Cystine in voeding hield echter wel de (paracellulaire) darmbarrièrefunctie in stand en verlaagde de translocatie van Salmonella in geïnfecteerde ratten. Deze studie legde een beschermende functie van cystine bloot die schijnbaar niet gerelateerd is aan glutathion gehaltes en zeker potentie heeft voor verder humaan onderzoek om de darmgezondheid te verbeteren.

In Hoofdstuk 6 werd de rol van de microbiota-gerelateerde weerstand van de gastheer tijdens Salmonella infectie onderzocht in Salmonella geïnfecteerde ratten die een orale clindamycine voorbehandeling kregen. Uit voorgaand onderzoek bleek dat een dergelijke voorbehandeling het microbiota-ecosysteem van de darm verstoord en leidt tot een verhoogde colonisatie van pathogenen. De studie besproken in Hoofdstuk 6 laat zien dat de darmbarrière negatief word beïnvloed door de clindamycine behandeling, hetgeen resulteert in barrièredefecten en deze defecten zijn geassocieerd met een hoge luminale cytotoxiteit. Het is een interessant nieuw inzicht dat sommige negatieve effecten van antibiotica behandeling mogelijk kunnen worden tegengegaan door te focussen op de luminale cytotoxiteit. Verdere studies zijn nodig om humane relevantie van deze symptomen te bevestigen. Het infectiemodel met de gecompromitteerde 
microbiota-geassocieerde weerstand werd tevens gebruikt om de beschermende effecten van calcium in voeding en tannic acid te onderzoeken. Calcium remt Salmonella colonisatie en translocatie in ratten met een normale weerstand (Hoofdstuk 2). Door de studie, beschreven in Hoofdstuk 6, weten wij nu dat deze effecten van calcium sterk afhangen van de microbiota in de darm. Daarentegen zijn andere beschermende effecten van calcium staande gebleven in dit infectie model. Dit zijn reductie van de luminale cytotoxiteit geassocieerd met een in stand gehouden epitheliale barrière en een afname van diarree. Dit geeft aan dat deze beschermende effecten wellicht niet tot stand komen via de microbiota maar waarschijnlijk via reductie van de luminale cytotoxiteit. Tannic acid reduceert en behoudt ook de epitheliale barrièrefunctie in geïnfecteerde ratten die werden voorbehandeld met clindamycine. Deze effecten waren echter niet geassocieerd met een gereduceerde luminale cytotoxiteit, en het werkingsmechanisme lijkt toegewijd te zijn aan de verbetering of versterking van het darmepitheel. Op dit moment kunnen we alleen maar speculeren over het mechanisme van bescherming door tannic acid; verdere studies met bijvoorbeeld epitheelcellen die bloot worden gesteld aan tannic acid moeten meer inzicht geven. In vitro antimicrobiële activiteit die voorheen werd beschreven voor polyfenolen zoals tannic acid leek niet aanwezig in vivo. Deze studie geeft dus het belang aan van evaluatie van dit soort effecten in een in vivo model.

Samenvattend tonen de studies die in dit proefschrift beschreven staan aan dat nutriënten of voedingscomponenten anders dan pre- en probiotica de weerstand tegen darminfectie kunnen verbeteren. Kandidaten zoals cystine en tannic acid lieten veelbelovende resultaten zien en gaven aan dat er meerdere opties voor toekomstig voedingsonderzoek zijn ter verbetering van de weerstand tegen darminfecties. Het belang van dit onderzoeksgebied is groeiende, omdat er steeds meer bacteriële pathogenen resistent zijn tegen de doorgaans gebruikte antibiotica. Hierdoor is er een groeiende vraag naar een goed functionerende weerstand van de gastheer. 


\section{ACKNOWLEDGMENTS/ \\ DANKWOORD}


Na ruim 5 jaar ligt hier dan mijn proefschrift. De eerste 2 jaar van het onderzoek waren niet bijzonder vruchtbaar maar het leek wel of dit vooral in het laatste jaar werd vergoed. Toch heb ik altijd met veel plezier aan het onderzoek gewerkt en werd het doorzetten beloond, ookal moest er nog veel worden gedaan na het einde van mijn contract. Wetenschap is nou eenmaal niet in bochten te wringen! Ik ben erg blij met het resultaat, dat ik natuurlijk nooit in mijn eentje had kunnen bereiken. Daarom wil ik graag de kans grijpen om alle mensen te bedanken die de afgelopen jaren een belangrijke rol hebben gespeeld.

Mijn promotor Prof. Dr. Robert-Jan Brummer. Beste Robert-Jan, hartelijk dank dat ik je AIO mocht zijn. In de beginjaren vond ik het nogal eens lastig om bepaalde ideeen te verwoorden. Het grappige was dat jij het altijd onmiddelijk begreep. Het was altijd prettig om even uit te "zoomen" op alle proeven tijdens onze meetings om dicht bij de essentie van het onderzoek te blijven. In de loop van de jaren is er nogal wat veranderd en kreeg jij een nieuwe uitdaging in Zweden. Gelukkig kon ik altijd nog bij je terecht voor raad en daad.

Dr. Ingeborg Bovee-Oudenhoven. Beste Ingeborg, jij bent mijn directe begeleider geweest en was jouw bijdrage als co-promotor cruciaal. Ik wil je bedanken voor alles wat ik van je heb geleerd de afgelopen jaren. Dankzij jouw toomloze inzet lukte het om na wat schrikmomentjes toch nog de knockoutmuizen naar Nederland te halen. Hiermee hebben we een geweldige studie gedaan, waar we wellicht in de toekomst nog meer van gaan horen.

Dr. R. van der Meer. Beste Roelof, dank voor al je inzichten, ideëen en aanstekelijke enthousiasme in de wetenschap. Jouw kritsch oog heb ik altijd erg gewaardeerd en ook erg veel van geleerd.

Dit proefschrift is onderdeel van het A011 project binnen het TI Food and Nutrition. Het A011-team: Marloes, Carolien en Arjan. Marloes, het was fijn om deze periode met je te delen. De ups en downs zijn we goed doorgekomen. Ik denk wij elkaar perfect aanvullen op inhoudelijk én persoonlijk vlak (en natuurlijk onze passie voor muziek!). Carolien en Arjan zonder jullie was dit boekje er nooit geweest. Carolien, jouw enthousiasme en missie om nieuwe dingen met beide handen aan te pakken heb ik altijd erg gewaardeerd. En niet te vergeten je vrolijkheid op het lab! Arjan altijd de vaste hand in experimenten en hebben we regelmatig in het weekend op het lab moeten staan. Om maar niet te praten over de honderden platen die we hebben moeten gieten (en dan ook weer uitplaten... én tellen). Ik ben dan ook erg blij dat je me ook op mijn promotiedag bij wilt staan, dank! Graag wil ik ook alle TI Food and Nutrition (ex)collega's binnen Programma 1 bedanken voor alle nuttige meetings. Onder andere ook veel dank aan Wendy, Evelien en Jaap. Het was fijn om met jullie het "PAP"-avontuur te starten gevoed met goede discussies en enthousiasme! Daarnaast wil ik ook graag de experts van verschillende bedrijven binnen het TI Food and Nutrition bedanken voor de betrokkenheid bij het onderzoek in de vorm van goede discussies en nuttige comments. Het was mij een eer om op de valreep ook nog een "exemplificatie-project" uit te voeren. 
De leden van de beoordelingscommissie wil ik graag bedanken voor de tijd die ze hebben genomen voor het bestuderen van mijn proefschrift. Naast voorzitter Prof. C. Bruggeman bestaat deze uit Prof. A. Bast, Dr. D. Jonkers, Dr. M. van Nieuwenhoven en Prof. R. Witkamp.

De rest van het "nuts-team" van Nizo Food Research in Ede: Hans, Sandra, Corinne, Harro en Rianne. Bedankt voor alle hulp, goede discussies en opbouwende kritiek. Denise, jij was onderdeel van de nuts maar gevoelsmatig ook onderdeel van het A011-team. Altijd kon ik met vragen bij jou terecht en werkt jouw passie voor onderzoek aanstekelijk. Dank je voor al je hulp en enthousiasme!

Ook wil ik allle andere mensen van het Nizo bedanken van de afdeling Health (and Safety), maar ook alle andere mensen (o.a. van de dinsdagmiddagmeetings). Naar mijn idee is het erg goed voor onderzoek en de mens zelf om wetenschappelijke resultaten met een breed georiënteerd publiek te bespreken.

Also my non-dutch collegues at Nizo, thank you for the good times and nice discussions! Er zijn ook aardig wat (ex-)Nizo-ers waar ik nog regelmatig mee geniet: Saskia, Iris, Gabriele, Mariela, Jolanda, Jacqueline, Roger en Marieke. Dank jullie voor alle leuke etentjes, borrels en/of sauna-momenten.

Wilma, Judith, Pam, Renee, Bert en andere CKP-ers bedankt voor alle zorg, hulp en nuttige tips tijdens mijn proeven! Het was niet altijd even fijn wanneer een oxidatie-gevoelig-voer pas aan het eind van de dag mocht worden gegeven. Of wanneer ik weer eens in het weekend jullie hulp nodig had. Mijn dank is groot voor jullie enorme inzet!

Linda Loonen, Jan Dekker en Jerry Wells (Host Microbe Interactomics, Wageningen University) heel erg bedankt voor onze fijne en vruchtbare samenwerking. Onze meeting waren altijd erg prettig en maakten mij alleen nog maar meer enthousiast. Linda, ik vond het erg leuk om met jou je eerste grote studie uit te voeren en de resultaten mogen er zeker zijn!

Dear Mathias Chamaillard and Juan Iovanna, thank you for giving us the opportunity to investigate the role of RegIII $\beta$ in infection. Also for you participation in the discussion about the results, I hope we will have more of these discussions in future.

Dank ook aan Henrike Hamer en Gerard Dijkstra voor het beschikbaar stellen van fecale monsters van IBD patienten en het enthousiasme om de potentie van PAP als biomarker te onderzoeken.

Al mijn lieve vrienden: dank voor de heerlijke momenten! Soms was mijn tijd wat schaars maar gelukkig maakte de quality-time zo nu en dan alles weer goed! Een van mijn vrienden staat zelfs als paranifm naast me! Remco ik ben blij dat je me op deze dag bij wilt staan. De afgelopen jaren kon ik altijd bij jou en Wiesje terecht voor een goed gesprek of zomaar. Meestal kon deze hongerige AIO na een dag hard werken gewoon bij jullie aanschuiven. Het is nu helemaal compleet nu Luana er ook is, ik ben een trotse tante W! Paul en Jet dank voor alle fijne momenten onder het genot van het heerlijke portugeese klimaat. 
Paul dank voor al je hulp met het voltooien van dit boekje! Daniel heel erg bedankt voor je hulp bij de afronding, ik hoop in de toekomst jou, Gabriele en Johanna nog vaak te zien. Bjorn en Renée niet alleen dank voor alle gezellige en fijne momenten, maar ook dank voor het ontwerpen van de prachtige cover van dit proefschift.

Ook wil ik mijn ouders en familie bedanken. Mijn dierbare oom en tante die altijd interesse hadden in mijn promotieonderzoek (ik mis jullie..). Mijn lieve "schoonouders" en "schoonfamilie" die ik eigenlijk gewoon als mijn familie beschouw: bedankt voor alle steun, begrip, interesse en fijne momenten.

Mijn ouders, dank voor jullie steun en interesse. Toen ik klein was vroeg ik me altijd af waarom mijn moeder bijna al mijn vragen kon beantwoorden en nam ik me voor later ook zoveel te weten. Volgens mij ben ik al een aardig eind op weg lieve mam! Mijn lieve zussen heel erg veel dank voor alle fijne momenten.

Dan ten slotte deze ereplaats. Die is maar voor 1 persoon weggelegd, lieve Rob jij luisterde kritisch naar mijn presentaties en gaf ijzersterke comments. Ik kan niet in een paar woorden uiten waar ik jou allemaal voor zou willen bedanken. Maar vooral dank je voor wie je bent, en zoals jij zelf ooit verwoordde, "thanks for all good times!". 


\section{CURRICULUM VITAE}

Marleen T.J. van Ampting was born on January the 19th 1978 in Doetinchem, the Netherlands and grew up in adjacent small village named Wehl. After completing secondary school in 1996 at the St. Ludgercollege in Doetinchem she studied medical laboratory research (HLO) and obtained her B.Sc. degree in 2002 at the Institute of Life Sciences and Chemistry at "Hogeschool van Utrecht". During her B.Sc. internship in the laboratory of Prof. S. Landfear at the Oregon Health and Sciences University in Portland, Oregon, in the United States of America she cloned and functionally characterized a newly discovered membrane protein of the parasite Trypanosoma brucei brucei.

She continued her education with a M.Sc. study biomedical sciences at the "Vrije Universiteit" in Amsterdam. She performed her first internship under supervision of Dr. P. Nuijten and Dr. D. Schuijffel at Intervet International, where she investigated specific in vivo expressed antigens of Ornithobaterium rhinotracheale. Her second internship was in the laboratory of Prof. Dr. J. Luirink at the Vrije Universiteit where she investigated, under supervision of Dr. W. Jong, $E$. coli targeting pathways to transport heterologous proteins to the periplasm, after which she graduated in 2005. In March 2005 she started as a Ph.D. student at Nizo food research (and Maastricht University), under supervision of Dr. I. Bovee-Oudenhoven working on a project from TI Food and Nutrion (TIFN, formerly known as WCFS) entitled "dietary modulation of intestinal infection and mucosal inflammation". The research performed during this period is presented in this thesis entitled: "Dietary interventions and intestinal defence to protect against Salmonella infection". She presented results at several national and international conferences and in 2008 she received a travel award at the European mucosal immunology meeting. 


\section{LIST OF PUBLICATIONS}

van Ampting MT, Vink C, Schonewille AJ, Brummer RJ, van der Meer R, BoveeOudenhoven IM.

Damage to the intestinal epithelial barrier by antibiotic pretreatment of Salmonella-infected rats is lessened by dietary calcium or tannic acid.

J Nut 2010; 140:2167-2172.

van Ampting MT, Schonewille AJ, Vink C, Brummer RJ, van der Meer R, BoveeOudenhoven IM.

Intestinal barrier function in response to abundant or depleted mucosal glutathione in Salmonella-infected rats.

BMC Physiology 2009; 9: 6.

van Ampting MT, Rodenburg W, Vink C, Kramer E, Schonewille AJ, Keijer J, van der Meer R, Bovee-Oudenhoven IM.

Ileal mucosal and faecal pancreatitis-associated protein levels reflect severity of Salmonella infection in rats.

Dig Dis Sci. 2009; 54:2588-2597

van Ampting MT, Loonen L, Schonewille AJ, Konings I, Vink C, Iovanna J, Chamaillard M, Dekker J, Wells J, van der Meer R, Bovee-Oudenhoven IM.

The intestinal secreted C-type lectin RegIII $\beta$ protects against Salmonellosis but not Listeriosis in mice

Submitted 2010

van Ampting MT, Vink C, Schonewille AJ, Hamer HM, Dijkstra G, Brummer RJ, van der MeerR, Bovee-Oudenhoven IM.

Faecal pancreatitis-associated protein is increased by Eschericia coli infection and in ulcerative colitis but not in Crohn's disease: an exploratory study

In preparation

van Ampting MT, Brummer RJ, Hamer HM, van der Meer R, Bovee-Oudenhoven IM.

Dietary interventions and intestinal defence to protect against Salmonella infection In preparation

Sanchez MA, Drutman S, van Ampting M, Matthews K, Landfear SM.

A novel purine nucleoside transporter whose expression is up-regulated in the short stumpy form of the Trypanosoma brucei life cycle.

Mol Biochem Parasitol. 2004 Aug; 136(2):265-72. 